\title{
Simulation of Temperature, Nutrients, Biochemical Oxygen Demand, and Dissolved Oxygen in the Ashley River Near Charleston, South Carolina
}

U.S. GEOLOGICAL SURVEY

Water-Resources Investigations Report 98-4150

Prepared in cooperation with the

SOUTH CAROLINA DEPARTMENT OF HEALTH AND ENVIRONMENTAL CONTROL, OFFICE OF OCEAN AND COASTAL RESOURCE MANAGEMENT, CHARLESTON HARBOR PROJECT 


\section{Simulation of Temperature, Nutrients, Biochemical Oxygen Demand, and Dissolved Oxygen in the Ashley \\ River Near Charleston, South Carolina}

By Paul A. Conrads

U.S. GEOLOGICAL SURVEY

Water-Resources Investigations Report 98-4150

Prepared in cooperation with the

SOUTH CAROLINA DEPARTMENT OF HEALTH AND ENVIRONMENTAL CONTROL, OFFICE OF OCEAN AND COASTAL RESOURCE MANAGEMENT, CHARLESTON HARBOR PROJECT

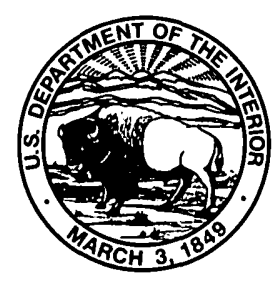




\section{U.S. DEPARTMENT OF THE INTERIOR \\ BRUCE BABBITT, Secretary}

U.S. GEOLOGICAL SURVEY

Thomas J. Casadevall, Acting Director

The use of firm, trade, and brand names in this report is for identification purposes only and does not constitute endorsement by the U.S. Government.

For additional information write to:

District Chief

U.S. Geological Survey

Stephenson Center-Suite 129

720 Gracern Road

Columbia, South Carolina 29210-7651
Copies of this report can be purchased from:

U.S. Geological Survey

Branch of Information Services

Box 25286

Denver, Colorado 80225-0286 


\section{CONTENTS}

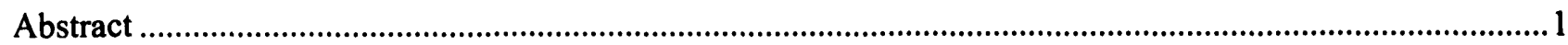

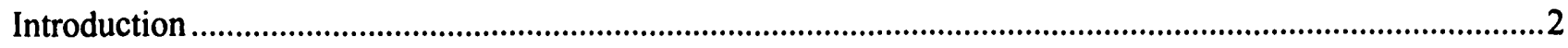

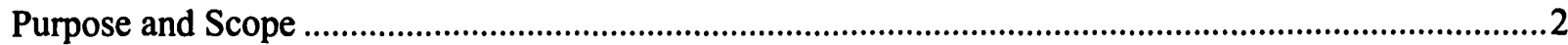

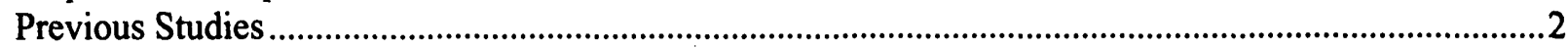

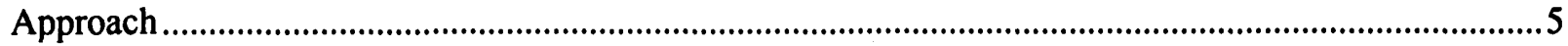

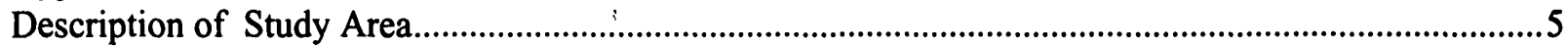

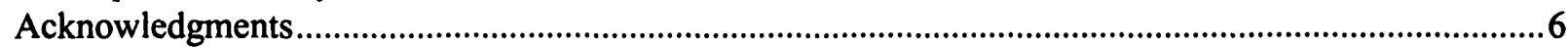

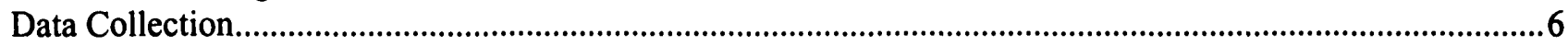

Continuous Water-Level and Water-Quality Data …………………...........................................................9

Streamflow and Discharge Data...................................................................................................................9

Water-Quality Sampling..........................................................................................................................9

Ancillary Data ................................................................................................................................

Simulation of Water Level, Streamflow, and Mass Transport ............................................................... 10

Water Level and Streamflow............................................................................................................. 12

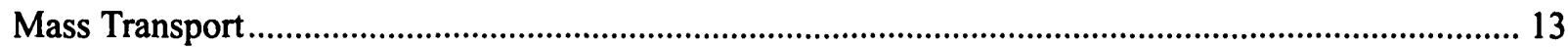

Schematization of Models............................................................................................................. 14

Calibration and Validation of Water Level, Streamflow, and Mass Transport.......................................... 17

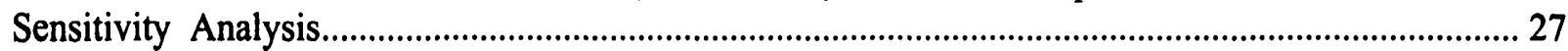

Simulation of Temperature, Nutrients, Biochemical Oxygen Demand, and Dissolved Oxygen ....................... 27

Calibration and Validation of Water Temperature.................................................................................. 31

Calibration and Validation of Nutrients, Biochemical Oxygen Demand, and Dissolved Oxygen ........... 33

Sensitivity Analysis........................................................................................................................ 44

Water-Quality Model Applications ……………………………………………………………………. 44

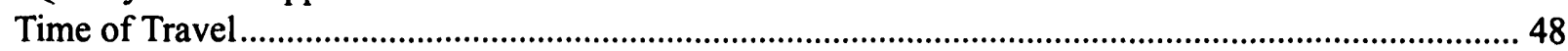

Levels of Wastewater Treatment........................................................................................................ 48

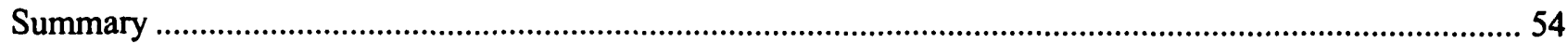

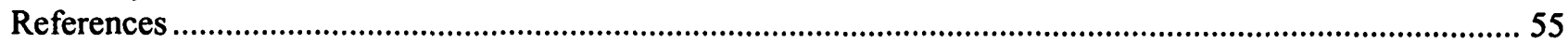




\section{FIGURES}

1-4. Maps showing:

1. Ashley River Basin, S.C. 3

2. Gaging stations on the Ashley River, S.C.

3. Location of National Pollutant Discharge Elimination System effluent discharges on the Ashley River and its tributaries, S.C

4. Location of data-collection stations on the Ashley River, S.C. .................................................. 11

5-6. Diagrams showing:

5. Idealized BRANCH model schematization

6. BRANCH model and Branched Lagrangian Transport Model schematizations for the Ashley River, S.C

7. Map showing location of branches and cross-sections used in the Branched Lagrangian Transport Model for the Ashley River, S.C.

8-15. Graphs showing:

8. Simulated and measured water levels used in the calibration and validation of the hydraulic model for station 021720869 on the Ashley River, S.C.

9. Simulated and measured streamflows used in the hydraulic model calibration for four locations on the Ashley River, S.C., September 25, 1992

10. Simulated and measured streamflows used in the hydraulic model validation for four locations on the Ashley River, S.C., July 28, 1992

11. Simulated and measured salinity concentrations used in the mass-transport model calibration and validation for station 021720869 on the Ashley River, S.C.

12. Simulated and measured salinity concentrations for four locations on the Ashley River, S.C., October 6-19, 1993

13. Simulated and measured salinity concentrations for four locations on the Ashley River, S.C., November 15 to December 15, 1993

14. Sensitivity of water levels and streamflow to changes in gage datum, cross-sectional area, and flow-resistance coefficient for station 021720869 on the Ashley River, S.C., July 28-30, 1992

15. Sensitivity of simulated salinity concentrations to changes in gage datum, cross-sectional area, flow-resistance coefficient, and dispersion factor for station 021720869 on the Ashley River, S.C., July 28-30, 1992

16. Diagram showing major constituent interactions in the QUAL2E subroutine of the Branched Lagrangian Transport Model

17-23. Graphs showing:

17. Simulated and measured water temperatures used in the water-quality model calibration and validation for station 021720869 on the Ashley River, S.C.

18. Simulated and measured water temperatures for four locations on the Ashley River, S.C.,

October 6-19, 1993.

19. Simulated and measured water temperatures for four locations on the Ashley River, S.C., November 15 to December 15, 1993 
20. Simulated and measured constituent concentrations used in the water-quality model calibration for three locations on the Ashley River, S.C., August 23-25, 1993

21. Simulated and measured constituent concentrations used in the water-quality model calibration for six locations on the Ashley River, S.C., September 25, 1992.

22. Simulated and measured constituent concentrations used in the water-quality model validation for three locations on the Ashley River, S.C., May 4-5, 1993.

23. Simulated and measured dissolved-oxygen concentrations for three periods at station 021720869 on the Ashley River, S.C.

24. Map showing sites used for model scenarios on the Ashley River, S.C

25-26. Graphs showing:

25. Flow hydrograph and tracer graphs for six sites on the Ashley River, S.C., September 1 - October 30, 1992

26. Longitudinal profiles of 24-hour mean and minimum dissolved-oxygen concentration differences from the no-load condition for four point-source loading conditions on the Ashley River, S.C., September 25, 1992

\section{TABLES}

1. National Pollutant Discharge Elimination System permit limits for wastewater-treatment facilities on the Ashley River and its tributaries, S.C.

2. Streamflow, continuous water-level, and water-quality sampling stations on the Ashley River, S.C., and the properties monitored

3. Summary of water-level calibration and validation simulations for station 021720869 on the Ashley River, S.C.

4. Summary of streamflow calibration and validation simulations for four locations on the Ashley River, S.C

5. Summary of salinity calibration and validation simulations for station 021720869 on the Ashley River, S.C

6. Rate constant coefficients, recommended values, and values used in the Branched Lagrangian Transport Model for the Ashley River, S.C.

7. Stations meeting calibration and validation criterion for nine constituents

8. Sensitivity indices for the Branched Lagrangian Transport Model inputs for station 021720869 on the Ashley River, S.C.

9. Time of leading edge, time of peak concentration, and peak concentration for sites on the Ashley River, S.C.

10. Biochemical oxygen demand, ammonia-nitrogen and dissolved-oxygen concentrations, and ultimate oxygen demand for three wastewater-treatment levels.

11. Simulated dissolved-oxygen concentrations for four point-source loading conditions for ten sites on the Ashley River, S.C. 


\section{ABBREVIATIONS AND ACRONYMS}

Abbreviations and acronyms used in this report

\begin{tabular}{|c|c|}
\hline BLTM & Branched Lagrangian Transport Model \\
\hline BOD & biochemical oxygen demand \\
\hline $\mathrm{BOD}_{\mathrm{u}}$ & ultimate biochemical oxygen demand \\
\hline $\mathrm{BOD}_{5}$ & 5-day biochemical oxygen demand \\
\hline $\mathrm{CBOD}_{\mathrm{u}}$ & ultimate carbonaceous biochemical oxygen demand \\
\hline $\mathrm{CBOD}_{30}$ & 30-day carbonaceous biochemical oxygen demand \\
\hline FW & freshwater \\
\hline NPDES & National Pollutant Discharge Elimination System \\
\hline ppt & parts per thousand \\
\hline QUAL2E & Enhanced Stream Water Quality Model \\
\hline SA & $\begin{array}{l}\text { tidal saltwaters suitable for primary and secondary contact recreation; daily aver- } \\
\text { age dissolved-oxygen concentration not less than } 5.0 \mathrm{mg} / \mathrm{L} \text { (milligrams per liter } \\
\text { with a low of } 4.0 \mathrm{mg} / \mathrm{L} \text {. }\end{array}$ \\
\hline SB & $\begin{array}{l}\text { tidal saltwaters suitable for primary and secondary contact recreation; dissolved- } \\
\text { oxygen concentration not less than } 4.0 \mathrm{mg} / \mathrm{L} \text {. }\end{array}$ \\
\hline SCDHEC & South Carolina Department of Health and Environmental Control \\
\hline STORET & $\begin{array}{l}\text { U.S. Environmental Protection Agency (STOrage and RETrieval) water-quality } \\
\text { data base }\end{array}$ \\
\hline TMDL & total maximum daily load \\
\hline UOD & ultimate oxygen demand \\
\hline USCOE & U.S. Army Corps of Engineers \\
\hline USEPA & U.S. Environmental Protection Agency \\
\hline USGS & U.S. Geological Survey \\
\hline
\end{tabular}

Sea level: In this report, "sea level" refers to the National Geodetic Vertical Datum of 1929--a geodetic datum derived from a general adjustment of the first-order level nets of the United States and Canada, formerly called Sea Level Datum of 1929. 


\title{
Simulation of Temperature, Nutrients, Biochemical Oxygen Demand, and Dissolved Oxygen in the Ashley River near Charleston, South Carolina, 1992-95
}

\author{
By Paul A. Conrads
}

\section{ABSTRACT}

Longitudinal dissolved-oxygen profiles of the Ashley River for various hydrologic and pointsource loading conditions were determined using results from water-quality simulations by the Branched Lagrangian Transport Model. The study area included the Ashley River from S.C. Highway 165 at Bacon Bridge to S.C. Highway 17 near the confluence with the Charleston Harbor. Hydraulic data for the Branched Lagrangian Transport Model were simulated using the U.S. Geological Survey BRANCH one-dimensional unsteady-flow model. Data used to apply and calibrate the BRANCH model included time series of water-level data at three locations and measured tidal-cycle streamflows at four locations. Data used to apply and calibrate the Branched Lagrangian Transport Model included time series of salinity concentrations at three locations, high- and low-slack tide longitudinal salinity profiles from six sampling locations, nutrient and biochemical oxygen demand concentrations collected over a tidal cycle during two sampling surveys for six locations, nutrient and biochemical oxygen demand concentrations collected over five slack tides over 2 and 3 days during two sampling surveys for three locations, and continuous water temperature data and dissolved oxygen concentrations at three locations.

A sensitivity analysis of the simulated dissolved-oxygen concentrations to model coefficients and data inputs indicated the simulated dissolvedoxygen concentrations were most sensitive to equilibrium temperatures due to the effect of temperature on reaction rate kinetics. Of the model coefficients, the simulated dissolved-oxygen con- centrations were most sensitive to sediment oxygen demand.

Scenario simulations were used to evaluate four point-source loading conditions to the system by comparing simulated dissolved-oxygen concentrations with a condition where there is no pointsource discharge into the system (no-load condition). The September 1992 loading condition decreased the 1-day dissolved-oxygen concentration of September 25, 1992, by 29.0 percent or less as compared to a no-load condition. Setting all the point-source loadings to advanced secondary treatment (10 milligrams per liter of ammonia-nitrogen $(\mathrm{mg} / \mathrm{L})$ and $20 \mathrm{mg} / \mathrm{L}$ of 5-day biochemical oxygen demand) decreased the total ultimate oxygen demand loading to the system by 28 percent and decreased the 1-day mean dissolved-oxygen concentrations from the no-load condition by 29.9 percent or less.

Setting all the point-source loadings to advanced treatment $(2 \mathrm{mg} / \mathrm{L}$ of ammonia-nitrogen and $10 \mathrm{mg} / \mathrm{L}$ of 5 -day biochemical oxygen demand) decreased the total ultimate oxygen demand loading to the system by 78 percent and decreased the 1-day mean dissolved-oxygen concentrations from the noload condition by 8.1 percent or less. Setting all the point-source loadings to reclaimed-use treatment $(0.5 \mathrm{mg} / \mathrm{L}$ of ammonia-nitrogen and $5 \mathrm{mg} / \mathrm{L}$ of $5-$ day biochemical oxygen demand) decreased the total ultimate oxygen demand loading to the system by 91 percent and decreased the 1-day mean dissolved-oxygen concentrations from the no-load condition by 5.2 percent or less. 


\section{INTRODUCTION}

The Ashley River is a tidally affected river that is a major tributary to the Charleston Harbor, which is located near the middle of the South Carolina coast (fig. 1). The Ashley River is a tidal slough that extends approximately 30 miles (mi) from the peninsula of Charleston to Cypress Swamp. The water quality of Charleston Harbor and its tributaries is increasingly being stressed by point-source (municipal and industrial wastewater effluent) and nonpointsource pollutant loadings. As the Charleston area continues to grow, demands on its water resources increasingly conflict. The Harbor and its tributaries are important economic, natural habitat, and aesthetic resources. Residential development continues to grow along much of the Ashley River, and industrial and commercial facilities are located along the east bank of the lower reaches of the river. The tributary rivers and tidal creeks also are critical fisheries habitats. In addition, the recreational use of these coastal waters is essential to the growing tourism and retirement communities of the Charleston area and the South Carolina coast

In May 1992, the U.S. Geological Survey (USGS), in cooperation with the South Carolina Department of Health and Environmental Control (SCDHEC), Office of Ocean and Coastal Resource Management, Charleston Harbor Project, initiated a study to develop a computer simulation model of water quality of the Ashley River. The simulation model will advance understanding of the hydrologic and chemical processes in the river and will allow State water-resource managers, regulators, and others to assess the effects of management decisions on the water quality in the Ashley River.

\section{Purpose and Scope}

The purpose of this report is to present the results of the application of the one-dimensional dynamic flow model (BRANCH) and the one-dimensional, dynamic Branched Lagrangian Transport Model (BLTM) to the Ashley River. The modeling effort was completed in two phases. The scope of the first phase was to calibrate and validate the unsteadyflow model (BRANCH) and the mass-transport model (BLTM) to simulate the movement of a conservative constituent (salinity) in the system. The scope of the second phase was to calibrate and validate the water- quality model (BLTM) to simulate the fate and transport of non-conservative constituents such as nutrients, biochemical oxygen demand (BOD), and dissolved oxygen.

\section{Previous Studies}

There have been numerous environmental, hydrologic, sedimentation, and modeling studies of Charleston Harbor and the Ashley River. The completion of the Cooper River Rediversion Project in 1985 significantly altered the hydrologic conditions of the Cooper, Wando, and Ashley Rivers and Charleston Harbor (Kjerfve, 1976; Kjerfve and Magill, 1990). In 1987, the Marine Resources Division of the South Carolina Wildlife and Marine Resources Department initiated a comprehensive assessment of the Charleston Harbor estuary. Results of the study showed that sampling stations in the upper Ashley River had significantly lower dissolved-oxygen concentrations and higher nutrient levels than stations in the harbor and other tributary rivers (Van Dolah and others, 1990). The SCDHEC analyzed monthly monitoring data collected during 1974-87 from Charleston Harbor and the three tributary rivers. The data indicated increasing temporal trends of dissolved oxygen, ammonia, total Kjeldahl nitrogen, and total phosphorus, and decreasing trends of 5-day biochemical oxygen demand $\left(\mathrm{BOD}_{5}\right)$, nitrite plus nitrate, and fecal coliform in the Ashley River (Chestnut, 1989).

Chigges and others (1989) investigated nonpoint source loadings to the Ashley River during three storm events. The Ashley River at Bacon Bridge and five creeks were sampled for nutrients, $\mathrm{BOD}_{5}$, and trace elements. Brickyard Creek (fig 2.), which drains a watershed of fairly high industrial/commercial density and moderate residential density, had the highest concentrations of $\mathrm{BOD}_{5}$ and ultimate $\mathrm{BOD}\left(\mathrm{BOD}_{\mathrm{u}}\right)$, with $\mathrm{BOD}_{5}$ concentrations as high as 37.0 milligrams per liter (mg/L). Ammonia and total Kjeldahl nitrogen concentrations during the three storms were higher in Dorchester, Eagle, Church, and Brickyard Creeks, which drain more developed watersheds, than in Popperdam Creek and the Ashley River at Bacon Bridge, which drain less developed watersheds (fig. 2). Blood and others (1995) applied rainfall-runoff models to the Ashley River Basin and estimated that 48 percent of the annual inorganic nitrogen load to the Ashley River is from nonpoint-source runoff (E.R. Blood, oral commun., September 4, 1997). 


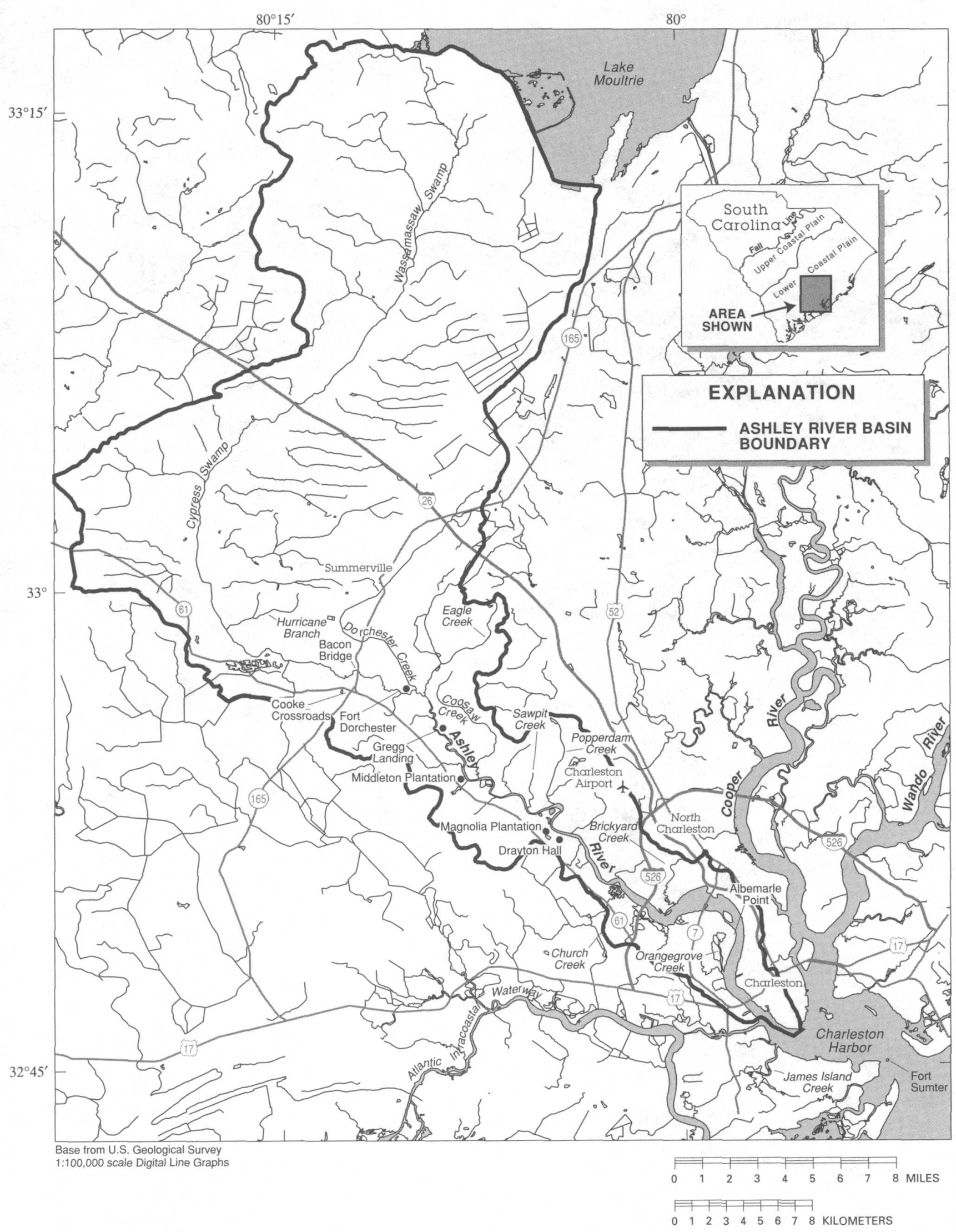

Figure 1. Ashley River Basin, South Carolina. 


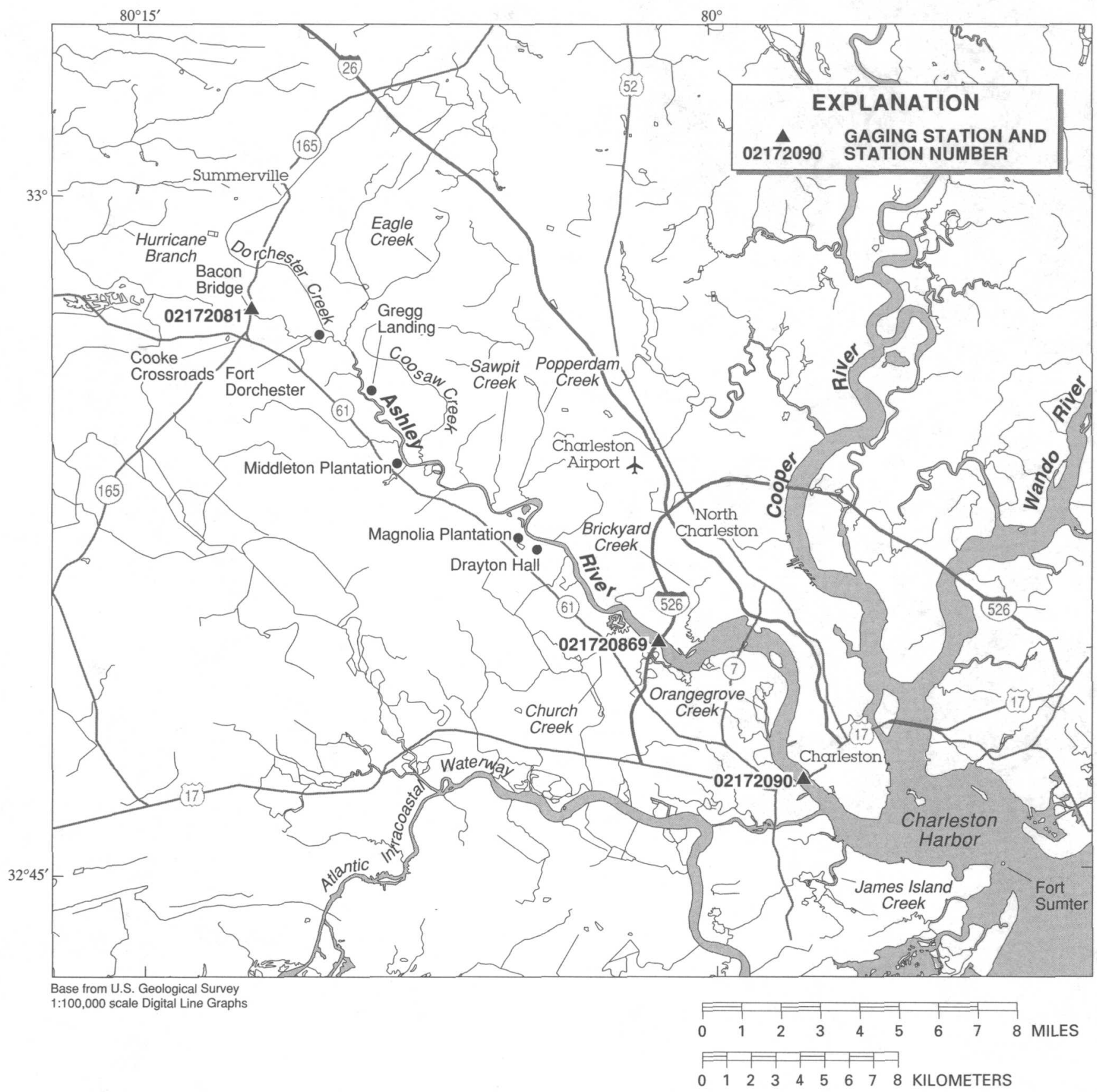

Figure 2. Gaging stations on the Ashley River, South Carolina. 


\section{Approach}

Dissolved-oxygen concentration is one of the primary water-quality constituents and is used as an indicator of the ecological health of a waterbody. The ability to simulate the concentration of dissolved oxygen is necessary for water-resource managers to assess the effects of point- and nonpoint-source pollution on a waterbody. The models described in this report can be used by water-resource managers to determine the assimilative capacity of the Ashley River. The capacity of a stream to assimilate oxygen-demanding substances is a function of streamflow, temperature, velocity, wind speed, depth, and channel configuration. In terms of water-resource management, this capacity or loading is expressed in terms of pounds per day of ultimate oxygen demand (UOD) that can be assimilated during a particular set of hydrologic conditions without violating the State water-quality standards for dissolved oxygen.

To maximize the usefulness of the information obtained from the model, the decision was made that the model selected for this study would have to be readily available and usable by water-resource managers to determine the assimilative capacity of the Ashley River. A one-dimensional dynamic-flow model and a one-dimensional dynamic transport and waterquality model were applied to the system. The dynamic-flow model, BRANCH, was used to generate the required hydraulic data for input into the BLTM, which was used to simulate constituent transport.

The general approach to applying the models was to calibrate and validate the hydraulic and masstransport models by first simulating the movement of a conservative constituent, which is not affected by biological degradation or chemical reaction but is affected by dilution in response to changing streamflow conditions. Salinity is a conservative constituent and is an effective natural tracer for calibrating and validating mass transport in the Ashley River. After successfully calibrating and validating the model for the mass transport of a conservative constituent (salinity), the non-conservative constituents (nutrients and dissolved oxygen) can be simulated. The concentration of a non-conservative constituent may be affected by biological degradation and chemical reaction, as well as dilution in response to changing streamflow conditions.

Several types of data were required for application of the models. A large data-collection effort was completed during 1992-95 (Conrads and others,
1997). The necessary data required to apply, calibrate, and validate the transport and water-quality models included (1) continuous water level, specific conductance, temperature, and dissolved-oxygen concentrations at the upstream and downstream boundaries and at an interior location; (2) tidal-cycle measurements of streamflow and nutrient concentrations at boundaries and selected interior locations; (3) channel geometry; and (4) municipal and industrial discharge-flow rates and effluent concentrations.

A successfully applied water-quality model of the river system should yield nutrient and dissolvedoxygen concentrations that agree closely with field measurements of those parameters. The water-quality model will be used to assist in the determination of wasteload allocations and total maximum daily loads (TMDL) that are based on National Pollutant Discharge Elimination System (NPDES) permit limitations for dissolved oxygen and BOD. Therefore, emphasis during the calibration and validation processes was placed on achieving satisfactory simulations of dissolved oxygen and BOD.

\section{Description of Study Area}

The Ashley River is located in the lower Coastal Plain physiographic province along the middle of the South Carolina Coast (fig. 1). The river has a long history dating back to Native American settlements on the upper Ashley River. In 1670, the first European settlement at Albermarle Point was established just north of present day Charleston. In 1680, the settlement was moved to a location between the Cooper and Ashley Rivers at Charles Town (prior to the establishment of Charleston). The introduction of rice cultivation in the 1680's significantly changed the area's economy. Rice dominated the economic and cultural life of the area, and large plantations were established along the river from the wealth generated by the rice and indigo trade. Surveys and the mining of phosphate deposits along the river were performed to find a source of inexpensive fertilizer to support the agricultural activities of the area. Many historical sites from these early periods, including Fort Dorchester, Magnolia Plantation and Garden, Middleton Plantation, and Drayton Hall, are still maintained along the river (fig. 2) (Townsend and Brock, 1992).

The Ashley River is a tidal slough that drains 376,000 acres, including Wassamassaw and Cypress Swamps, and Dorchester and Eagle Creeks (fig. 1). 
The drainage basin is 12.6 percent urban, 4.1 percent agricultural, 7.2 percent scrub or scrub land, 0.2 percent barren land, 58.7 percent forested, 10.5 percent forested wetland, 4.6 percent non-forested wetland, and 2.1 percent water (South Carolina Land Resources Conservation Commission, 1990; South Carolina Department of Health and Environmental Control, 1996). Two major tributaries to the Ashley River, Dorchester and Eagle Creeks, drain a major urban watershed of 24,300 acres, which includes the town of Summerville. Many other smaller tidal creeks drain smaller watersheds. The banks of the river are dominated by extensive Spartina alterniflora marshes.

Charleston Harbor experiences semi-diurnal tides with mean- and spring-tidal ranges of 5.09 and 5.90 feet ( $\mathrm{ft}$ ), respectively, at the harbor entrance at Fort Sumter (fig. 2). The tidal ranges of the Ashley River are amplified as they progress upstream. The mean- and spring-tidal ranges at James Island Creek, near the confluence with Charleston Harbor, are 5.36 and $6.27 \mathrm{ft}$, respectively. As the tide progresses upstream, the mean- and spring-tidal ranges increase to 6.06 and $7.03 \mathrm{ft}$, respectively, at Gregg Landing (fig. 1). Farther upstream at Bacon Bridge, the tide ranges attenuate and the mean- and spring-tidal ranges are 1.94 and $2.25 \mathrm{ft}$, respectively (National Oceanic and Atmospheric Administration, 1995).

The extent of saltwater intrusion on the Ashley River varies greatly with the hydrologic conditions in the basin. During extremely dry periods with little freshwater draining from Cypress Swamp (fig. 1), saltwater extends through most of the Ashley River. During periods of heavy precipitation, saltwater can be limited to the lower reaches of the river below Drayton Hall (fig. 2).

The SCDHEC has classified the Ashley River from Hurricane Branch to Bacon Bridge as freshwater (FW) and the reach from Bacon Bridge to Charleston Harbor as tidal saltwater (SA). Most of the river has a dissolved-oxygen water-quality standard of a daily average of not less than $5.0 \mathrm{mg} / \mathrm{L}$ with a minimum of $4.0 \mathrm{mg} / \mathrm{L}$. The reach from Church Creek to Orangegrove Creek is the exception with a dissolved-oxygen water-quality standard of not less than $4 \mathrm{mg} / \mathrm{L}$ (South Carolina Department of Health and Environmental Control, 1996).

Currently (1998), there are nine industries and seven municipalities that are permitted to discharge to the Ashley River (nine industries and five municipalities within the study area from Bacon Bridge to S.C.
Highway 17). Four municipal discharges (three within the study area) are considered major facilities with flows in excess of 1.0 million gallons per day (Mgal/d). The NPDES permit limits for wastewatertreatment facilities are listed in table 1 and the locations are shown in fig. 3.

\section{Acknowledgments}

A study of this complexity required interagency cooperation as well as individual contributions. The author thanks J. Heyward Robinson, former Director of the Charleston Harbor Project, for providing the support and coordination of the local interests in the Charleston area; David Chestnut, the late Russell W. Sherer, Nancy R. Sullins, and Edward Younginer of the SCDHEC for their assistance in field sampling, laboratory analysis, and technical support; the permitted dischargers for providing effluent data during the synoptic sampling surveys; Michael J. Wachowski for his contributions while at the SCDHEC; and the members of the Water-Quality Modeling Project Advisory Board of the Charleston Harbor Project for their annual review of the study. Board members include Ralph Cheng of the USGS, David Correl of the Smithsonian Institute, and James Greenfield of the USEPA.

\section{DATA COLLECTION}

Data collected for this study included (1) continuous water level, specific conductance, temperature, and dissolved-oxygen concentrations at three gaging stations; (2) tidal-cycle streamflow measurements at four stations; (3) tidal-cycle nutrient sampling at six locations; (4) longitudinal profiles during high- and low-slack tides of specific conductance, water temperature, and dissolved-oxygen concentration; (5) meteorological data; (6) effluent concentrations and discharge data from the municipal and industrial facilities; and (7) channel geometry. Permitted wastewater-discharge data from treatment plants and monthly water-quality monitoring data were provided by the SCDHEC. 
Table 1. National Pollutant Discharge Elimination System permit limits for wastewater-treatment facilities on the Ashley River and its tributaries, South Carolina.

[Mgal/d, million gallons per day; $\mathrm{BOD}_{5}, 5$-day biochemical oxygen demand: $\mathrm{NH}_{3}-\mathrm{N}$, ammonia-nitrogen; $\mathrm{DO}$, dissolved oxygen; UOD, ultimate oxygen demand; $\mathrm{mg} / \mathrm{L}$, milligrams per liter; lb/d, pounds per day; [20], not limited on permit-value used in UOD calculation; M/R, monitor and report; --, not applicable; max, maximum]

\begin{tabular}{|c|c|c|c|c|c|c|}
\hline $\begin{array}{c}\text { Site } \\
\text { (fig. 3) }\end{array}$ & $\begin{array}{l}\text { Receiving } \\
\text { waters }\end{array}$ & $\begin{array}{l}\text { Effluent } \\
\text { (Mgal/d) }\end{array}$ & $\begin{array}{l}\mathrm{BOD}_{5} \\
(\mathrm{mg} / \mathrm{L})\end{array}$ & $\begin{array}{l}\mathrm{NH}_{3}-\mathrm{N} \\
(\mathbf{m g} / \mathrm{L})\end{array}$ & $\begin{array}{c}\text { DO } \\
(\mathrm{mg} / \mathrm{L})\end{array}$ & $\begin{array}{l}\text { UOD } \\
\text { (Ib/d) }\end{array}$ \\
\hline$t_{1}$ & Ashley River & 6.0 & 25 & 7.5 & 5 & 3,592 \\
\hline 2 & Ashley River & 0.238 & 30 & 15.2 & 5 & 227 \\
\hline 23 & Coosaw Creek & 2.0 & 30 & 10 & 5 & 1,513 \\
\hline 4 & Ashley River & 0.014 & 30 & [20] & 2 & 16 \\
\hline${ }^{3} 5$ & Sawpit Creek & $M / R$ & 20 & - & -- & -- \\
\hline 46 & $\begin{array}{l}\text { Tributary to Ash- } \\
\text { ley River }\end{array}$ & $\mathbf{M} / \mathbf{R}$ & -- & - & - & -- \\
\hline 7 & Church Creek & 1.5 & 25 & 2.8 & 5 & 629 \\
\hline${ }^{48}$ & Ashley River & $\mathbf{M} / \mathbf{R}$ & 20 & -- & -- & -- \\
\hline $4_{9}$ & Brickyard Creek & $\mathrm{M} / \mathrm{R}$ & -- & -- & -- & -- \\
\hline${ }^{4} 10$ & Brickyard Creek & $\mathbf{M} / \mathbf{R}$ & 10 & -- & 1 & - \\
\hline${ }^{4} 11$ & Brickyard Creek & $\mathbf{M} / \mathbf{R}$ & -- & - & -- & -- \\
\hline${ }^{4} 12$ & Ashley River & $\mathbf{M} / \mathbf{R}$ & -- & -- & -- & -- \\
\hline${ }^{4} 13$ & Ashley River & $\mathbf{M} / \mathbf{R}$ & 10 & - & -- & -- \\
\hline${ }^{4} 14$ & Ashley River & $\mathbf{M} / \mathbf{R}$ & 10 & - & -- & -- \\
\hline${ }^{4} 15$ & Ashley River & 0.049 & -- & - & - & -- \\
\hline${ }^{5} 16$ & Ashley River & 27.0 & 30 & 20 & 1 & 30,700 \\
\hline $5_{17}$ & Ashley River & 0.03 & 10 & 6 & 5 & 10.6 \\
\hline${ }^{6} 18$ & Popperdam Creek & $0.8 \max$ & 30 & [20] & 5 & 910 \\
\hline
\end{tabular}

I Permit reduced to 1,601 lb/d UOD, effective October 1995.

2 Permit reduced to $903 \mathrm{lb} / \mathrm{d}$ UOD, effective October 1993.

3 Permit inactive as of March 27, 1996.

${ }^{4}$ Not used in total UOD computation.

5 Facility outside of model domain.

6 Permit inactive as of October 6, 1995. 


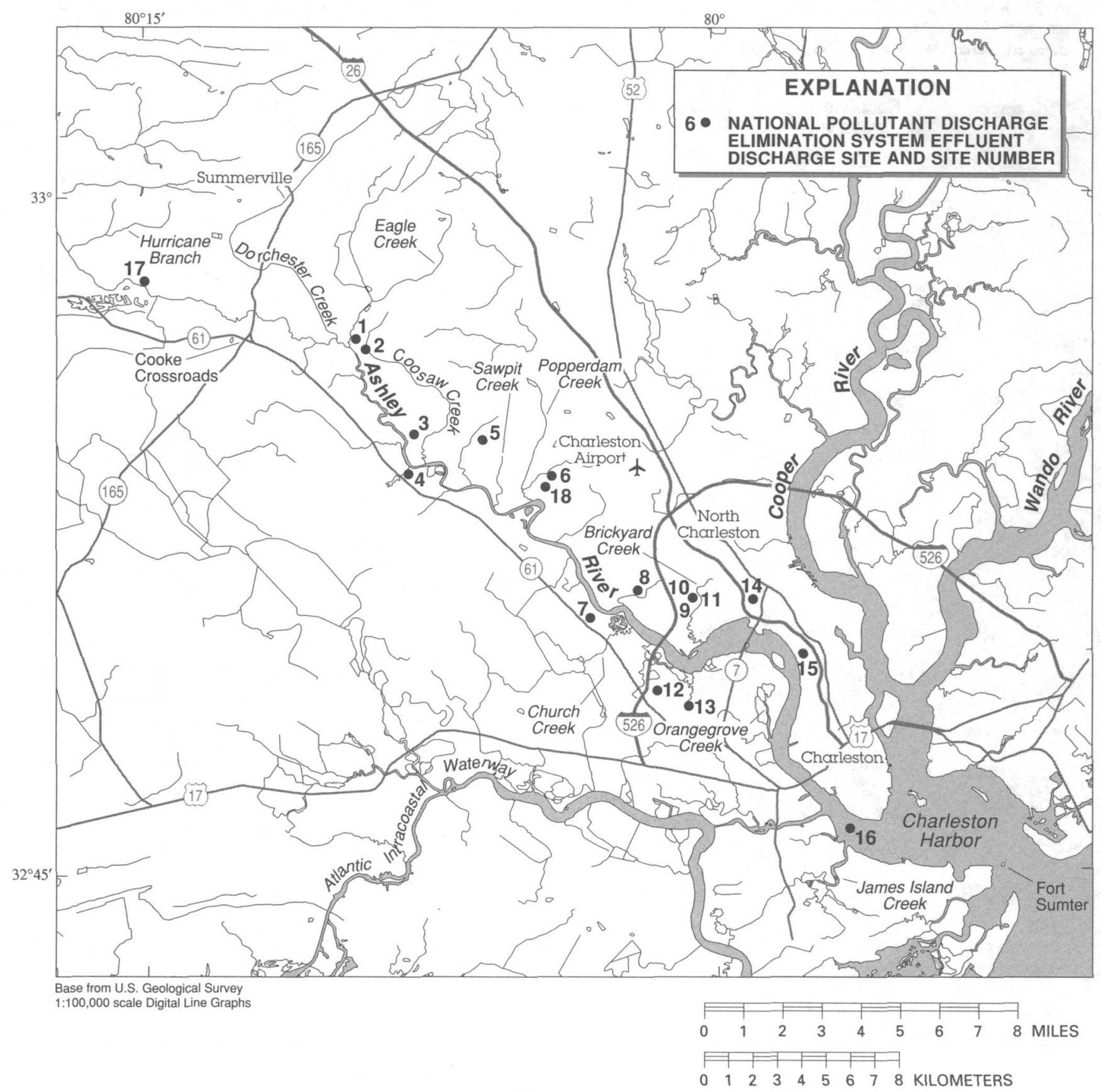

Figure 3. Location of National Pollutant Discharge Elimination System effluent discharges on the Ashley River and its tributaries, South Carolina. 


\section{Continuous Water-Level and Water- Quality Data}

Water level, specific conductance, water temperature, and dissolved-oxygen data were recorded at 15minute intervals by automated data-collection platforms. Water-level gages used stilling wells with a float-counterweight system interfaced to shaft encoders. The datum for each gaging station was determined by surveys from established benchmarks. The water-quality probes were interfaced with USGS water-quality minimonitors. At station 02172081 (fig. 2 , table 2), water-quality probes were set at the middepth of the water column. To monitor possible stratification in the lower reaches of the Ashley River, two stations (stations 021720869 and 02172090 ) were instrumented with probes near the top and near the bottom of the water column. Salinity concentrations were calculated from specific conductance data using the algorithms described by Miller and others (1988).

\section{Streamflow and Discharge Data}

Streamflow and discharge data for the calibration and validation of the hydraulic model were obtained from field measurements in subreaches of the study area. During the sampling periods, point-source discharge data were obtained from the monthly Discharge Monitoring Reports submitted by the NPDES permit holders to the SCDHEC (N.R. Sullins, South Carolina Department of Health and Environmental Control, electronic commun., 1997). Streamflows were measured by USGS personnel from bridges and boats at four locations in the study area. Although an attempt was made to measure flow over a complete flood- and ebb-tidal cycle, most measurements covered a 10-hour period. Maximum positive or negative streamflows were measured in most cases. Positive flow is in the seaward direction. Streamflows of the Ashley River were measured at four locations on July 28 and September 25, 1992 (fig. 4, table 2).

At bridge sites and where a cable could be stretched across the channel, multiple passes were made across the river to obtain depth and velocities at fixed locations in the cross sections. These depth and velocity readings were then interpolated at a uniform time interval of 15 minutes and flows were computed for each time interval at each fixed location. The total flow for each measurement was computed by sum- ming all of the flows at the fixed location for each time interval.

\section{Water-Quality Sampling}

During 1992 and 1993, samples for nutrients, suspended sediment, and BOD analyses were collected in four surveys (Conrads and others, 1997). Samples were collected for stations 02172081 to 02172090 , on July 28 and September 25, 19.92. Depth-integrated samples were collected at six stations during a 12-hour tidal cycle at high- ard lowslack tides and at maximum flood and ebb tides (fig. 4, table 2). Nutrient concentrations were determined by the USGS Water-Quality Service Unit in Orala, Fla.

The lower reaches of the Ashley River, from station 021720869 to 02172090 , were sampled in May and August of 1993 in cooperation with the SCDHEC as part of nutrient-sampling surveys of Charleston Harbor and the lower reaches of the Harbor's three tributary rivers. Discrete top and bottom samples were collected at three sites on the Ashley River during high- and low-slack tides (fig. 4, table 2). During the first synoptic sampling period, May 4-5, 1993, samples were collected during five slack tides over 2 days. During the second synoptic sampling period, August 23-25, 1993, samples were collected during five slack tides over 3 days. Samples were analyzed in the SCDHEC laboratory in Columbia, S.C., for total ammonia nitrogen, total Kjeldahl nitrogen, total phosphorus, dissolved orthophosphorus, and chlorophyll-a. For the 1992 and 1993 sampling surveys, total suspended solids was determined by the USGS sediment laboratory in Tuscaloosa, Ala. Ultimate carbonaceous biochemical oxygen demand $\left(\mathrm{CBOD}_{\mathrm{u}}\right)$ and 30-day carbonaceous biochemical oxygen demand $\left(\mathrm{CBOD}_{30}\right)$ were determined by USGS personnel using a nitrogen inhibitor.

\section{Ancillary Data}

Data were also collected for longitudinal highand low-slack tide profiles, special studies, and channel geometry. In the fall of 1993, eight longitudinal high- and low-slack tide profiles of the Ashley River were collected by obtaining field measurements of specific conductance, temperature, and dissolved-oxygen concentration at the six nutrient simpling sites. Sampling began at the most downstream station and 
Table 2. Streamflow, continuous water-level, and water-quality sampling stations on the Ashley River, South Carolina, and properties monitored

[WL, water level; T, temperature; DO, dissolved oxygen; SC, specific conductance; na, not applicable]

\begin{tabular}{|c|c|c|c|c|}
\hline \multicolumn{2}{|r|}{ Station } & \multirow[b]{2}{*}{$\begin{array}{l}\text { River } \\
\text { mile }\end{array}$} & \multirow[b]{2}{*}{ Constituents } & \multirow[b]{2}{*}{$\begin{array}{l}\text { STORET } \\
\text { number } 1\end{array}$} \\
\hline $\begin{array}{l}\text { Number } \\
\text { (fig. 2) }\end{array}$ & Name & & & \\
\hline${ }^{2,3} 02172081$ & Ashley River at Cooke Crossroads & 27.9 & WL, T, DO, SC & CSTL-102 \\
\hline${ }^{3} 02172083$ & Ashley River at Middleton Plantation & 20.1 & na & na \\
\hline${ }^{2,3} 02172083$ & Ashley River at Middleton Plantation & 20.1 & na & na \\
\hline $2,3,4021720869$ & Ashley River near North Charleston & 9.8 & $\begin{array}{c}\mathrm{WL}, \mathrm{T}^{4}, \mathrm{DO}^{4}, \\
\mathrm{SC}^{4}\end{array}$ & MD-767 \\
\hline${ }^{3} 02172088$ & Ashley River at S.C. Highway 7 & 7.1 & na & MD-135 \\
\hline $2,3,402172090$ & Ashley River at Charleston & 2.2 & $\begin{array}{c}\mathrm{WL}, \mathrm{T}^{4}, \mathrm{DO}^{4} \\
\mathrm{SC}^{4}\end{array}$ & MD-768 \\
\hline
\end{tabular}

${ }^{1}$ U.S. Environmental Protection Agency STORET (STOrage and RETrieval) station number.

2 Streamflow measurement stations.

${ }^{3}$ Water-quality sampling stations.

${ }^{4}$ Near top and near bottom probes.

progressed upstream with the slack tide. Longitudinal sampling was done on October 15 and 25; November $1,8,15,22$, and 30; and December 12, 1993.

A network of monthly monitoring stations throughout South Carolina is maintained by the SCDHEC (South Carolina Department of Health and Environmental Control, 1996). In addition to monthly monitoring, special studies are performed by the SCDHEC to evaluate particular environmental concerns. These data were retrieved and incorporated as needed into the study.

Channel-geometry data were collected at selected locations on the Ashley River by USGS personnel. Additional channel-geometry data below the I526 bridge were obtained from National Oceanic and
Atmospheric Administration nautical charts (National Oceanic and Atmospheric Administration, 1992a).

\section{SIMULATION OF WATER LEVEL, STREAMFLOW, AND MASS TRANSPORT}

Simulations of the fate and transport of nutrients and dissolved oxygen in the Ashley River require accurate simulations of water level, streamflow, and mass transport in the system. The one-dimensional, dynamic-flow model (BRANCH) was used to simulate the hydraulic properties within the system. Because BRANCH does not simulate mass transport, it was necessary to use a one-dimensional, dynamic-transport model (BLTM) to simulate the mass transport of salinity, nutrients, BOD, and dissolved oxygen. 


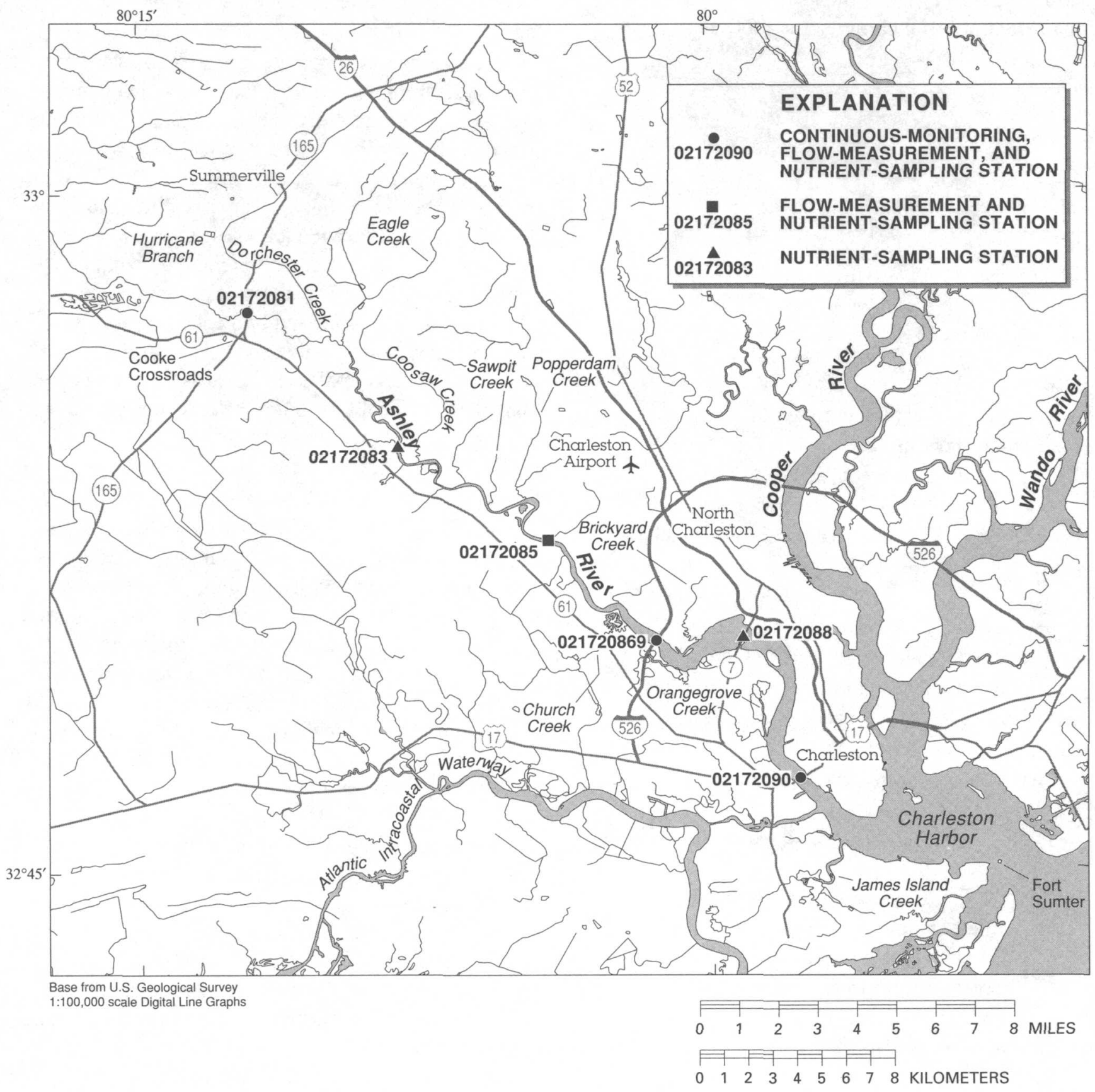

Figure 4. Location of data-collection stations on the Ashley River, South Carolina. 


\section{Water Level and Streamflow}

The BRANCH model is a one-dimensional, dynamic flow computer model for simulation of streamflow in interconnected channels (Schaffranek and others, 1981). The model solves the one-dimensional equations of continuity and motion:

$$
\begin{gathered}
B \frac{\partial Z}{\partial t}+\frac{\partial Q}{\partial x}-q=0, \\
\frac{\partial Q}{\partial t}+\frac{\partial\left(\beta Q^{2} / A\right)}{\partial x}+g A \frac{\partial Z}{\partial x}+\frac{g k}{A R^{4 / 3}} Q|Q|-q u^{\prime} \\
-\xi B_{c} U_{a}^{2} \cos \alpha=0,
\end{gathered}
$$

where

$B$ is the total channel top width, in feet;

$Z$ is the stage, in feet;

$t$ is the time, in seconds;

$Q$ is the discharge, in cubic feet per second;

$x$ is the longitudinal distance along the channel, in feet;

$q$ is the lateral side-channel flow, in cubic feet per second, per foot;

$\beta$ is the dimensionless momentum coefficient;

$A$ is the cross-sectional area, in square feet;

$g$ is the gravitational acceleration constant, in feet per second per second;

$k$ is a function defining flow-resistance;

$R$ is the hydraulic radius, in feet;

$u^{\prime}$ is the $\mathrm{x}$-component of the lateral side-channel

flow velocity, in feet per second;

$\xi$ is the dimensionless wind resistance coefficient;

$B_{c}$ is the top width of the conveyance part of the cross section, in feet; and

$U_{a}$ is the wind velocity in feet per second, occurring at an angle $\alpha$ from the positive $x$-axis.

The flow-resistance function is expressed as $k=(\eta / 1.486)^{2}$, where eta is a flow-resistance coefficient.

In the derivation of equations 1 and 2 , it is assumed that the fluid is homogeneous in density. The channel is assumed to (1) be reasonably straight, (2) have a simple cross-sectional geometry, such as a rect- angular or trapezoidal shape, and (3) have a mild and reasonably constant bottom slope. Approximate solutions for the nonlinear partial-differential unsteadyflow equations are obtained by finite-difference techniques (Schaffranek and others, 1981). A weighted four-point finite-difference approximation is used in the BRANCH model.

In the model, rivers are represented as a series of cross sections and channel lengths, which define segments, junctions, and branches. Channel-geometry data that characterize the conveyance, area, width, and storage capacity at each cross section are input into the model. A segment is defined by an upstream and a downstream cross section and the distance between them. A group of segments separated by junctions is called a branch. The beginning or ending junctions of a branch with no continuing branches are known as external boundaries. Water-level or streamflow data are input at the external boundaries as boundary conditions for the model. All other water levels and streamflows are computed at cross sections. An idealized BRANCH network model schematization is shown in figure 5.

Although there are inherent limitations to applying a one-dimensional model to a highly complex, three-dimensional estuarine system, the BRANCH model has been successfully applied to other estuarine systems, and is appropriate to apply to the Ashley River. Some reaches of the Ashley River are partially stratified; however, there is very little stratification for extended periods. The complex channel geometry of tidal marshes and old rice fields can be simplified in BRANCH as large storage areas that fill and drain with each tidal cycle. BRANCH, unlike some other riverine models, can simulate the converging and branching of interconnected channels. Bower and others (1993) applied the model to the Cooper River and Bushy Park Reservoir, S.C., to analyze retention times in the riverine reservoir. Weiss and others (1994) applied the BRANCH and BLTM models to the tidal Hudson River in New York to simulate streamflow and chloride transport. Drewes and Conrads (1995) applied the BRANCH and BLTM models to the Waccamaw and Pee Dee Rivers and the Atlantic Intracoastal Waterway in South Carolina to determine the assimilative capacity of the system. Conrads and Smith $(1996,1997)$ applied the BRANCH and BLTM models to the Cooper and Wando Rivers in South Carolina to evaluate various point-source loading scenarios. 


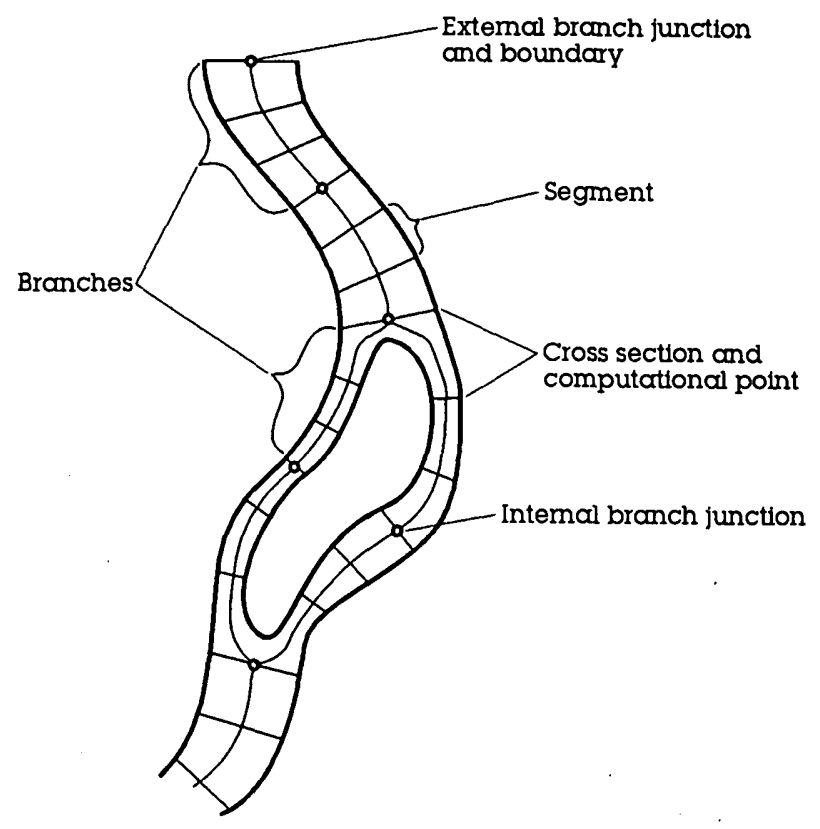

Figure 5. Idealized BRANCH model schematization.

\section{Mass Transport}

The BLTM was used to simulate mass transport in the Ashley River. The BLTM solves the convective-dispersion equation by using a Lagrangian-reference frame in which the computational nodes move with the flow (Jobson and Schoelhamer, 1987). In the Lagrangian-reference frame, the continuity of mass equation is:

$$
\frac{\partial C}{\partial t}=\frac{\partial}{\partial \xi}\left[D \frac{\partial C}{\partial \xi}\right]+S+\Phi+K(C-C R),
$$

where

$C$ is the concentration, in milligrams per liter;

$t$ is time, in seconds;

$\xi$ is the Lagrangian-distance coordinate, in feet; $D$ is the longitudinal dispersion coefficient, in square feet per second;
$S$ is the rate of production of the concentration, which is independent of the concentration (zero-order production rate), in milligrams per liter per second;

$\Phi$ is the rate of change in concentration due to tributary inflow, in milligrams per liter per second;

$K$ is the rate of production of the constituent, in per second; and,

$C R$ is the equilibrium concentration (that is, the concentration at which the internal production ceases), in milligrams per liter.

The Lagrangian-distance coordinate, $\xi$, is given by

$$
\xi=x-x_{o}-\int_{t_{o}}^{t} u d t
$$

where

$x$ is the Eulerian (stationary) distance coordinate along the river, in feet; 
$x_{o}$ is the location of the parcel of water at time $t_{0}$; and,

$u$ is the cross-sectional mean stream velocity, in feet per second.

The BLTM uses a dimensionless dispersion factor in the Lagrangian transport solutions. The dispersion factor is inversely proportional to the square of the stream velocity. The factor is defined as:

$$
\mathrm{D}_{f}=\frac{\mathrm{D}}{\Delta t \mu^{2}}
$$

where

$\mathrm{D}_{f}$ is dispersion factor, dimensionless;

$D$ is dispersion rate, in square feet per second;

$\Delta t$ is simulation time step, in seconds; and

$\mu$ is the representative stream velocity, in feet per second.

The advantage of the Lagrangian-reference frame, especially in a mesotidal environment such as the Ashley River, is that there is minimal numerical dispersion. The BLTM assumes that parcels of water are completely mixed and that volumes are affected only by tributary flows. The variation of concentrations in space and time in a river reach is approximated by solving equation 3 for a series of parcels spaced along the river at intervals approximately equal to $\mu \Delta t$. The resulting concentration at any point is the concentration of the parcel at that location. The assumption of completely mixed parcels may cause interpolation errors when determining the concentration at a given point. The accuracy of a Lagrangian model, as compared to an Eulerian model, is that this interpolation error applies only to the output computations. The grid concentration is not used in further computations, and therefore, the error is not compounded. In an Eulerian model, similar interpolation errors are made at every time-step, and grid concentrations are used as the basis for all further computations, resulting in compounding errors (Jobson, 1981). In BLTM, some numerical dispersion is introduced into the solution scheme at internal junctions.

The advantages of the Lagrangian approach, as outlined above, are (1) the scheme is more accurate in modeling the convection and dispersion terms than the Eulerian approach (Jobson, 1980; Thomson and others, 1984), and (2) the Lagrangian model is stable for any time-step (Jobson, 1981).

\section{Schematization of Models}

The BRANCH model for the Ashley River was schematized using 6 branches, 5 internal junctions, 24 cross sections, and 2 external boundaries (fig. 6). The BLTM for the Ashley River is schematized using 2 branches, 2 external boundaries, and 1 internal junction (figs. 6, 7). In the schematization of the BLTM (fig. 7), internal junctions $1,2,4$, and 5 in the BRANCH model schematization were removed to minimize numerical dispersion.

Numerical instability was observed in the model near the upper boundary. The instability can be attributed to the large difference in streamflows between these upper reaches and lower reaches (200 to 100,000 $\mathrm{ft}^{3} / \mathrm{s}$, respectively). Variables in the model that had the greatest effect in controlling the numerical instability were the streamflow convergence criterion (QQTOL), water-level convergence criterion (ZZTOL), finite-difference weighting factor for the spatial derivatives (THETA), and the finite-difference weighting factor for function values in the equation of motion (CHI). These variables were set to the following values: 200 $\mathrm{ft}^{3} / \mathrm{s} ; 0.10 \mathrm{ft} ; 1.00$; and 0.70 , respectively.

The model was tested for convergence to determine the optimum simulation time-step and space-step (the distance between cross sections) for the simulations. A finite-difference solution to the partial-differential governing equations is convergent if the numerical solution approaches the true solution of the differential equation as the numerical time-step and space-step are decreased (Smith, 1985). Convergence can be tested by repeated simulations of the model with a fixed set of boundary conditions for successively smaller computational time-steps and spacesteps. The model is convergent if no further change in the model results is observed as the time-step and space-step are refined (Thompson, 1992).

Model simulations were generated for successively smaller computational time-steps of $60,30,15$, and 7.5 minutes. Significant differences in model results occurred between the 60 - and 30-minute timesteps and between the 30- and 15-minute time-steps. The differences between the 15- and 7.5-minute timesteps were considered insignificant. Therefore, a 15minute time-step was used in the model. Cross sections defining the system were spaced at approximately 4-, 2-, and 1-mi intervals. No significant differences in the model results were observed. A space-step of 1 to $2 \mathrm{mi}$ was used in the model. 
a) BRANCH Model

Schematization
02172081

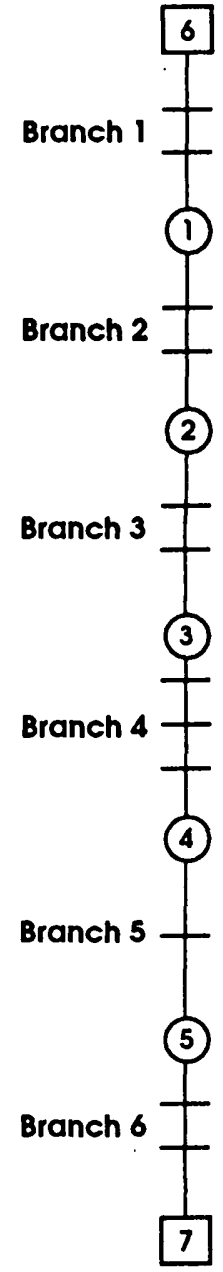

Bacon Brit b) Branched Lagranglan Transport Model Schematization

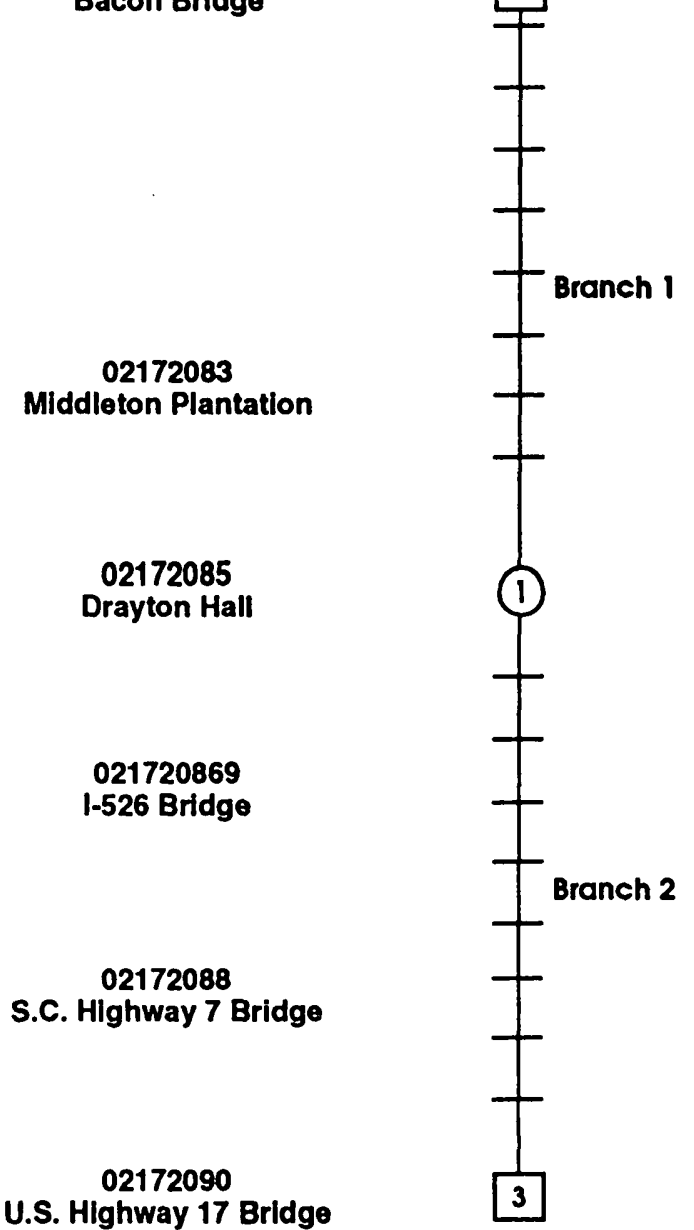

EXPLANATION

6 EXTERNAL BOUINDARY AND CROSS SECITION

INTERNAL JUNCTON AND CROSS SEITTION

CROSS SECTION

Figure 6. BRANCH model (a) and Branched Lagrangian Transport Model (b) schematizations for the Ashley River, South Carolina. 


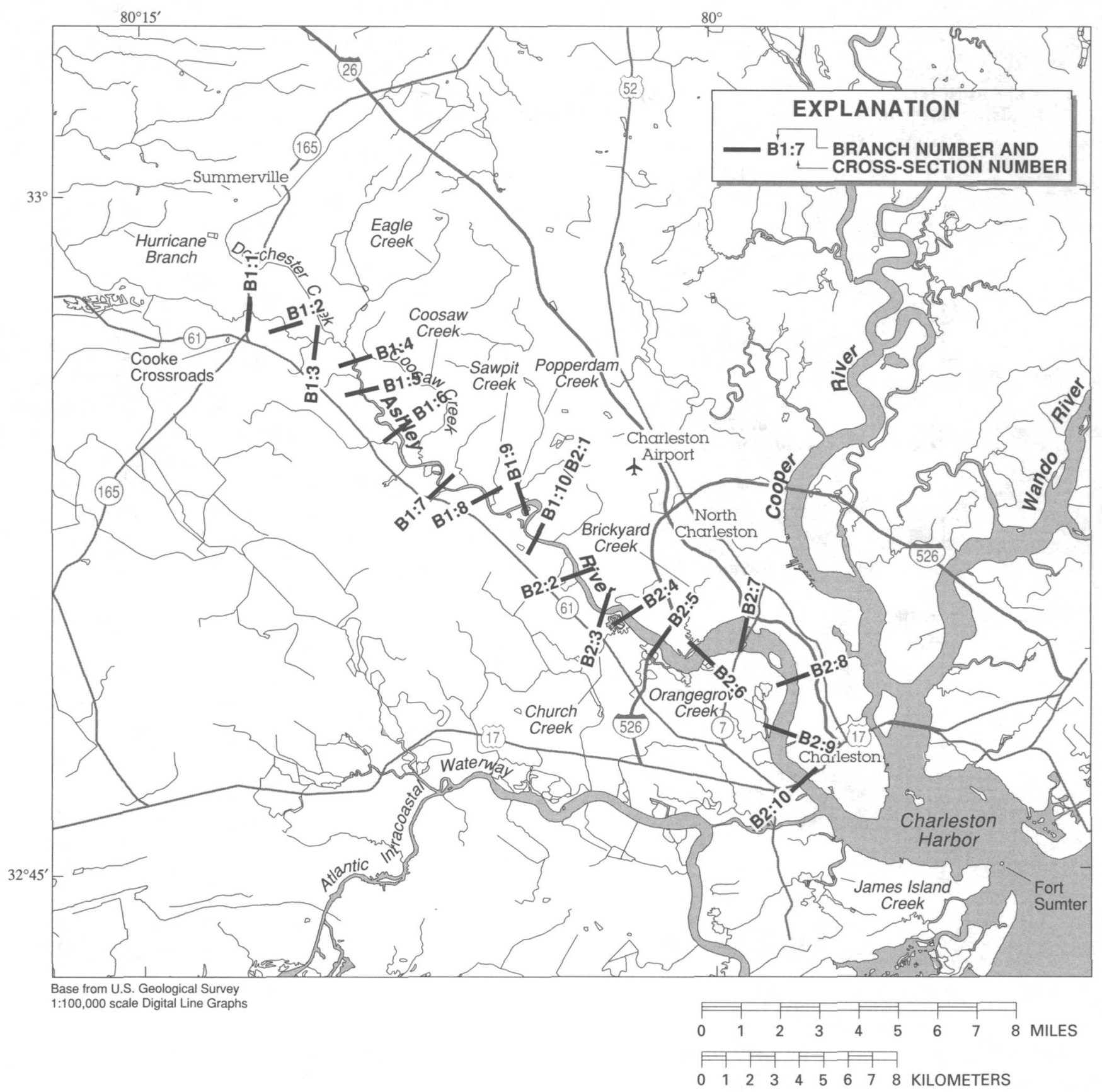

Figure 7. Location of branches and cross-sections used in the Branched Lagrangian Transport Model for the Ashley River, South Carolina. 


\section{Calibration and Validation of Water Level, Streamflow, and Mass Transport}

Measured water-level, streamflow, and salinity data collected during the summer and fall of 1992 and longitudinal salinity profiles collected during the fall of 1993 were used to calibrate and validate the BRANCH and BLTM models. Calibration was accomplished by adjusting flow-resistance coefficients, gage datums, cross-sectional areas, storage volumes, and dispersion-rate model parameters until simulated and measured (or calculated) values agreed. Because the model will ultimately be used to simulate the fate and transport of conservative and non-conservative constituents, emphasis was placed on the salinity-transport simulations during the calibration and validation. The models were validated using measured data different from those used for calibration. The parameters used to calibrate the hydraulic and mass-transport models were not changed in the validation process. To be consistent with the calibration and validation periods used for the water-quality models, September 1992 was used for calibration and July 1992 was used for validation.

Results of the flow-model calibration and validation are presented in hydrographs of simulated and measured water level and streamflow; results of the transport model are presented as time series of simulated and calculated salinity. Summary statistics were generated to quantify the error of the calibration and validation simulations and are presented in tabular form. Summary statistics for water-level simulations include timing error, mean of the residuals, and the standard deviation of the residuals. Quite often, the model simulates the shape of a plot of the measured data but has a timing error where the data are simulated earlier or later than the measured data. The timing error was computed by correlating measured values with the simulated values offset forward or backwards in time. The time period having the highest correlation coefficient was assumed to be the timing error of the simulation. The mean and standard deviation of the residuals were computed after the adjustment for the timing error. An adjustment was made for the timing error, because modeled results that maintain the shape of the plotted measured data are acceptable, even with moderate timing errors. The mean of the residuals is a measure of the bias of the simulation, and is an indication of how much higher or lower the simulated values were relative to the measured values. The standard deviation of the residuals is a measure of the scatter of the residuals about the mean of the residuals.

For the streamflow simulations, the timing error was computed by the same method used for the waterlevel simulations. After correcting the simulations for the timing error, an index of the mean of the residuals (given as a percentage) was computed by multiplying 100 times the mean of the residuals divided by the mean of the absolute values of the measured streamflows. Normally, percent residuals can be scaled by using logarithms of streamflows, but logarithms cannot be used for negative streamflows. Percent residuals also could be scaled by the mean streamflow, but the mean for tidal streamflows is often zero or near zero. Therefore, the mean of the absolute values of the streamflows was used to give an indication of the magnitude of streamflows being measured at the location of the simulation. The index is not a true percentage, because it will not be representative throughout the ranges of streamflows of the simulations (especially when those values are low or pass through zero as the streamflow reverses). However, the index of the mean of the residuals does indicate whether the model is over- or under-simulating the measured streamflow and is a usable index for comparing simulations at one station and between stations. An index of the standard deviation of the residuals (also given as a percentage) was computed by multiplying 100 times the standard deviation of the residuals divided by the mean of the absolute values of the measured streamflow. As with the index of the mean of the residuals, the index is not a true percentage but is a useful indicator of the scatter of the simulations.

The mean value should be considered in evaluating the magnitude of the indices of the mean or standard deviation of the residuals. For example, a large value for the index of the mean of the residuals for a small mean streamflow does not have the same effect on the transport in the main stem as an identical index associated with a large mean streamflow. The mean absolute values of measured streamflow also are listed with the statistical summaries.

For the salinity simulations, indices of mean residuals and the standard deviation of residuals were computed by the same method used for streamflow simulations, except that it was unnecessary to take the absolute values of the calculated salinities. The mean values of measured calculated salinities also are listed with the statistical summaries. 
The widths of the storage areas adjacent to the Ashley River were varied to calibrate the hydraulic model. The Ashley River is characterized by extensive Spartina alterniflora marshes with meandering tidal creeks that extend for several miles. During every flood tide, these creeks and marshes are inundated with a few feet of water that drains into the river on the subsequent ebb tide. To simulate this hydraulic feature, the "dead" storage function in the BRANCH model was used. The BRANCH model routes water into "dead" storage where water only moves laterally into and out of storage and there is no net upstream or downstream flow of water over the storage area.

A gage-height datum adjustment to the downstream boundary station (02172090) of $-0.15 \mathrm{ft}$ was used to improve the salinity concentration simulations (fig. 4). Without the datum adjustment, the transport model would over predict the salinity concentrations and under predict the tidal amplitude of the measured salinity concentrations. The datum adjustment increased the slope of the system and, therefore, increased the amount of ebb tide (positive flow) and decreased the amount of flood tide (negative flow). A datum adjustment of $-0.15 \mathrm{ft}$ is an adjustment of 0.000001 foot per foot $(\mathrm{ft} / \mathrm{ft})$ over the length of the modeled reach of the Ashley River. The $-0.15 \mathrm{ft}$ datum adjustment to the downstream boundary had a positive effect on the salinity transport, but with adversely affecting the water-level and streamflow simulations. At station 021720869 , the water-level simulations using the datum adjustment decreased the height of the high- and low-slack tides by the amount of the adjustment applied to the downstream station.

Comparisons of the simulated and measured water levels at station 021720869 (fig. 8, table 3) show that the model under predicted the water level for the calibration and validation simulations. The mean of the residuals of the water levels for both simulations was $-0.36 \mathrm{ft}$ and the standard deviation of the residuals was 0.18 and $0.17 \mathrm{ft}$, respectively. The timing errors of the simulations were 15 minutes or less for the two simulations.

For the calibration period (September 1992), the simulated streamflows for the lower three stations $(02172085,021720869$, and 02172090) under predicted the peak streamflow, but compared more closely with the measured streamflows than for the upper station (02172081) (fig. 9, table 4). It is often difficult to get satisfactory agreement between measured and simulated streamflows in tidal sloughs, such as the Ashley River, when the streamflows vary by two or more orders of magnitude between the upstream and downstream boundaries. During model calibration, emphasis was placed on producing accurate simulations of the large volume of water exchanged on every tidal cycle through the middle and lower reaches of the Ashley River. At the upper model boundary (station 02172081) (fig. 9a), the shapes of the simulated and measured streamflow calibration hydrographs did not agree as demonstrated by the large index of the standard deviation of the residuals ( 93.7 percent) and by the magnitude of the simulated and measured streamflows as seen in the index of the mean of the residuals of -59.1 percent. The large error in the index of standard deviation was acceptable because of the low streamflows. These streamflows are only a small percentage of streamflows elsewhere in the study area. The streamflow calibration simulations of the other three stations ( 02172085 , 021720869 , and 02172090 ) under predicted the measured streamflow by $1.0,9.2$, and 4.5 percent, respectively (fig. 9b-d). The index of the standard deviation of the residuals at the three sites ranged from 14.9 to 24.3 percent.

For the validation period (July 1992), the simulated streamflows for the lower two stations (021720869 and 02172090) compared more favorably with the measured streamflows than for the upper two stations (02172081 and 02172085) (fig.10, table 4). At the upper model boundary (station 02172081) (fig. $10 \mathrm{a})$, there was not favorable agreement between the shapes of the simulated and measured streamflow validation hydrographs as seen in the large index of the standard deviation of the residuals of 203 percent. However, there was favorable agreement between the magnitude of the simulated and measured streamflows as seen by the low index of the mean of the residuals of 2.3 percent. The streamflow validation simulations of the other three stations $(02172085,021720869$ and 02172090) under predicted the measured streamflow by $4.8,8.7$, and 4.0 percent, respectively (fig. $10 \mathrm{~b}-\mathrm{d}$ ). The index of the standard deviation of the residuals at the three sites ranged from 10.7 to 40.2 percent.

The calibration of the mass-transport model was accomplished by a datum adjustment of $-0.15 \mathrm{ft}$ to the downstream boundary station (02172090), as previously discussed with regards to the hydraulic model, and by adjustments to the dispersion factor. In the upper reaches of the Ashley River, where there are meanders and debris within the channel, a dispersion 

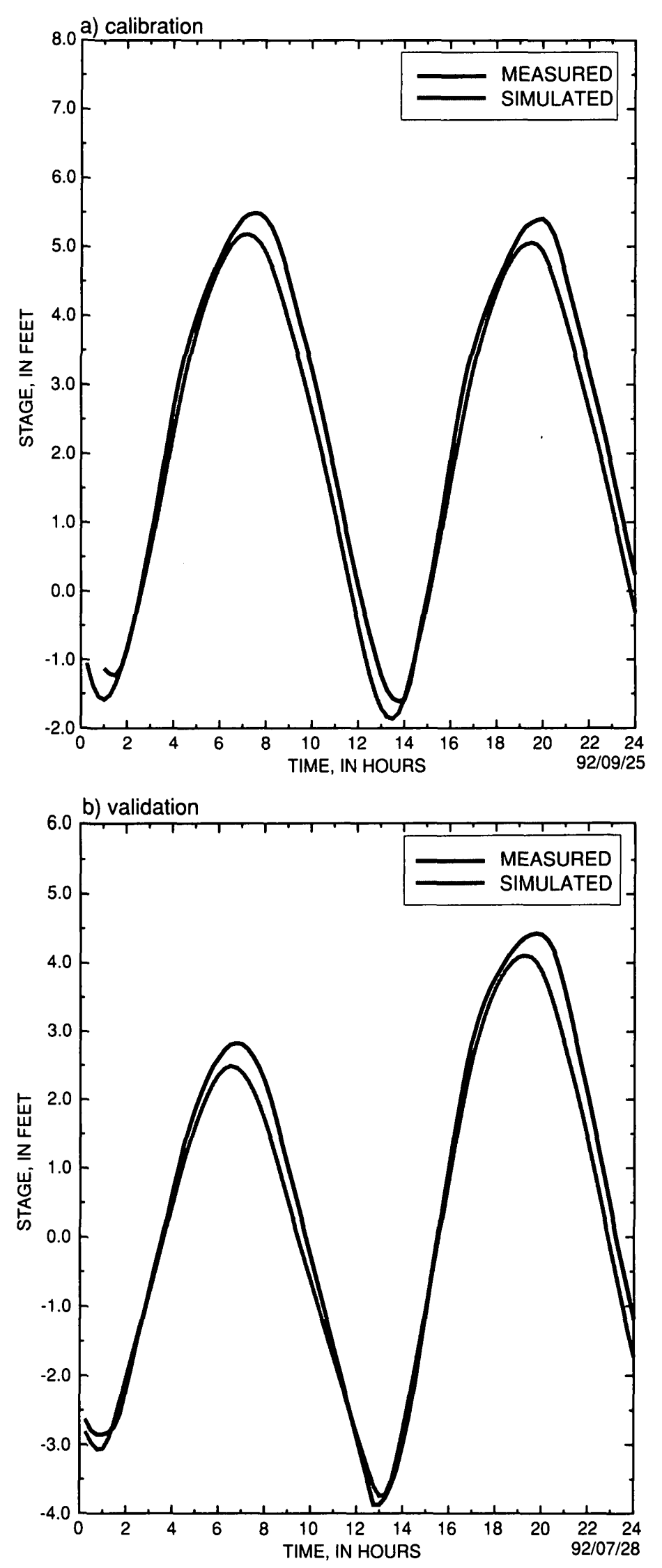

Figure 8. Simulated and measured water levels used in the (a) calibration and (b) validation of the hydraulic model of station 021720869 on the Ashley River, South Carolina. 

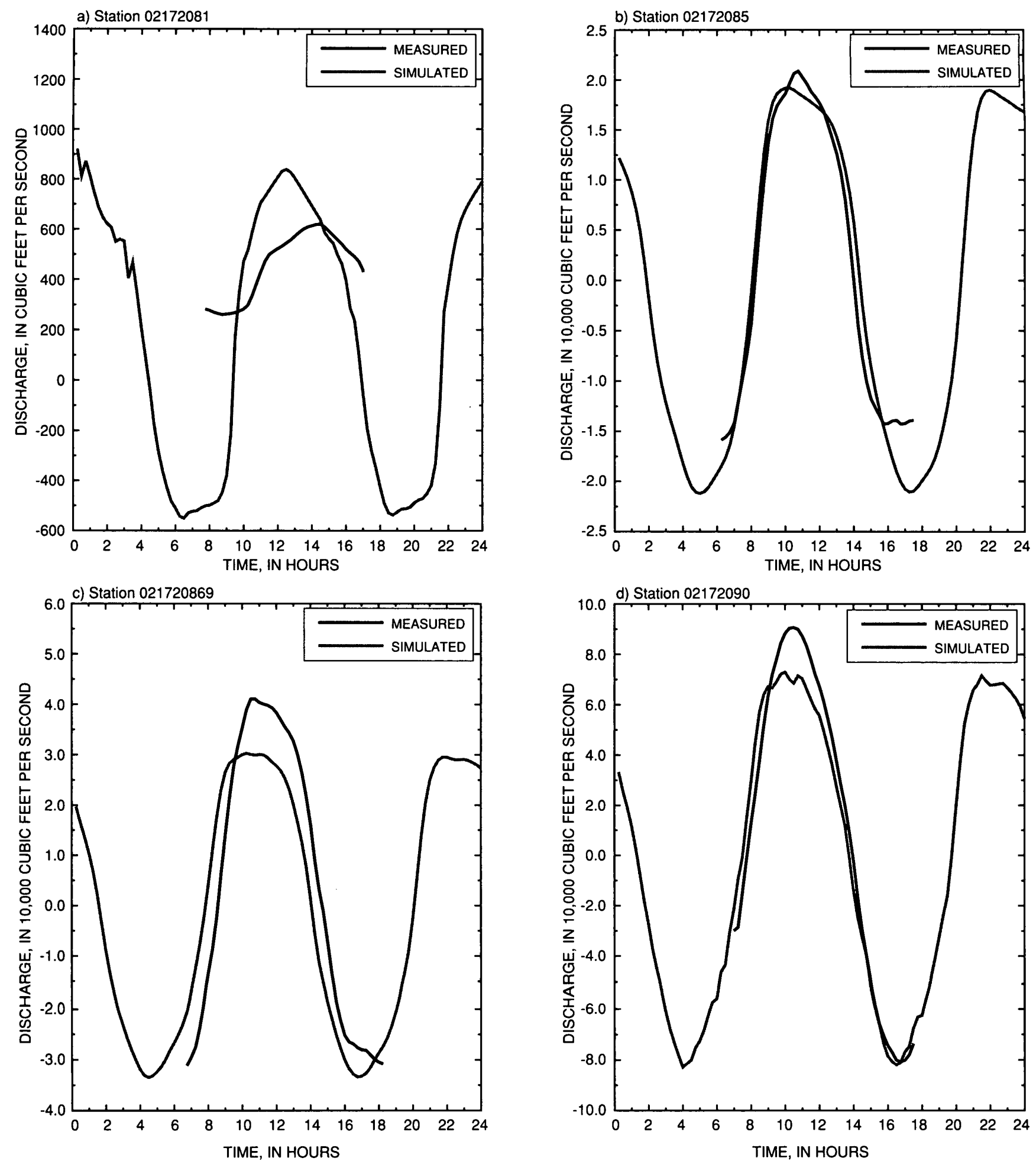

Figure 9. Simulated and measured streamflows used in the hydraulic model calibration for four locations on the Ashley River, South Carolina, September 25, 1992. 
Table 3. Summary of water-level calibration and validation simulations for station 021720869 on the Ashley River, South Carolina

\begin{tabular}{ccccc}
\hline Date & $\begin{array}{c}\text { Number of } \\
\text { data points }\end{array}$ & $\begin{array}{c}\text { Timing error } \\
\text { (minutes) }\end{array}$ & $\begin{array}{c}\text { Mean of } \\
\text { residuals }{ }^{2} \\
\text { (feet) }\end{array}$ & $\begin{array}{c}\text { Standard } \\
\text { deviation of } \\
\text { residuals } \\
\text { (feet) }\end{array}$ \\
\hline $9 / 25 / 92$ & 92 & Calibration & & \\
$7 / 28 / 92$ & 97 & -15 & -0.36 & 0.18 \\
\hline
\end{tabular}

1 Positive timing error means the simulated water-level time series occurred later than the measured water-level time series.

2 Residual is computed by subtracting the measured water level from the simulated water level, after adjusting the simulated water levels for timing errors.

Table 4. Summary of streamflow calibration and validation simulations for four locations on the Ashley River, South Carolina $\left[\mathrm{ft}^{3} / \mathrm{s}\right.$, cubic feet per second]

\begin{tabular}{|c|c|c|c|c|c|c|}
\hline $\begin{array}{l}\text { Station } \\
\text { (flg. 4) }\end{array}$ & Date & $\begin{array}{l}\text { Number of } \\
\text { data points }\end{array}$ & $\begin{array}{l}\text { Timing } \\
\text { error }^{1} \\
\text { (minutes) }\end{array}$ & $\begin{array}{l}\text { Index of the } \\
\text { mean of the } \\
\text { residuals }{ }^{2} \\
\text { (percent) }\end{array}$ & $\begin{array}{l}\text { Index of the } \\
\text { mean of the } \\
\text { standard } \\
\text { deviation } \\
\text { of the } \\
\text { residuals } \\
\text { (percent) }\end{array}$ & $\begin{array}{c}\text { Mean } \\
\text { absolute } \\
\text { measured } \\
\text { streamflow } \\
\left(\mathrm{ft}^{3} / \mathrm{s}\right)\end{array}$ \\
\hline \multicolumn{7}{|c|}{ Calibration } \\
\hline 02172081 & 9/25/92 & 44 & -75 & -59.1 & 93.7 & 431 \\
\hline 02172085 & $9 / 25 / 92$ & 46 & 0 & -1.0 & 24.3 & 13,100 \\
\hline 021720869 & $9 / 25 / 92$ & 49 & -45 & -9.2 & 18.8 & 25,800 \\
\hline 02172090 & $9 / 25 / 92$ & 43 & -15 & -4.5 & 14.9 & 55,300 \\
\hline \multicolumn{7}{|c|}{ Validation } \\
\hline 02172081 & $7 / 30 / 92$ & 48 & 15 & 2.3 & 203 & 93.9 \\
\hline 02172085 & $7 / 30 / 92$ & 48 & -15 & -4.8 & 40.2 & 8,670 \\
\hline 021720869 & $7 / 30 / 92$ & 51 & 0 & -8.7 & 16.8 & 17,100 \\
\hline 02172090 & 7/30/92 & 44 & 0 & -4.0 & 10.7 & 45,200 \\
\hline
\end{tabular}

1 Positive timing error means the simulated streamflows occurred later than the measured streamflows.

2 Percentage of the mean of the residual is computed by dividing the mean of the streamflow residual by the mean absolute measured streamflow, after adjusting the simulated streamflows for timing errors.

3 Percentage of the standard deviation of the residuals is computed by dividing the standard deviation of the streamflow residuals by the mean absolute measured streamflow, after adjusting the simulated streamflows for timing errors. 

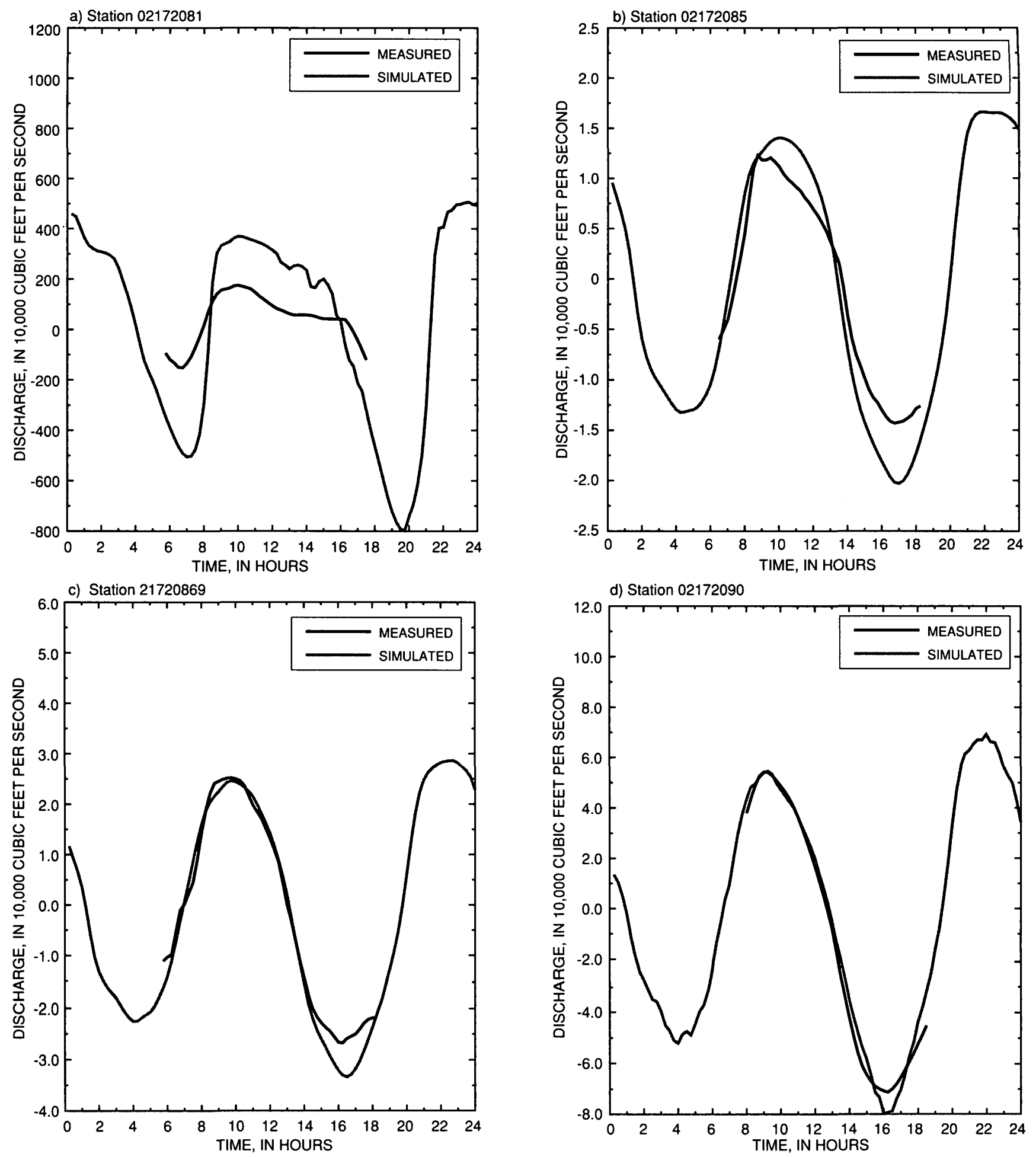

Figure 10. Simulated and measured streamflows used in the hydraulic model validation for four locations on the Ashley River, South Carolina, July 28, 1992. 
factor of 1.25 was used. The dispersion factor was decreased to 0.50 for the lower reaches of the model. The simulated and measured salinity values compare favorably for the calibration and validation periods for station 021720869 (fig. 11, table 5). The model slightly over simulated the salinity concentrations as seen in the low, but positive, index of the mean of the residuals of less than 6 percent for all four simulations. For the calibration and validation periods, the simulated salinity time series did not have the amplitude of the measured salinity concentrations. The calibration simulations had a timing error of 1 hour. The three validation simulations had timing errors of 1 hour or less.

In addition to the validation simulation of July 30, 1992, two periods from the fall and winter of 1993 were simulated to incorporate the periods when the high- and low-slack tide longitudinal salinity profiles were measured (figs. 12, 13; table 5). These simulations are particularly useful in evaluating the performance of the mass-transport model in the vicinity of Middleton Plantation (station 02172083, fig. 4).

Although continuous measured salinity concentrations are not available at this station, the comparison of high- and low-slack tide concentrations with simulated values shows that the model is adequately simulating the mass transport in this reach of the model (figs. 12a, 13a). Overall, the model simulations of water levels, streamflows, and salinity concentrations are satisfactory for the purposes of this study.

Table 5. Summary of salinity calibration and validation simulations for station 021720869 on the Ashley River, S.C.

[ppt, parts per thousand]

\begin{tabular}{|c|c|c|c|c|c|}
\hline Date & $\begin{array}{l}\text { Number of } \\
\text { data points }\end{array}$ & $\begin{array}{l}\text { Timing } \\
\text { errori } \\
\text { (minutes) }\end{array}$ & $\begin{array}{l}\text { Index of the } \\
\text { mean of the } \\
\text { residuals } \\
\text { (percent) }\end{array}$ & $\begin{array}{l}\text { Index of the } \\
\text { mean of the } \\
\text { standard } \\
\text { deviation of } \\
\text { the } \\
\text { residuals } \\
\text { (percent) }\end{array}$ & $\begin{array}{c}\text { Mean } \\
\text { measured } \\
\text { salinity } \\
(p p t)\end{array}$ \\
\hline \multicolumn{6}{|c|}{ Calibration } \\
\hline 9/24-26/92 & 70 & 60 & 3.3 & 18.3 & 9.3 \\
\hline \multicolumn{6}{|c|}{ Validation } \\
\hline $7 / 28-8 / 3 / 92$ & 152 & 0 & 5.4 & 9.0 & 14.9 \\
\hline $10 / 1-15 / 93$ & 311 & 60 & 4.2 & 3.6 & 20.0 \\
\hline $11 / 15-12 / 15 / 93$ & 743 & 60 & 2.2 & 6.0 & 19.6 \\
\hline
\end{tabular}

${ }^{1}$ Positive timing error means the simulated salinity time series occurred later than the calculated salinity time series.

2 Percentage of the mean of the residual is computed by dividing the mean of the simulated salinity residual by the mean measured salinity, after adjusting for timing errors.

${ }^{3}$ Percentage of the standard deviation of the residuals is computed by dividing the standard deviation of the simulated salinity residuals by the mean measured salinity, after adjusting for timing errors. 


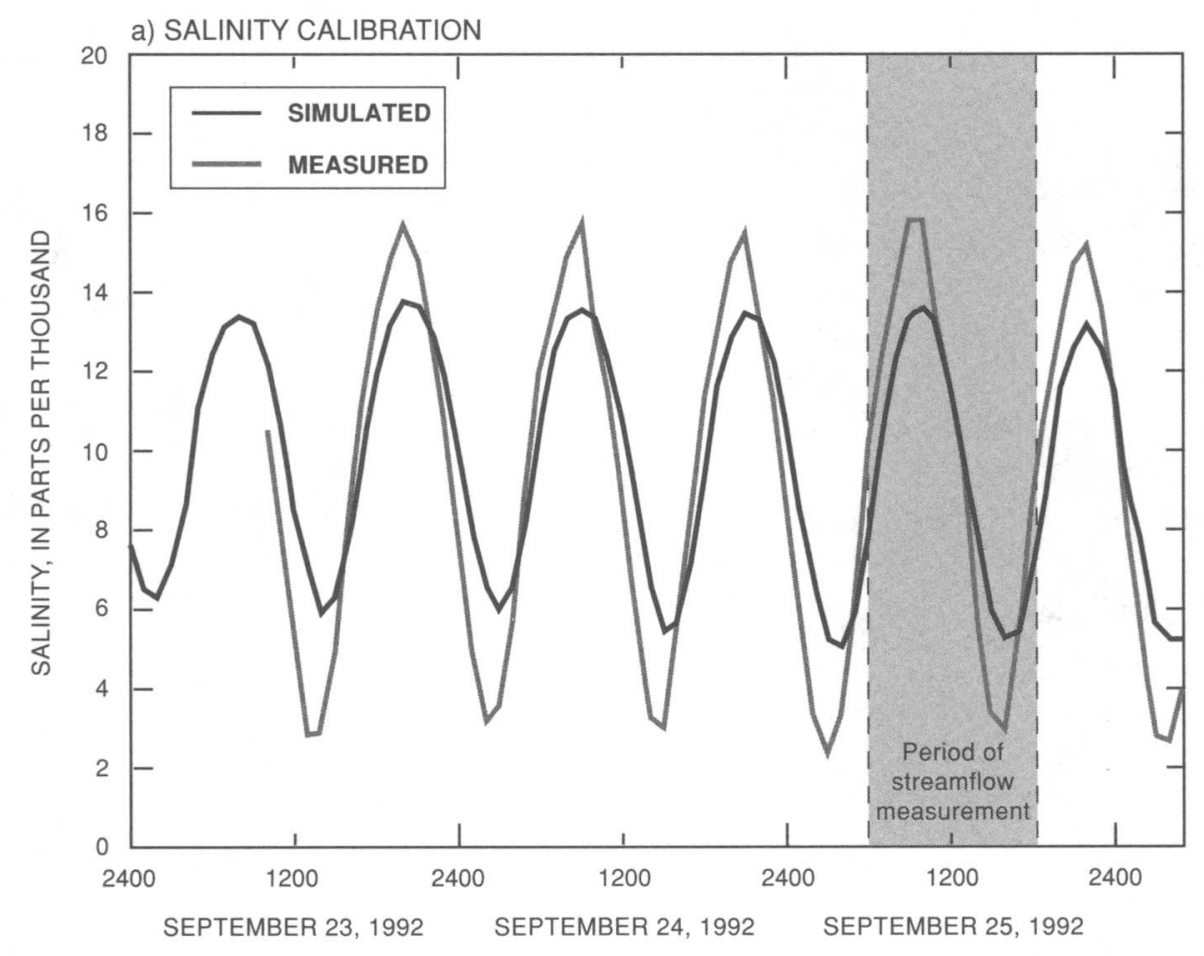

b) SALINITY VALIDATION

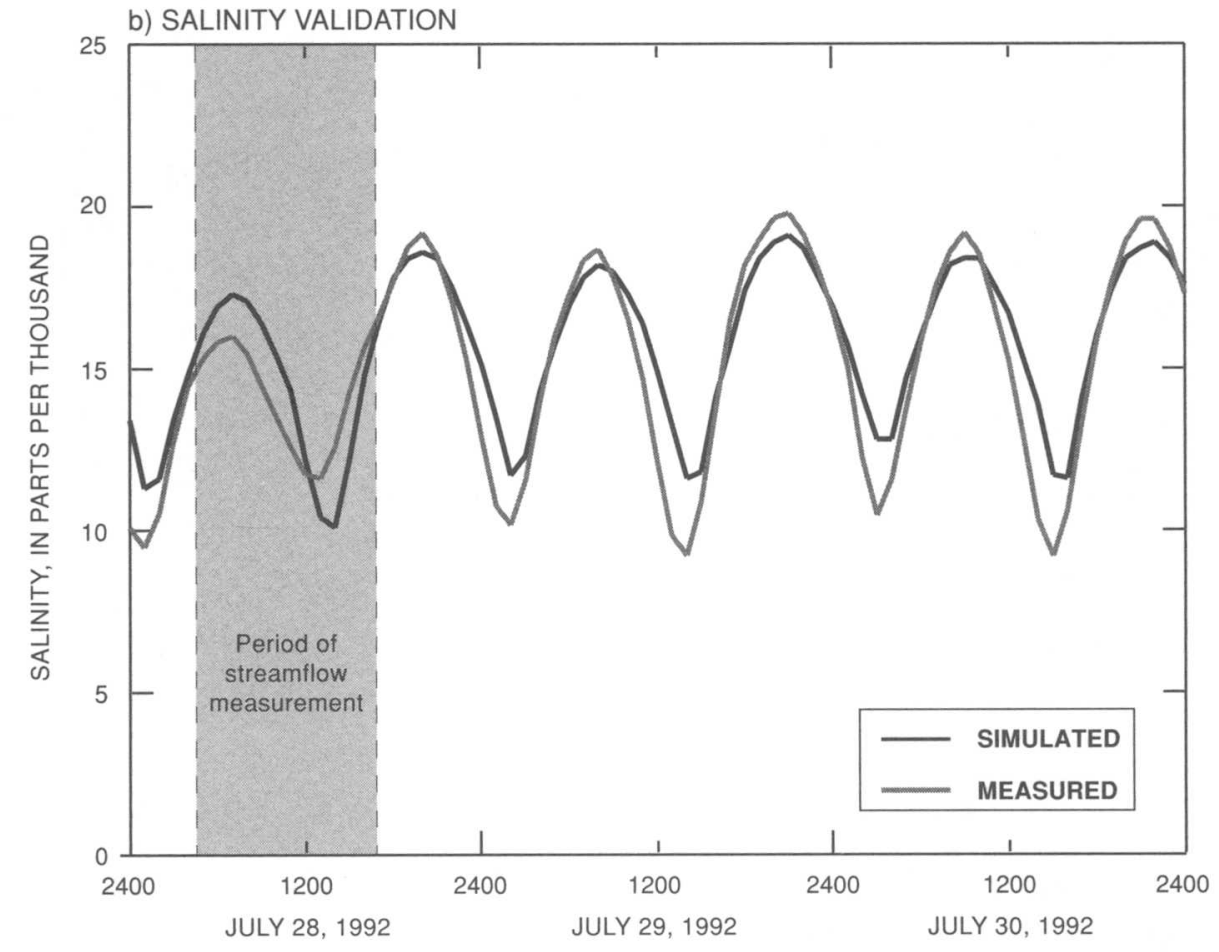

Figure 11. Simulated and measured salinity concentrations used in the mass-transport model calibration and validation for station 021720869 on the Ashley River, South Carolina. 
a) Station 02172083

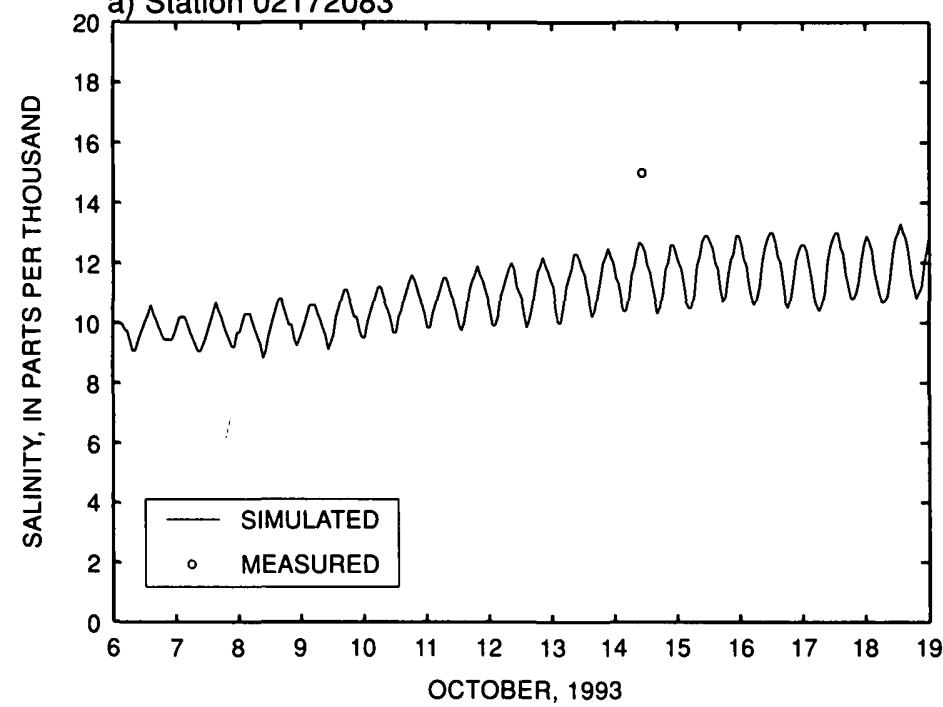

c) Station 021720869

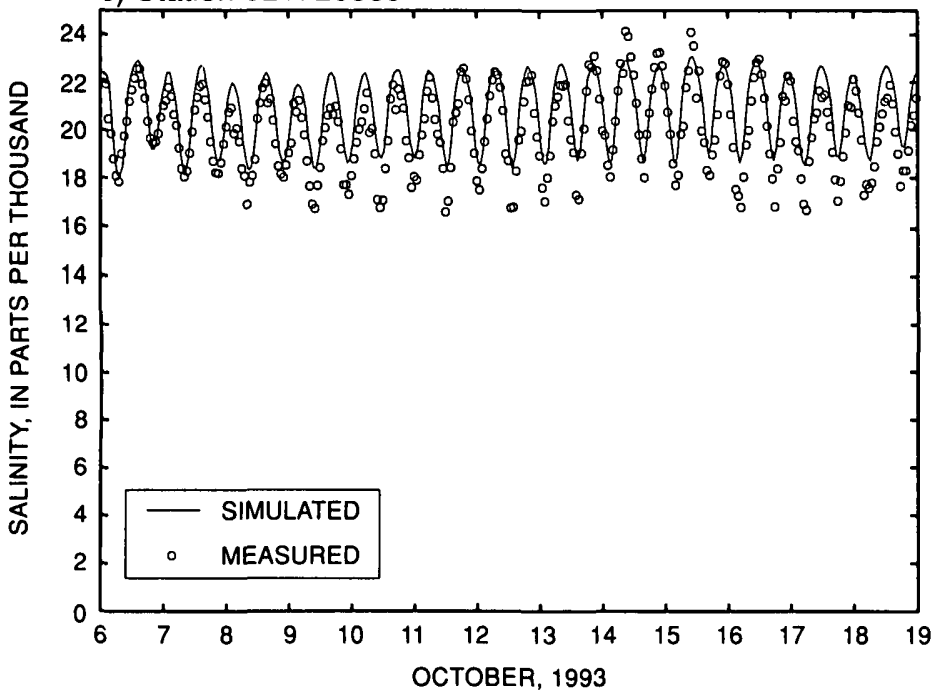

b) Station 02172085
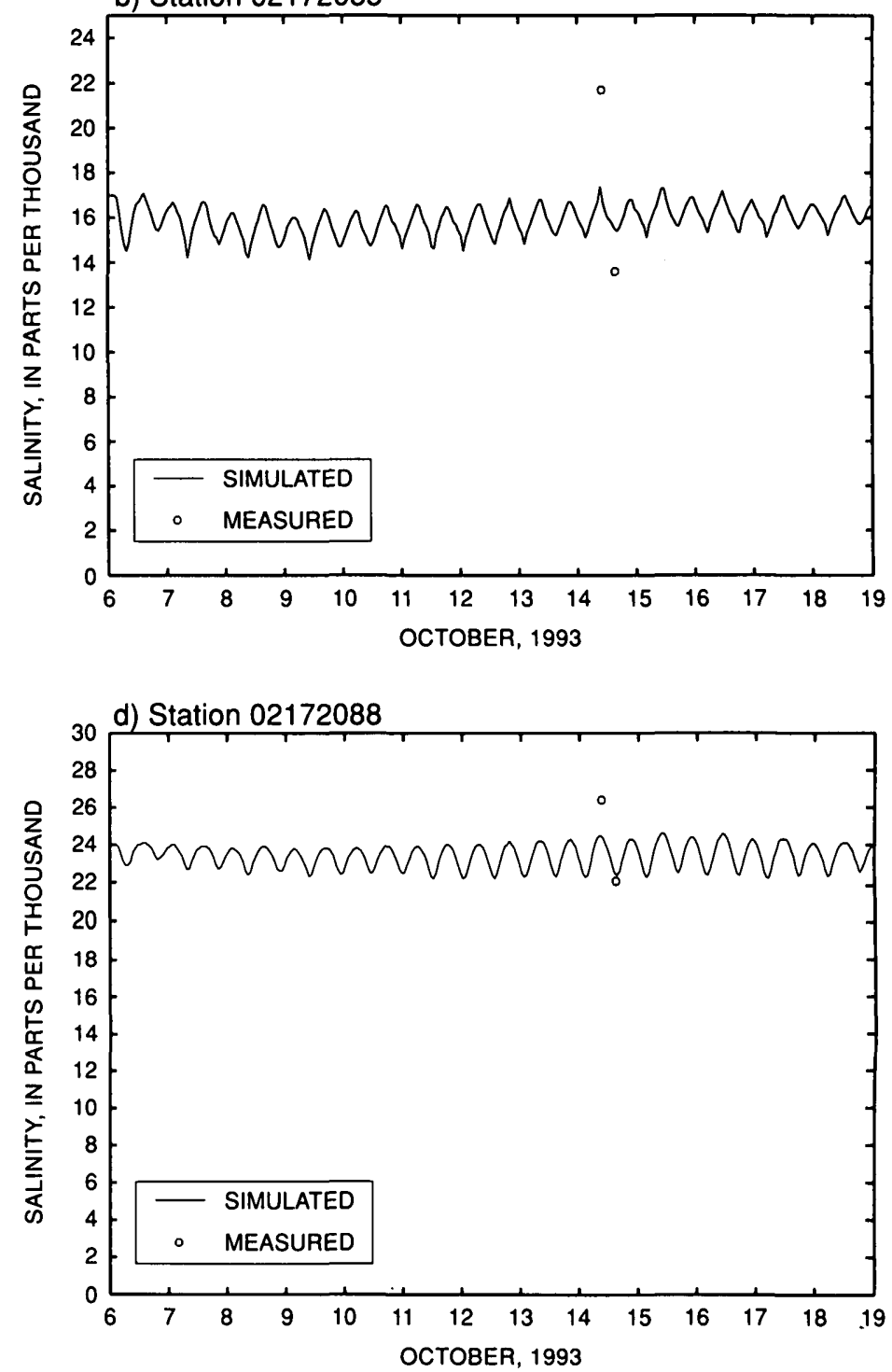

Figure 12. Simulated and measured salinity concentrations for four locations on the Ashley River, South Carolina, October 6-19, 1993. 
a) Station 02172083
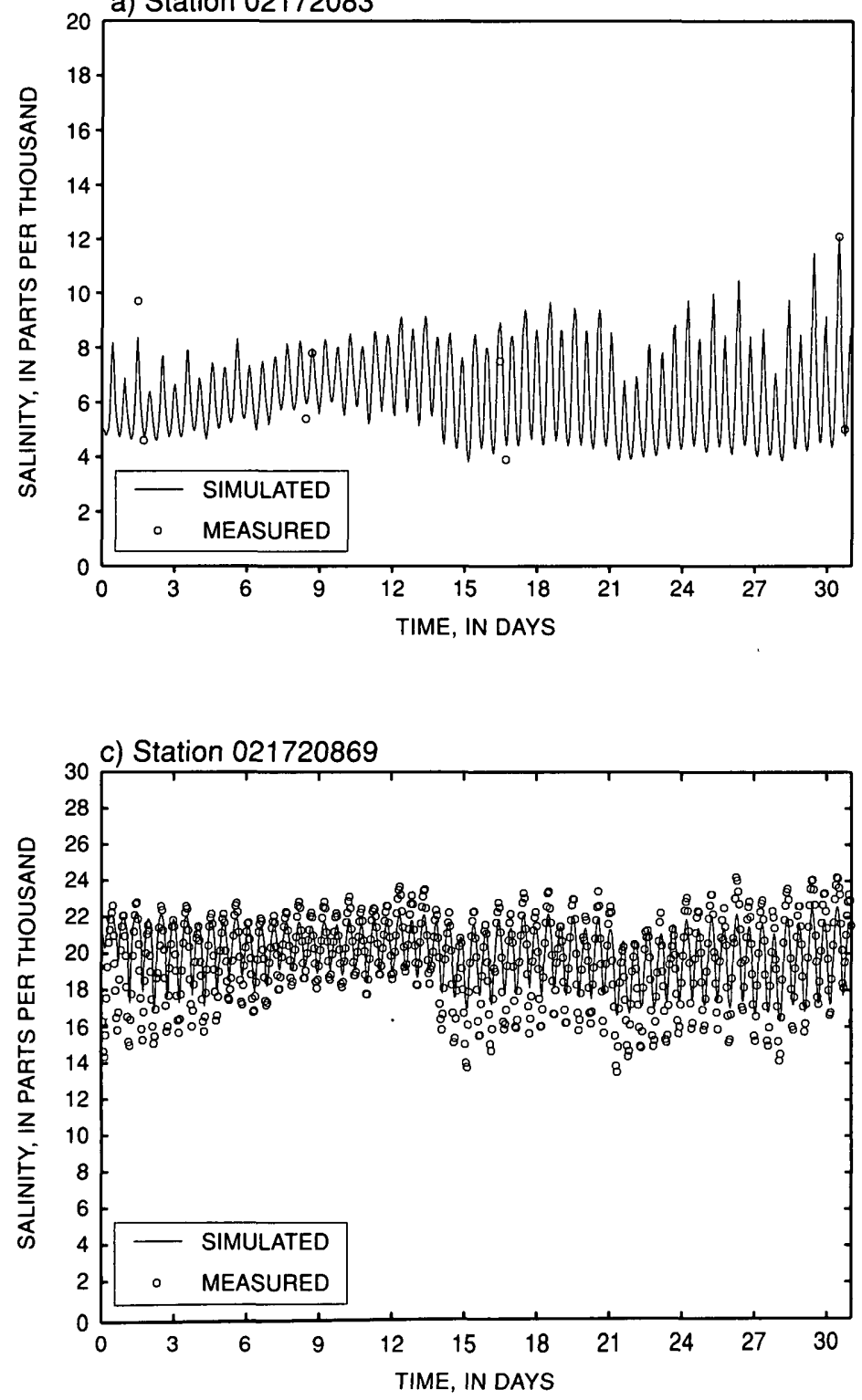

b) Station 02172085

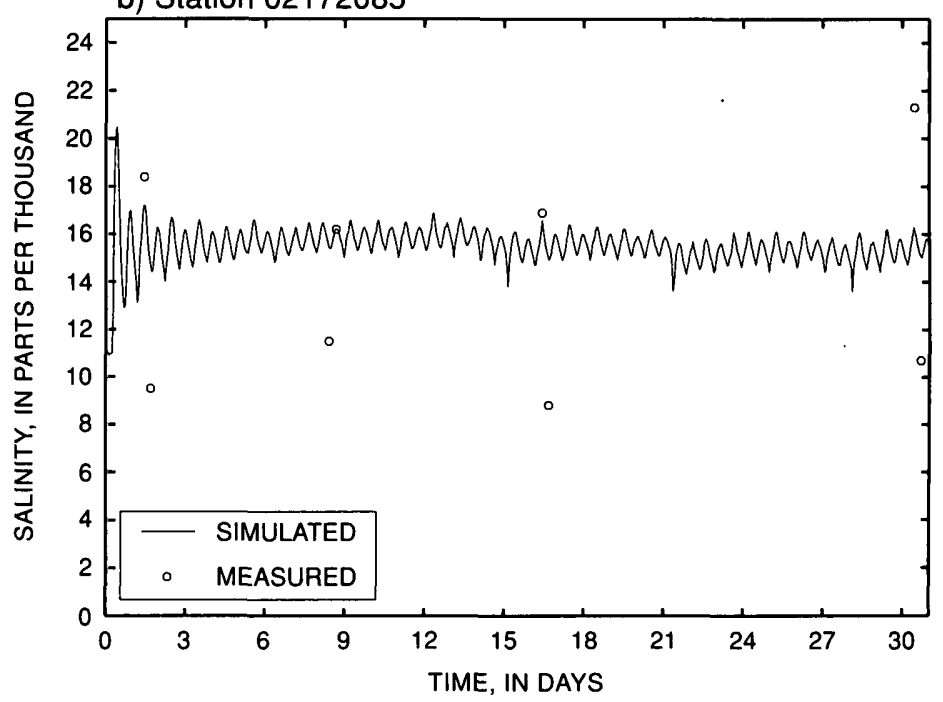

d) Station 02172088

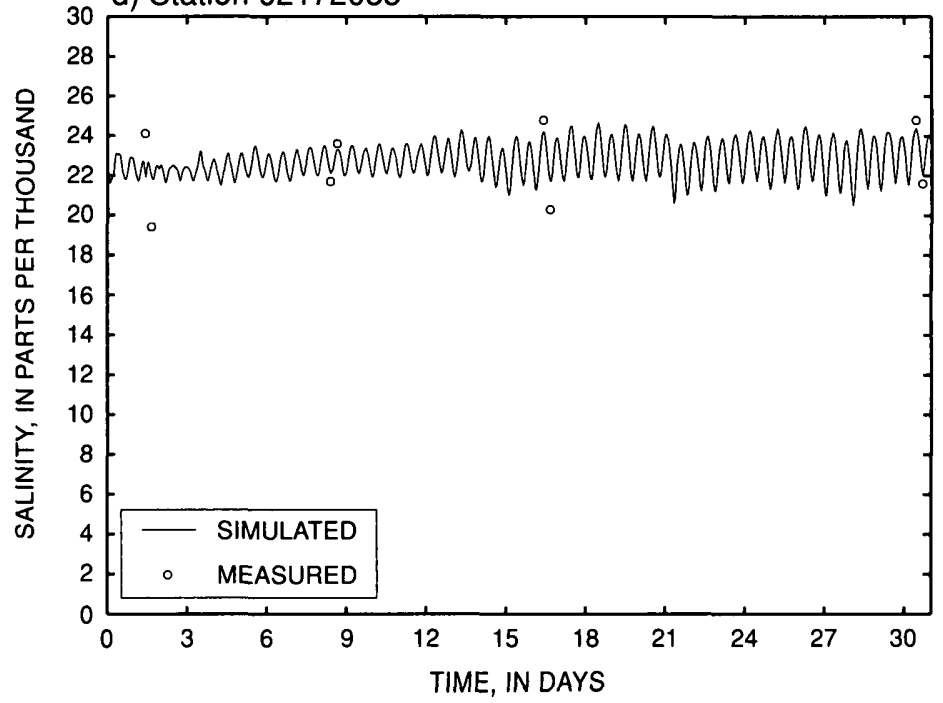

Figure 13. Simulated and measured salinity concentrations for four locations on the Ashley River, South Carolina, November 15 to December 15, 1993. 


\section{Sensitivity Analysis}

The sensitivities of the simulated water level, streamflow, and salinity concentrations to changes in downstream gage datum, cross-sectional area, and flow-resistance coefficient in the BRANCH model, and the sensitivity of the simulated salinity to changes in dispersion factors in the BLTM were analyzed. The models were used to simulate water level, streamflow, and salinity transport at station 021720869 during July 28-30, 1992.

The water-level simulations were most sensitive to changes in the downstream gage datum (fig. 14a). Lowering the downstream gage datum by $0.5 \mathrm{ft}$ (from -9.85 to $-10.35 \mathrm{ft}$ ) decreased the high-slack tide on July 28,1992 , from 2.47 to $1.97 \mathrm{ft}$ and decreased the low-slack tide from -2.71 to $-3.29 \mathrm{ft}$. Water levels were least sensitive to changes in cross-sectional area (fig. 14c). A 50-percent increase or decrease in the cross-sectional area throughout the model had very little effect on the simulated water level (fig. 14c).

Whereas the water-level simulations were insensitive to changes in the cross-sectional area, streamflow simulations were sensitive to these changes (fig. 14d). A 50-percent increase in the crosssectional area (equivalent to a 50-percent increase in the volume of the model) increased the peak floodand ebb-tidal streamflow of July 29, 1992, from 21,100 to $-31,600 \mathrm{ft}^{3} / \mathrm{s}$ and 17,900 to $26,800 \mathrm{ft}^{3} / \mathrm{s}$, respectively. A 50-percent decrease in the cross-sectional area decreased the peak flood- and ebb-tidal streamflow from $-21,100$ to $-10,500 \mathrm{ft}^{3} / \mathrm{s}$ and 17,900 to $8,900 \mathrm{ft}^{3} / \mathrm{s}$, respectively. Streamflows also were sensitive to changes in the flow-resistance coefficient (eta) (fig. 14f). Increasing eta by 50 percent decreased the peak flood- and ebb-tidal streamflows of July 29 , 1992 , from $-21,100$ to $-16,000 \mathrm{ft}^{3} / \mathrm{s}$ and 17,900 to $12,700 \mathrm{ft}^{3} / \mathrm{s}$, respectively. Decreasing eta by 50 percent increased the peak flood- and ebb-tidal streamflow from $-21,100$ to $-26,400 \mathrm{ft}^{3} / \mathrm{s}$ and 17,900 to $26,000 \mathrm{ft}^{3} / \mathrm{s}$, respectively. Raising or lowering the downstream gage datum by $0.5 \mathrm{ft}$ had little effect on the simulated streamflow (fig. 14b).

The simulated salinity concentrations are sensitive to changes in gage datum, flow-resistance coefficient, and dispersion factor, and relatively insensitive to changes in cross-sectional area (fig. 15). An increase of $0.5 \mathrm{ft}$ in the downstream gage datum (from -9.85 to $-9.35 \mathrm{ft}$ ) increased the salinity concentrations, especially the minimum concentrations (fig. 15a). The mean salinity concentration for the 3-day simulation
(July 28-30, 1992) increased 6 percent (15.5 to 16.4 parts per thousand (ppt)). The standard deviation of the simulated salinity concentrations decreased from 2.5 to $2.2 \mathrm{ppt}$. A decrease of $0.5 \mathrm{ft}$ in the downstream gage datum (from -9.85 to $-10.35 \mathrm{ft}$ ) decreased the 3day mean salinity concentration by 6 percent $(15.5$ to $14.6 \mathrm{ppt}$ ) and the standard deviation increased from 2.5 to $2.8 \mathrm{ppt}$. A 50-percent increase or decrease in the cross-sectional area had no significant effect on the simulated salinity concentrations (fig. 15b).

The effects of a 50-percent change in the flowresistance coefficient on salinity concentrations were calculated. A 50-percent decrease in eta increased the flows through the system, decreased the 3-day mean salinity concentration by 7 percent ( 15.5 to $14.4 \mathrm{ppt}$ ), and increased the standard deviation from 2.5 to 3.6 ppt (fig. 15c). A 50-percent increase in eta decreased the flows in the system, increased the 3-day mean salinity concentration by 3 percent ( 15.5 to $16.0 \mathrm{ppt}$ ), and decreased the standard deviation from 2.5 to 1.9 ppt.

A 50-percent change in the dispersion factor had a minimal effect on salinity concentrations. An increase in the dispersion factor of 50 percent increased the 3-day mean salinity concentration by 1 percent ( 15.5 to $15.7 \mathrm{ppt}$ ) and decreased the standard deviation from 2.5 to $2.4 \mathrm{ppt}$ (fig. 15d). A 50-percent decrease in the dispersion factor decreased the 3-day mean salinity concentration by 1 percent ( 15.5 to 15.3 $\mathrm{ppt}$ ) and increased the standard deviation from 2.5 to $2.6 \mathrm{ppt}$.

\section{SIMULATION OF TEMPERATURE, NUTRI- ENTS, BIOCHEMICAL OXYGEN DEMAND, AND DISSOLVED OXYGEN}

The BLTM uses the water-quality reaction kinetics used in the QUAL2E model to simulate the fate and transport of nutrients, BOD, and dissolved oxygen (Brown and Barnwell, 1987; Jobson and Schoelhamer, 1987). The model can simulate up to 10 water-quality constituents that affect dissolved-oxygen concentration dynamics. The model has the ability to simulate multiple wastewater discharges, withdrawals, tributary flows, and incremental inflows and outflows. A conceptualization of the constituents and their interactions in the QUAL2E subroutine in the BLTM model is shown in figure 16. 

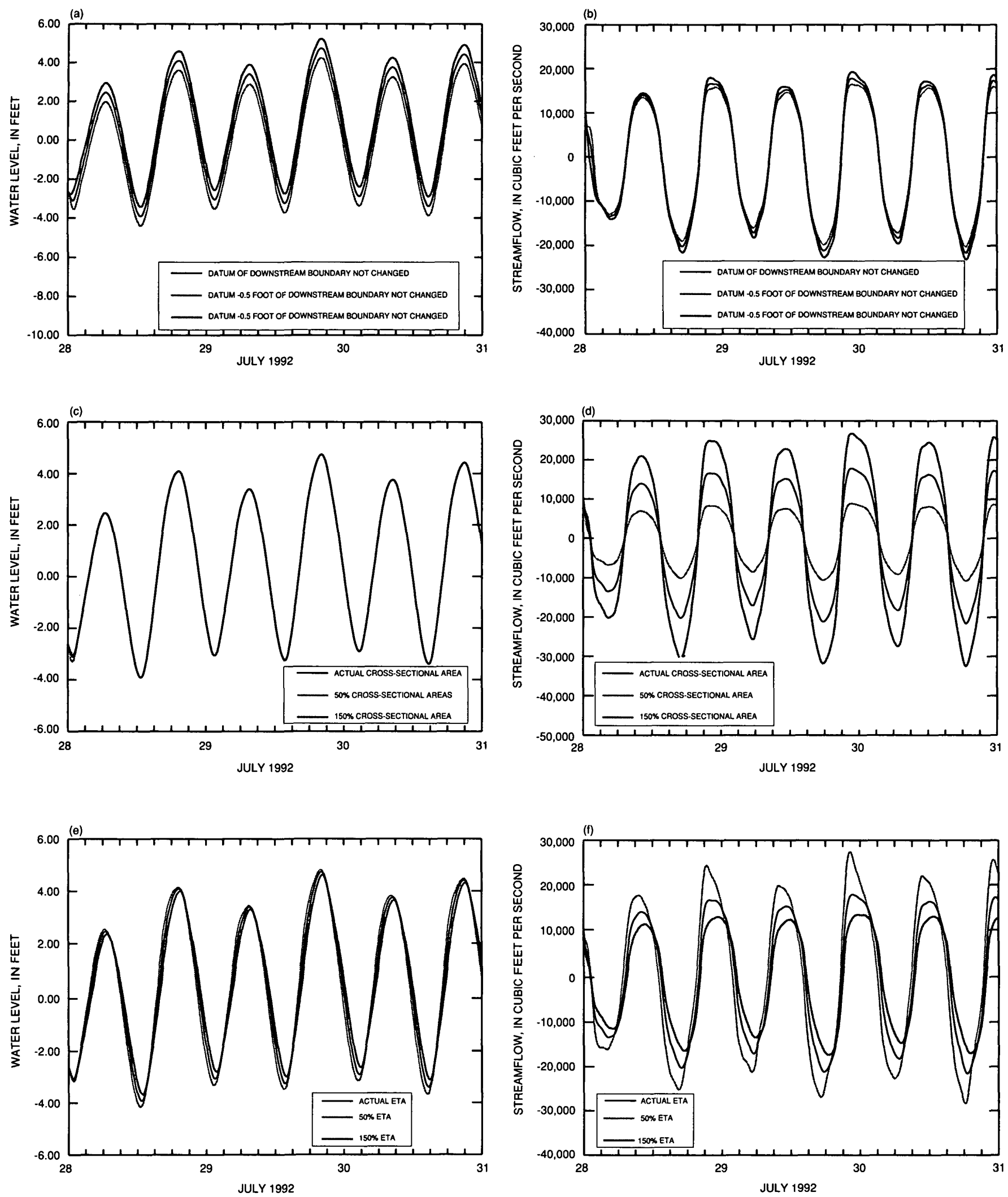

Figure 14. Sensitivity of water levels and streamflow to changes in gage datum ( $a$ and $b$ ), cross-sectional area (c and d), and flow-resistance coefficient (e and f) for station 021720869 on the Ashley River, South Carolina, July 28-30. 1992. 

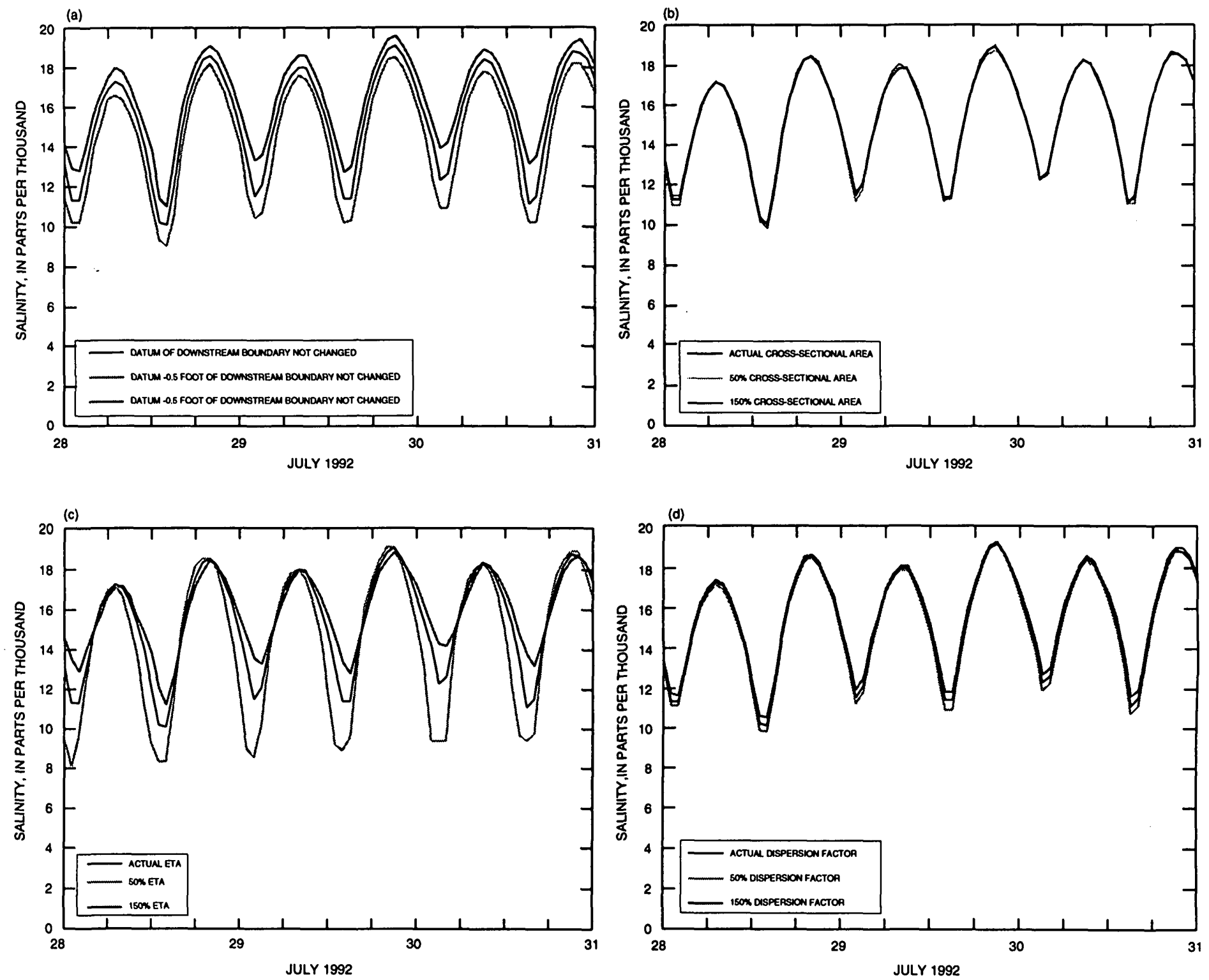

Figure 15. Sensitivity of simulated salinity concentrations to changes in gage datum (a), cross-sectional area (b) flow-resistance coefficient (c), and dlspersion factor (d) for station 021720869 on the Ashley River, South Carolina, July 28-30, 1992 . 


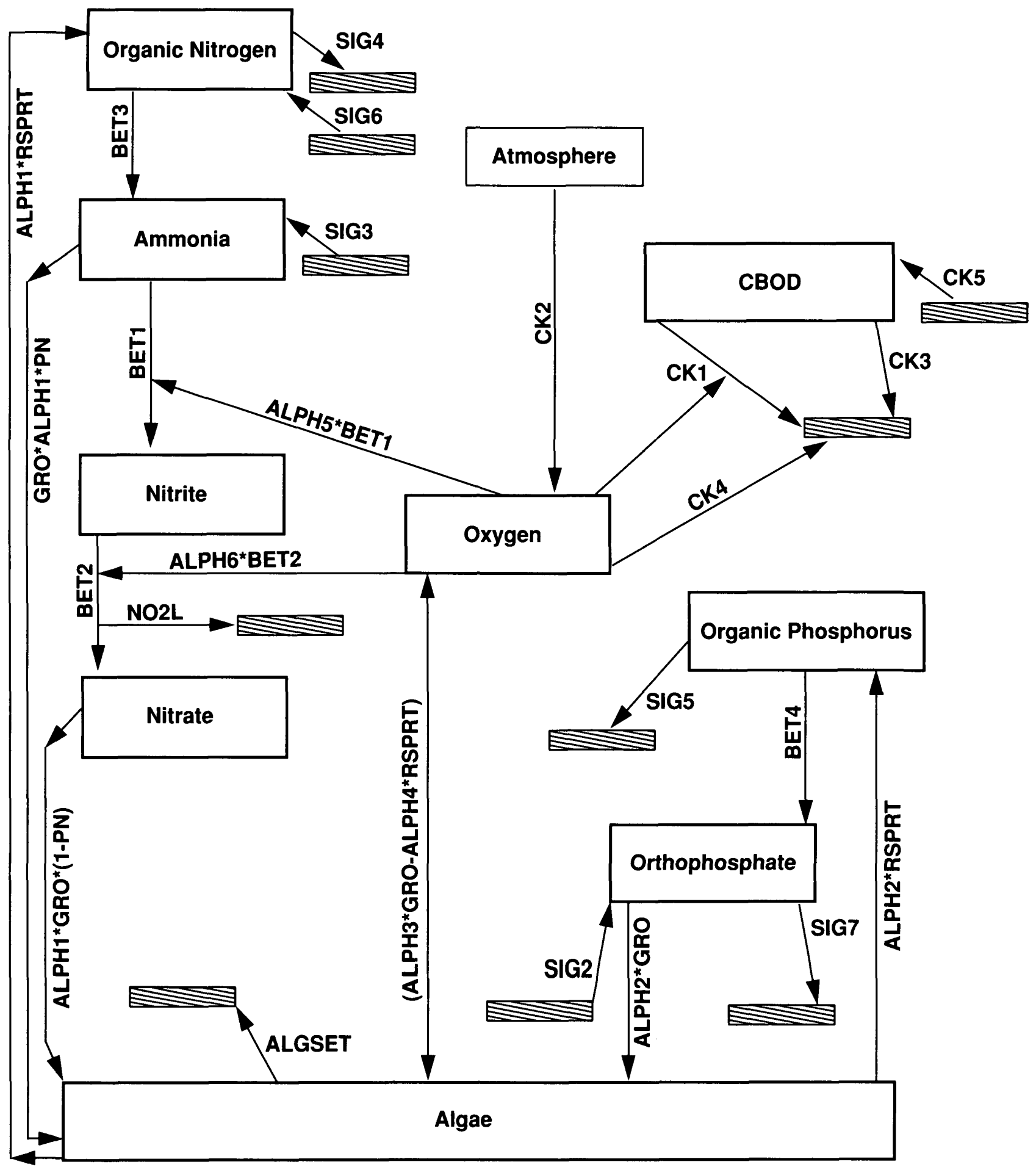

Figure 16. Major constituent interactions in the QUAL2E subroutine and Branched Lagrangian Transport Model. 
The rates of most chemical and biological reactions in the QUAL2E subroutine are temperature dependent; therefore, it is necessary to accurately simulate the water temperature of the system. The QUAL2E subroutine uses an equilibrium temperature algorithm to simulate the water temperature (Jobson, 1977, 1980). The equilibrium temperature is defined as the water temperature at which the net surface heat exchange becomes zero. For example, a pool of water would come to this temperature and remain at this temperature as long as the meteorological conditions (solar radiation, atmospheric radiation, wind speed, air temperature, and relative humidity) remained constant.

Applying the principle of conservation of thermal energy to a one-dimensional open channel, the conservation of temperature equation, in its Lagrangian form, becomes:

$$
\frac{d T}{d t}+U \frac{d T}{d x}-\left(D_{x} \frac{d^{2} T}{d x^{2}}\right)=\frac{H_{t} W}{C_{p} \rho A}
$$

where $\mathrm{T}$ is the cross-sectional average water temperature, $t$ is time, $U$ is stream velocity, $x$ is the longitudinal coordinate, $D_{x}$ is the longitudinal dispersion coefficient, $\mathrm{H}_{\mathrm{t}}$ is the flux of thermal energy from the air to the water, $\mathrm{W}$ is the top width of the channel, $\mathrm{C}_{\mathrm{p}}$ is the specific heat of water at constant pressure, $\rho$ is the density of water, and $\mathrm{A}$ is cross-sectional area. The term on the right side of equation 6 represents the rate of change of water temperature due to the exchange of energy between the atmosphere and water.

The simulation of temperature can be simplified by determining the equilibrium temperature. It is easier, and often acceptable, to estimate the equilibrium temperature than to measure all the necessary meteorological inputs (solar radiation, atmospheric radiation, wind speed, air temperature, and relative humidity) necessary for a detailed heat budget. Time series estimates of equilibrium temperature for the calibration and validation time periods were computed using the program EQULTMP (Jobson, 1997). The program uses inputs of daily extremes of air temperature (and their respective times) and average daily wind speed to compute the equilibrium temperatures for a specified timestep.
The QUAL2E subroutine in BLTM simulates the growth of phytoplankton, which is dependent on the amount of available solar radiation. Time series estimates of solar radiation were computed using the program SOLAR (Jobson, 1997). Inputs for the program include longitude, longitude of the local time meridian, latitude, altitude of sunrise and sunset, atmospheric pressure, coefficients in empirical equation to determine precipitable water content of the atmosphere, cloud cover, and dew point.

A modified version of QUAL2E kinetics in BLTM was applied to the Ashley River, as well as to the Cooper and Wando Rivers by Conrads and Smith (1997). Modifications to the model include a loss factor (NO2L) for the oxidation of nitrite to nitrate, source terms for BOD (CK5) and organic nitrogen (SIG6), and a settling term for dissolved phosphorus (SIG7) (fig. 16). An additional reaeration algorithm for estuarine environments that estimates reaeration as a function of channel depth and wind speed was added to the BLTM (Thomann and Fitzpatrick, 1982) and evaluated for the Ashley River application.

\section{Calibration and Validation of Water Temperature}

Temperature data collected during the summer and fall of 1992, spring and summer of 1993, and longitudinal temperature profiles collected during the fall of 1993 were used to calibrate and validate the temperature model in BLTM. Data of daily high and daily low air temperatures and wind speed from Charleston Airport were used to estimate the necessary meteorological input data for each data set of wind speed, equilibrium temperature, and solar radiation (National Oceanic and Atmospheric Administration, 1992b; 1992c; 1993a-g). Water-temperature simulations were calibrated by adjusting the free convection and masstransfer coefficients in the wind function of the BLTM.

The simulated water temperature for the August 1993 and September 1992 calibration was generally lower than the measured data. The simulated temperatures for the August 1993 calibration period followed the trend of the measured data but under simulated the water-temperature by 1 or 2 degrees Celsius $\left({ }^{\circ} \mathrm{C}\right.$ ) (fig 17a). For the September 1992 calibration period, the simulated temperature did not follow the gradual rise in the measured data between September 15-19, 1992, but did follow the $3^{\circ} \mathrm{C}$ drop in temperatures between September $24-27,1992$ (fig. 17b). 

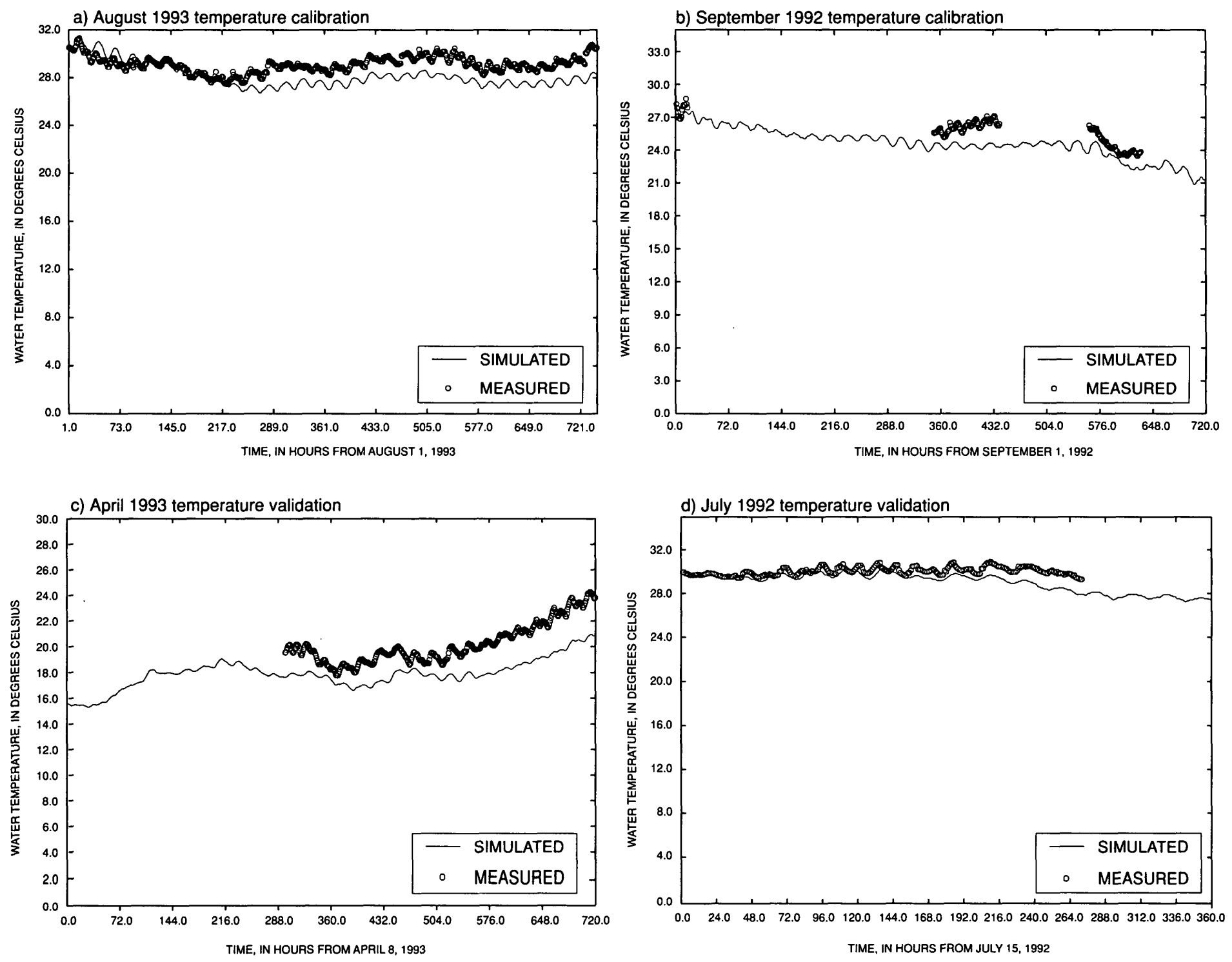

Figure 17. Simulated and measured water temperatures used in the water-quality model calibration and validation for station 021720869 on the Ashley River, South Carolina. 
The simulated temperatures for the May 1993 calibration period (April 8 - May 8, 1993) followed the trend of the measured data but under simulated the water-temperature by 1 or $3{ }^{\circ} \mathrm{C}$ (fig 17c). For the July 1992 validation, the simulated water temperatures generally followed the trend of the measured temperatures but under simulated the temperature by 1 or $2^{\circ} \mathrm{C}$ (fig. 17d).

In addition to the validation period of July 1992 , two periods from the fall and winter of 1993 were simulated to incorporate the periods of the high- and lowslack tide longitudinal water-temperature profiles (figs. 18, 19). These simulations are particularly useful in evaluating the performance of the temperature algorithm of the model throughout the length of the model. Although continuous water-temperature data are not available at station 02172083,02172085 , and 02172088, the comparison of high- and low-slack tide temperatures with simulated values shows that the model simulations follow the trend of the measured data and are within a degree of the measured data (figs. 18, 19).

The model generally under simulated water temperature by a couple of degrees Celsius. These under simulations will have an effect on the reaction kinetics in the model. A $2{ }^{\circ} \mathrm{C}$ difference will have approximately 15 percent difference to reaction kinetics. Setting the reaction kinetics in the calibration process compensated for this difference. Reaction rates are set slightly higher due to the under predicted water temperatures. If the model is to be used during periods of better simulations of the measured water temperatures, the reactions kinetics may need to be adjusted to reflect the improved water temperature simulations.

\section{Calibration and Validation of Nutrients, Biochemical Oxygen Demand, and Dissolved Oxygen}

Ten constituents were simulated using the BLTM for the Ashley River: water temperature, dissolved oxygen, algal biomass, organic nitrogen, ammonia, nitrite, nitrate, organic phosphorus, dissolved phosphorus, and $\mathrm{CBOD}_{\mathrm{u}}$. The water-quality constituent of most interest to the SCDHEC in defining and managing the river's quality is dissolved oxygen. Dissolved-oxygen concentration is dependent on many factors, including water temperature, streamflow, atmospheric reaeration, photosynthesis, plant and animal respiration, BOD, nitrification, and benthic oxygen demand. The wastewater permittees discharge ammonia and BOD into the Ashley River; both constituents have a significant effect on dissolved-oxygen concentration.

Four data sets were collected on the Ashley River during the summers of 1992 and 1993, and there are important differences and limitations in the data sets from the two summers. The two data sets collected during the summer of 1992 include data for six sampling stations throughout the modeled reach, but the analysis did not include chlorophyll-a, an indicator of the algal biomass concentration. Analyses included nitrite in addition to nitrate, and the level of detection for ammonia-nitrogen was $0.01 \mathrm{mg} / \mathrm{L}$. For the July 1992 data set, extended periods of the continuous dissolved-oxygen concentration data were missing; therefore, an input data set was not created for this sampling period. The data sets for the summer of 1993 included chlorophyll-a, but only the lower three stations of the river were sampled. (The lower reaches of the river were part of a sampling survey of Charleston Harbor and the Ashley, Cooper, and Wando Rivers.) Water-quality analyses for 1993 did not include nitrite, and the level of detection for ammonia-nitrogen was $0.05 \mathrm{mg} / \mathrm{L}$.

The BLTM was calibrated using nutrient data collected during August 23-25, 1993, and September 25,1992 , and was validated using the nutrient data collected during May 4-5, 1993. The critical period for dissolved oxygen is during the warm summer months. The August 1993 and September 1992 data sets were used for calibration, because they more closely approximated the "critical conditions" used for wasteload allocation than did the May 1993 data set. Because the model will ultimately be used to determine wasteload allocations for ammonia and BOD, emphasis was placed on satisfactory simulations of these constituents during calibration and validation.

Thirty-day data sets for the 10 modeled constituents were generated for each boundary of the model for the calibration and validation periods. Continuous (hourly) temperature and dissolved-oxygen data were used at the external boundaries. For the other eight constituents, concentration data from station 02172090 were averaged and used as the downstream steady-state boundary concentration for the 1992 and 1993 data sets. Upstream boundary data were not collected at station 02172081 in 1993; therefore, STORET data were taken from the SCDHEC monthly 
a) Station 02172083

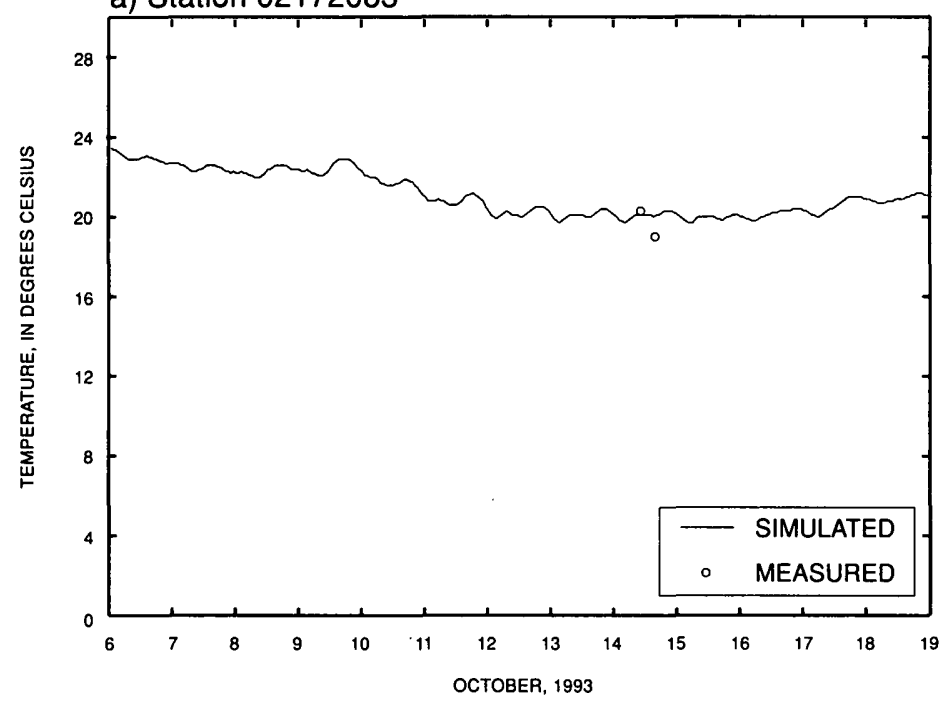

c) Station 021720869

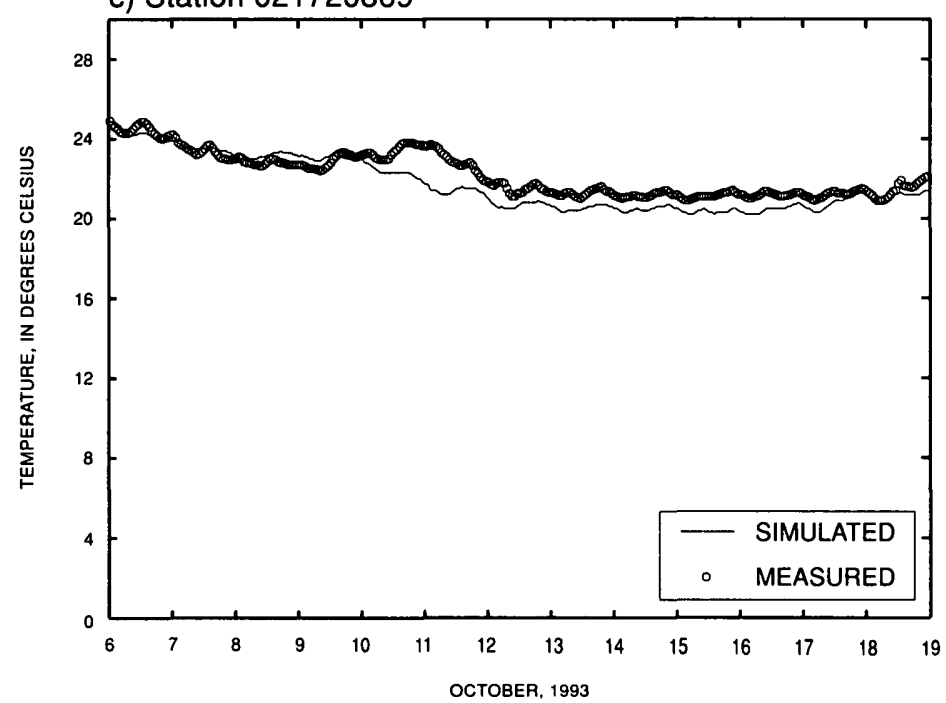

b) Station 02172085

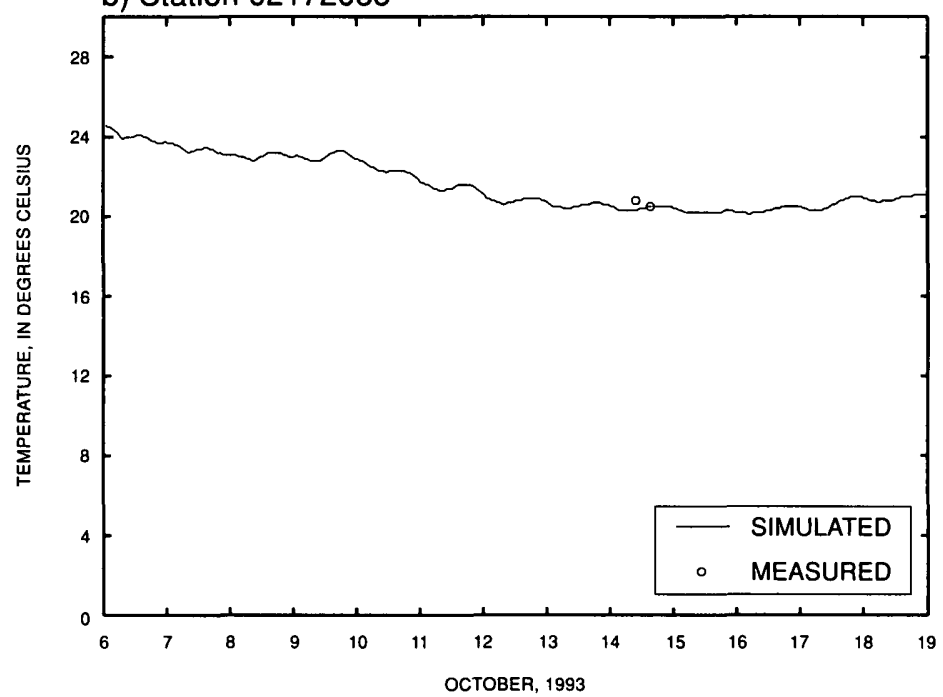

d) Station 02172088

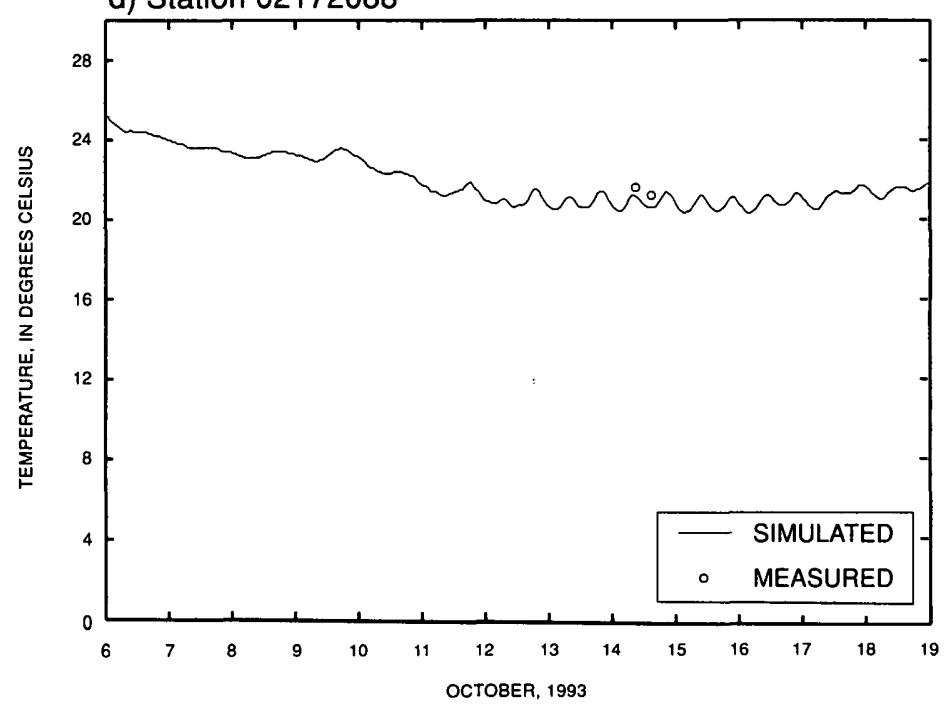

Figure 18. Simulated and measured water temperatures for four locations on the Ashley River, South Carolina, October 6-19, 1993. 
a) Station 02172083

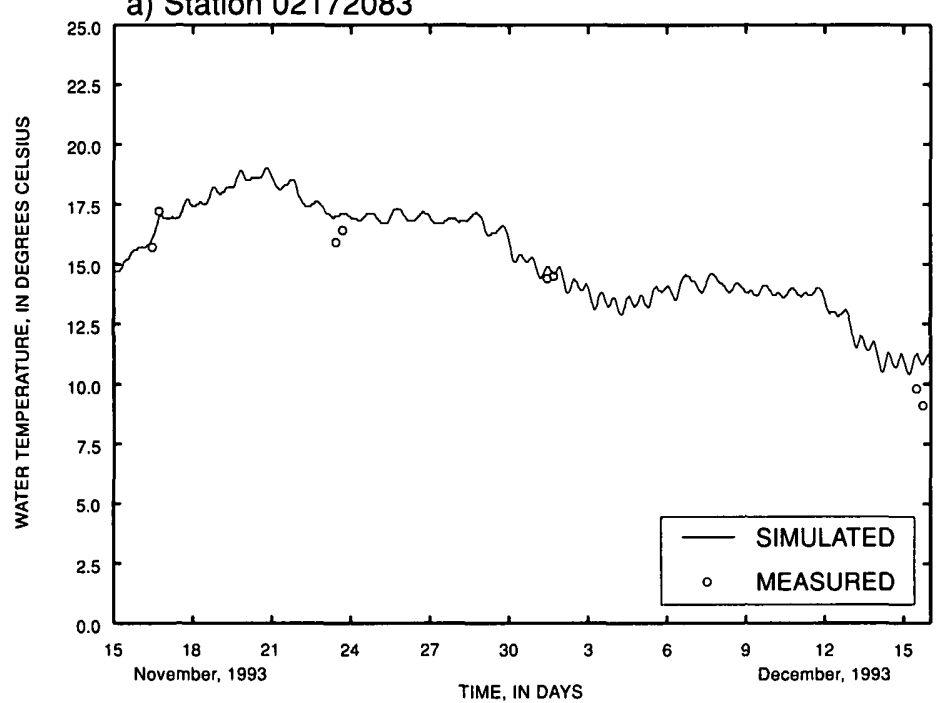

c) Station 021720869

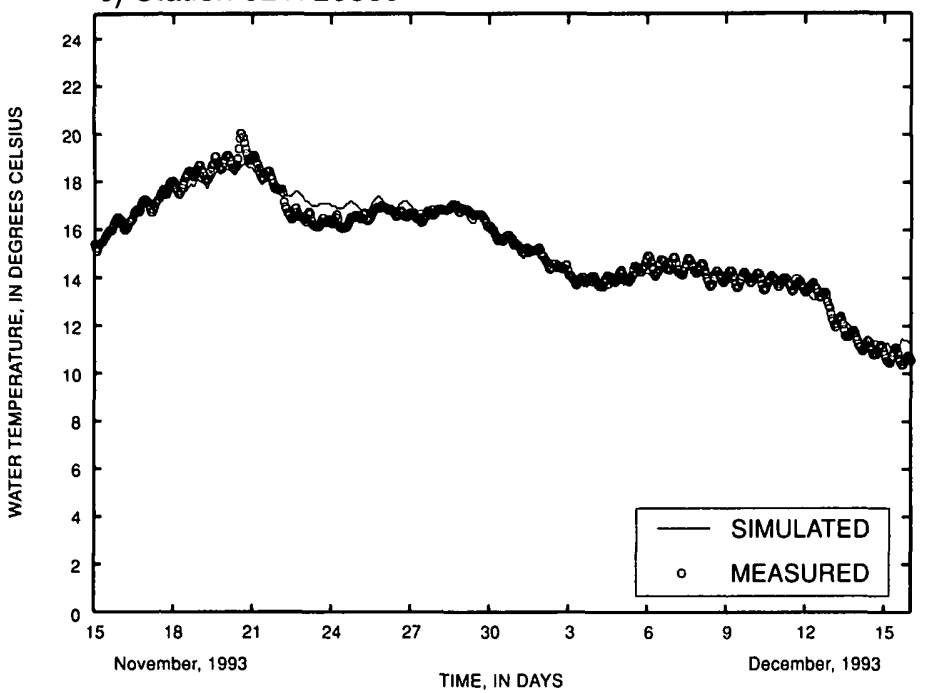

b) Station 02172085

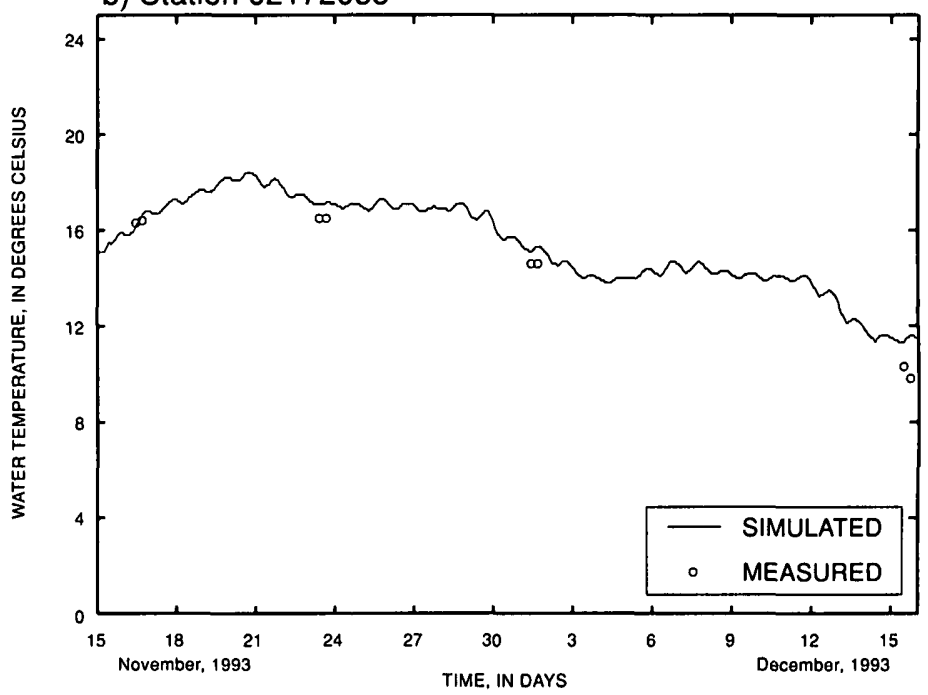

d) Station 02172088

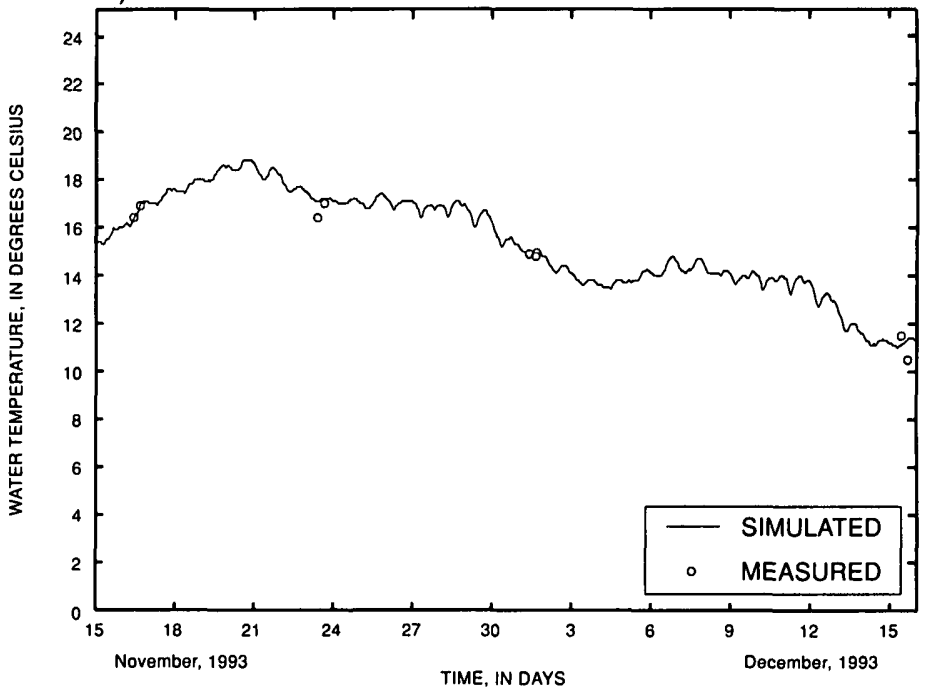

Figure 19. Simulated and measured water temperatures for four locations on the Ashley River, South Carolina, November 15 to December 15, 1993. 
monitoring program for boundary data for the two 1993 data sets. Average monthly point-source effluent concentrations during the sampling periods were obtained from the monthly Discharge Monitoring Reports submitted by the NPDES permit holders to SCDHEC. These data were averaged over the calibration and validation data set periods and entered into the model as constant point-source loads.

The water-quality model was calibrated by adjusting constant (global) and variable (local) kinetic rate coefficients within ranges described by Bowie and others (1985) and Brown and Barnwell (1987) until the simulated constituent concentrations approximated the measured concentrations. Simulated concentrations were considered acceptable when the average simulated constituent concentrations for the period of observed data were within the range of observed concentrations for a given location. The general approach to the model calibration was to use the August 1993 data set to calibrate the algal dynamics and nutrient cycling of the lower reaches of the river, and then use the September 1992 data set to calibrate the entire river. The algal concentration used in the August 1993 data set was assumed for the September 1992 data set. Nitrite concentrations from the September 1992 data set were used to set the reaction rates for the biological oxidation of ammonia to nitrite (BET1) and for the biological oxidation of nitrite to nitrate (BET2) (fig. 16). Kinetic rate coefficients used in the model and recommended values are listed in table 6 .

The reaeration algorithms in the QUAL2E subroutine including Thomann and Fitzpatrick (1982) were evaluated. All of the algorithms except O'Conner and Dobbins (1958) under predicted the simulated dissolved-oxygen concentrations in the upper reach (station 02172083) of the Ashley River by 2 to $3 \mathrm{mg} /$ L. O'Conner and Dobbins (1958) over predicted the dissolved-oxygen concentration by $3 \mathrm{mg} / \mathrm{L}$. It was decided to read in the reaeration coefficients as input (option 1) rather than have the QUAL2E subroutine compute a reaeration coefficient.

For the calibration and validation simulations, model output for each constituent consisted of hourly values over a 30 -day period ( 720 simulated data points). Measured data for the September 1992 calibration data set were limited to five data points for each constituent at approximately 3-hour intervals over a 12-hour sampling period. The August $1993 \mathrm{cal}-$ ibration data set and May 1993 validation data set consist of five data points for each constituent at approximately 12 -hour intervals over 2 or 3 days. Only those simulated data that corresponded to the time of measured data were used for comparison with the measured data. Therefore, for each 30-day simulation, only the simulated data concurrent with the measured data were averaged and compared with the measured data. The criterion used to evaluate calibration and validation of the model was a target range bracketed by the maximum and minimum concentrations of the measured data. This criterion was considered achieved when the simulated mean was within the range of the measured data. Simulated means also were compared to a calculated range 20 percent larger than the actual measured range to include those simulated means that did not meet the defined criterion, but were considered close to meeting it. The standard deviation was calculated for simulated data over this period in order to compare the simulated constituent concentration variability with actual measured data variability.

Measured ammonia-nitrogen concentrations for the May and August 1993 data set were equal to or less than $0.05 \mathrm{mg} / \mathrm{L}$, the lower limit of detection for the analysis, for 29 of the 30 analyses. Because there was no variability to the measured data, the evaluation criterion could not be applied. Therefore, the range from 0.00 to $0.05 \mathrm{mg} / \mathrm{L}$ was defined as the evaluation criterion for the simulated mean ammonia concentrations and 0.00 to $0.06 \mathrm{mg} / \mathrm{L}$ for the 20 percent expanded criteria.

Results of the water-quality model calibration and validation are presented as longitudinal profiles of constituent concentrations versus river mile (figs. 20, $21,22)$ and as time-series graphs of dissolved-oxygen concentrations for gaging station 021720869 (fig.

23). The mean simulated values and one standard deviation are shown with the minimum and maximum observed values except for the ammonia values where the measured data were at or below $0.05 \mathrm{mg} / \mathrm{L}$, the lower limit of detection (figs. $21 \mathrm{~b}$ and $22 \mathrm{c}$ ). The percentage of stations meeting the calibration and validation criterion and expanded criterion for each constituent is shown in table 7. Temperature simulations were shown in a previous section of this report. 


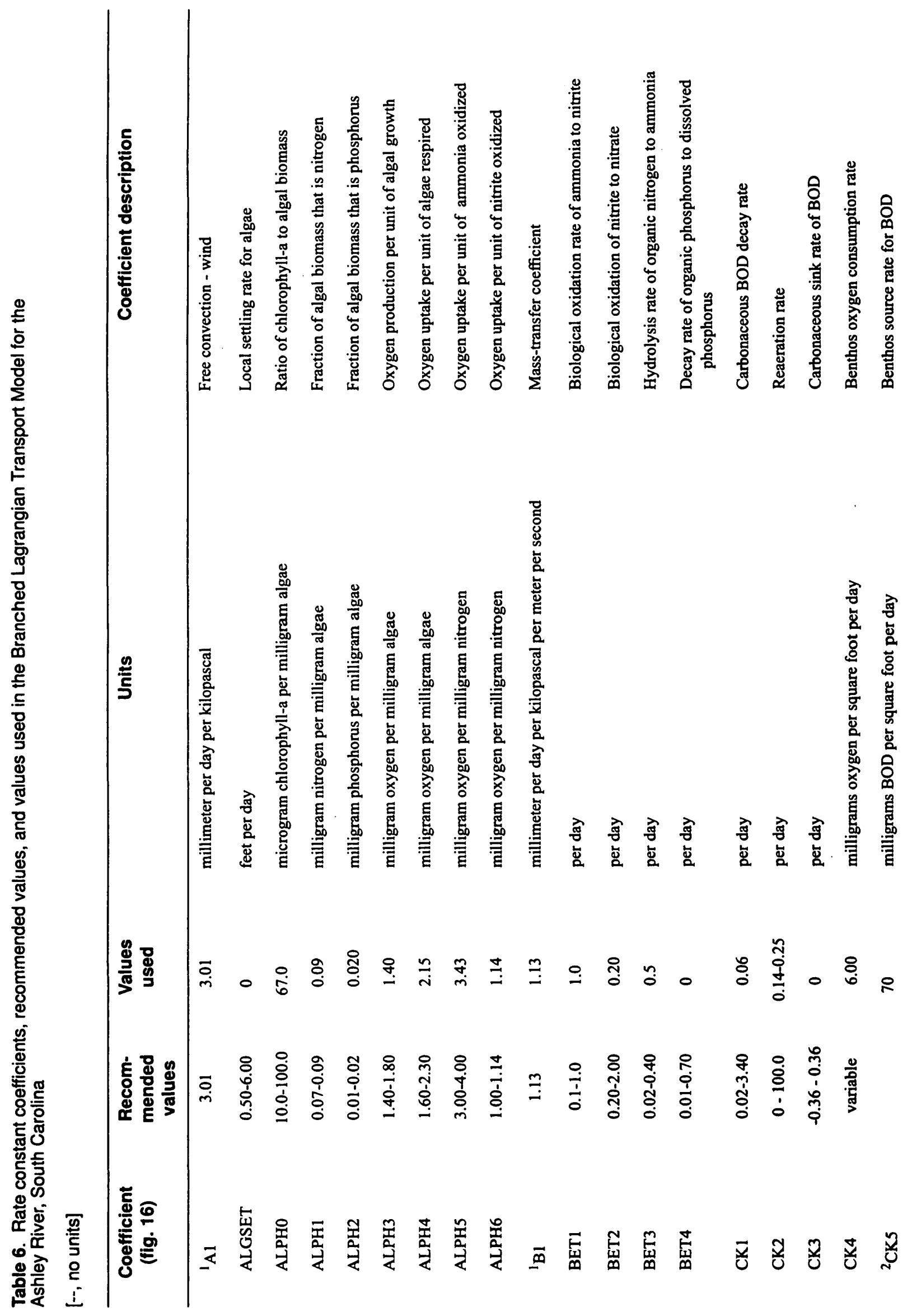




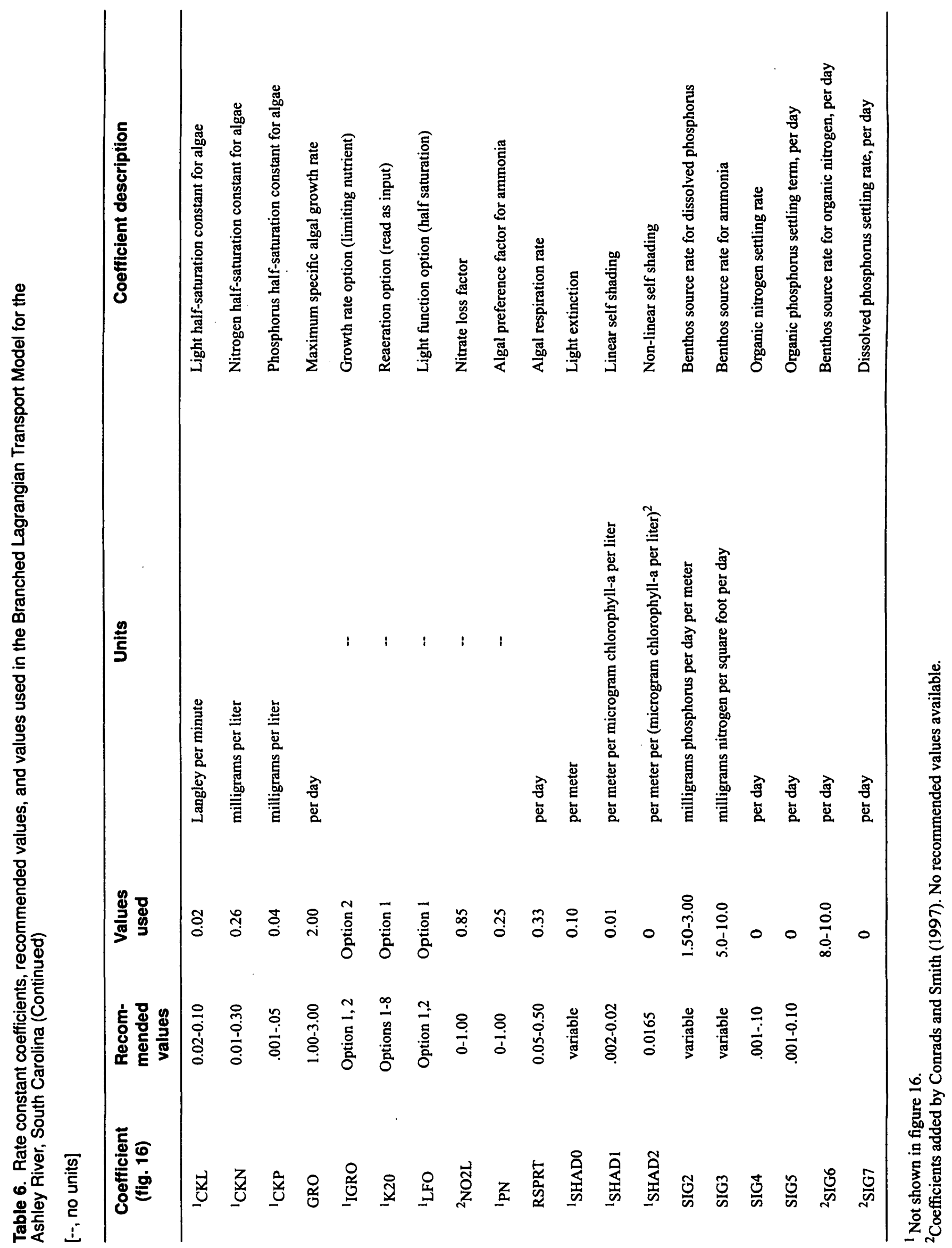



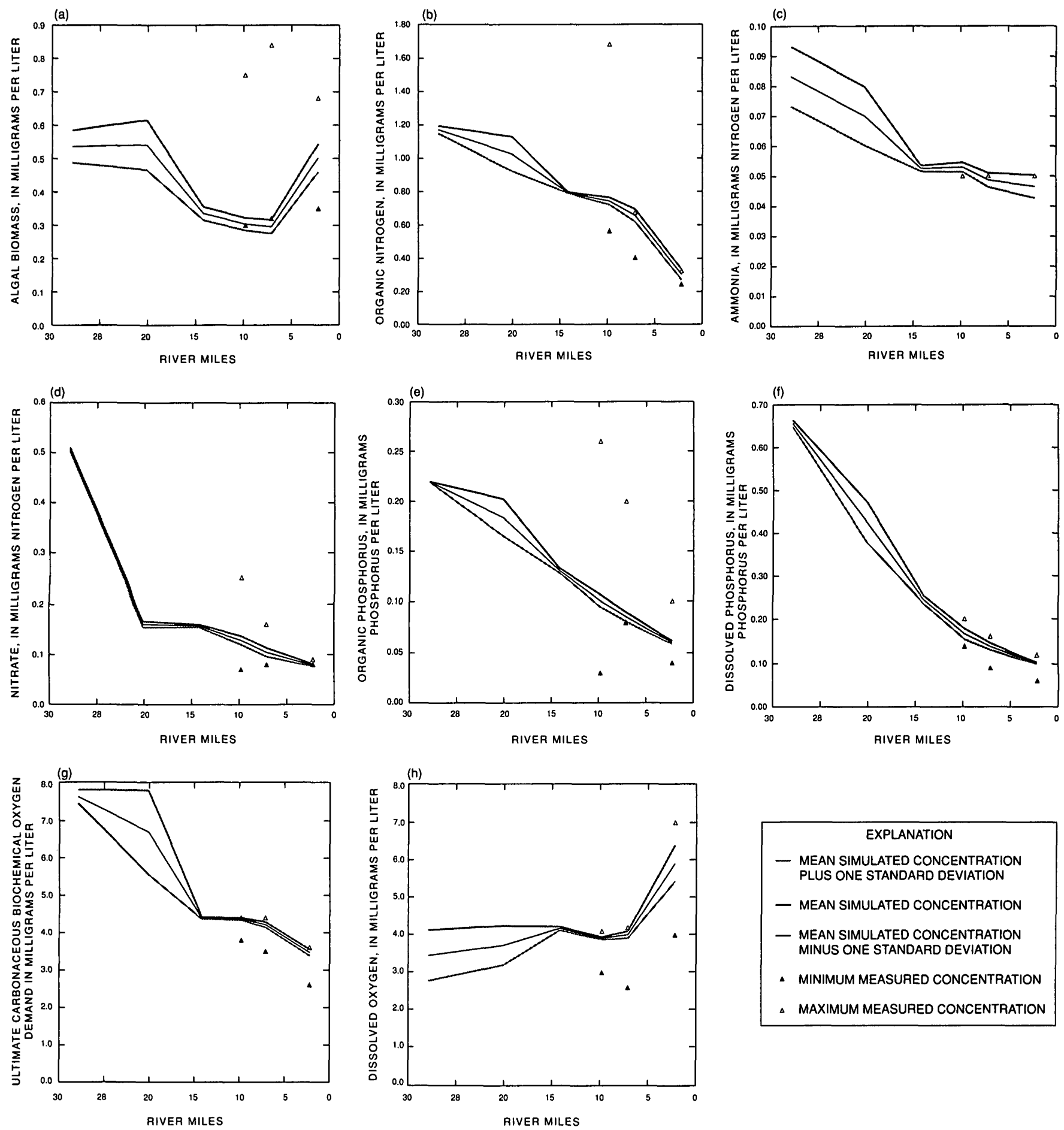

Figure 20. Simulated and measured constituent used in the water-quality model calibration for three locations on the Ashley River, South Carolina, August 23-25,1993. 

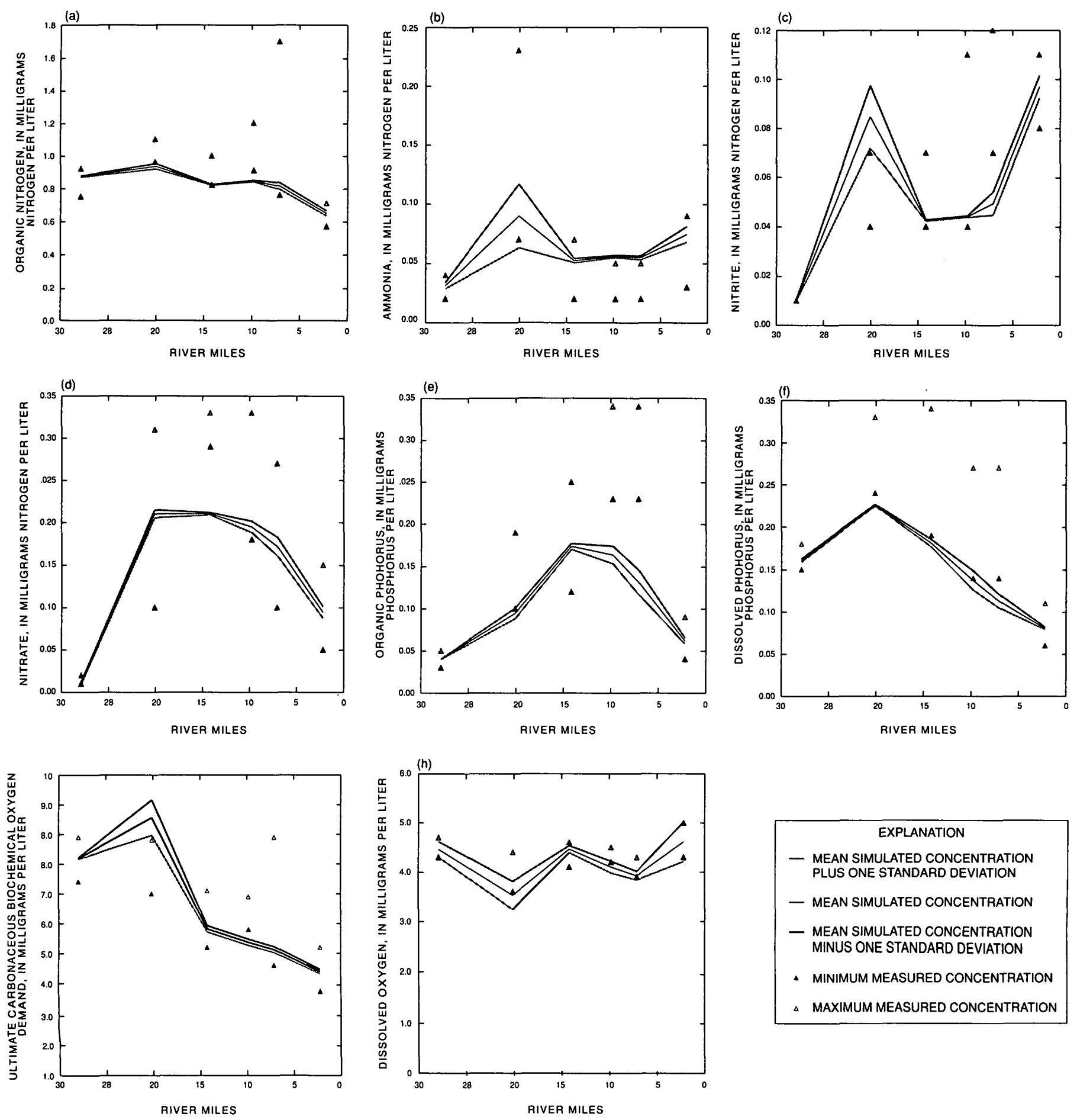

EXPLANATION

- MeAN Simulated concentration PLUS ONE STANDARD DEVIATION

- MEAN SIMULATED CONCENTRATION

- MEAN SIMULATED CONCENTRATION MINUS ONE STANDARD DEVIATION

- MINIMUM MEASURED CONCENTRATION

$\triangle$ MAXIMUM MEASURED CONCENTRATION

Figure 21. Simulated and measured concentrations used in the water-quality model calibration for six locations on the Ashley River, South Carolina, Spetember 25,1992. 

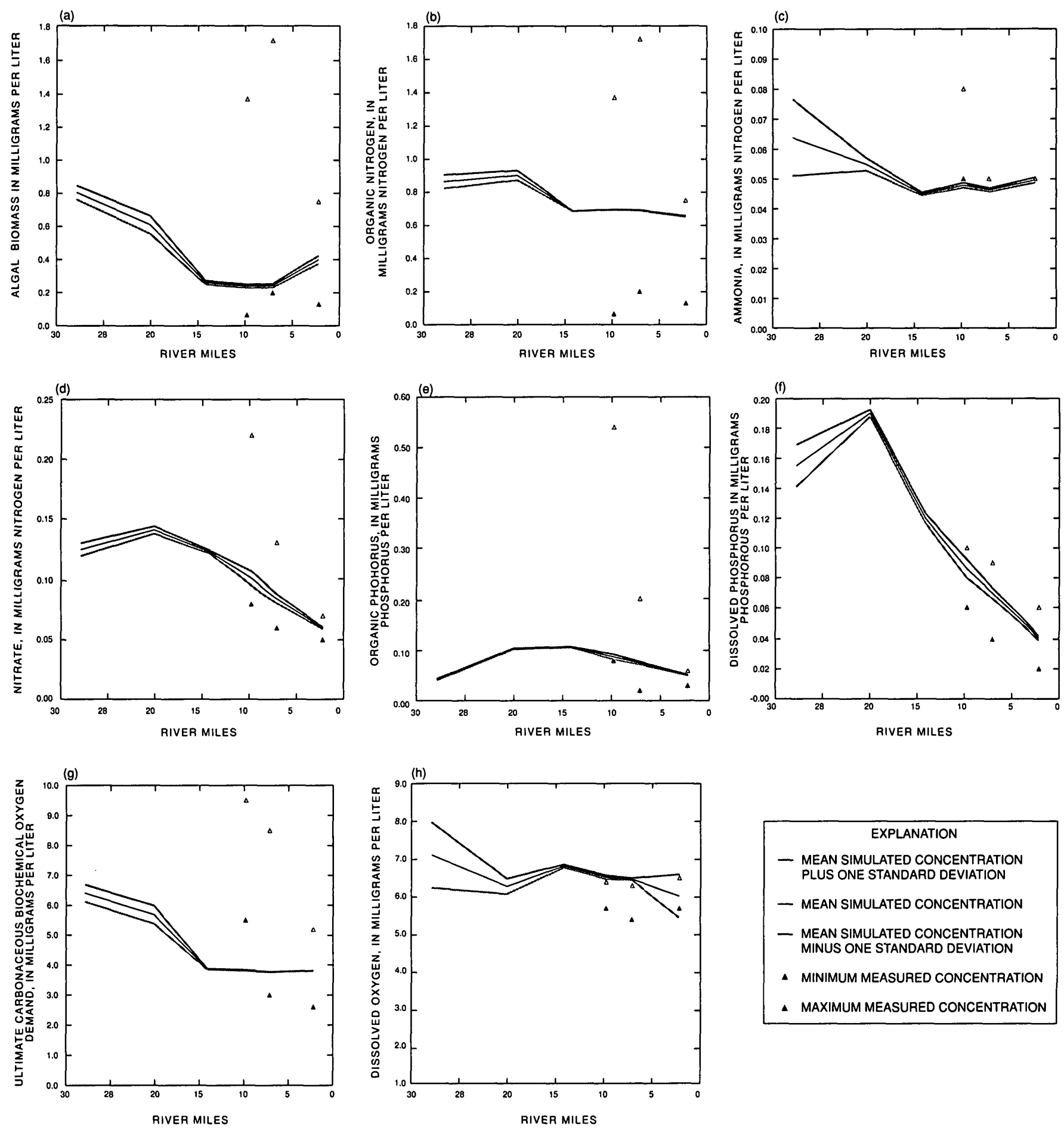

Figure 22. Simulated and measured constituent cocentrations used in the water-quality model validation for three locations on the Ashley River, South Carolina, May 4-5, 1993. 

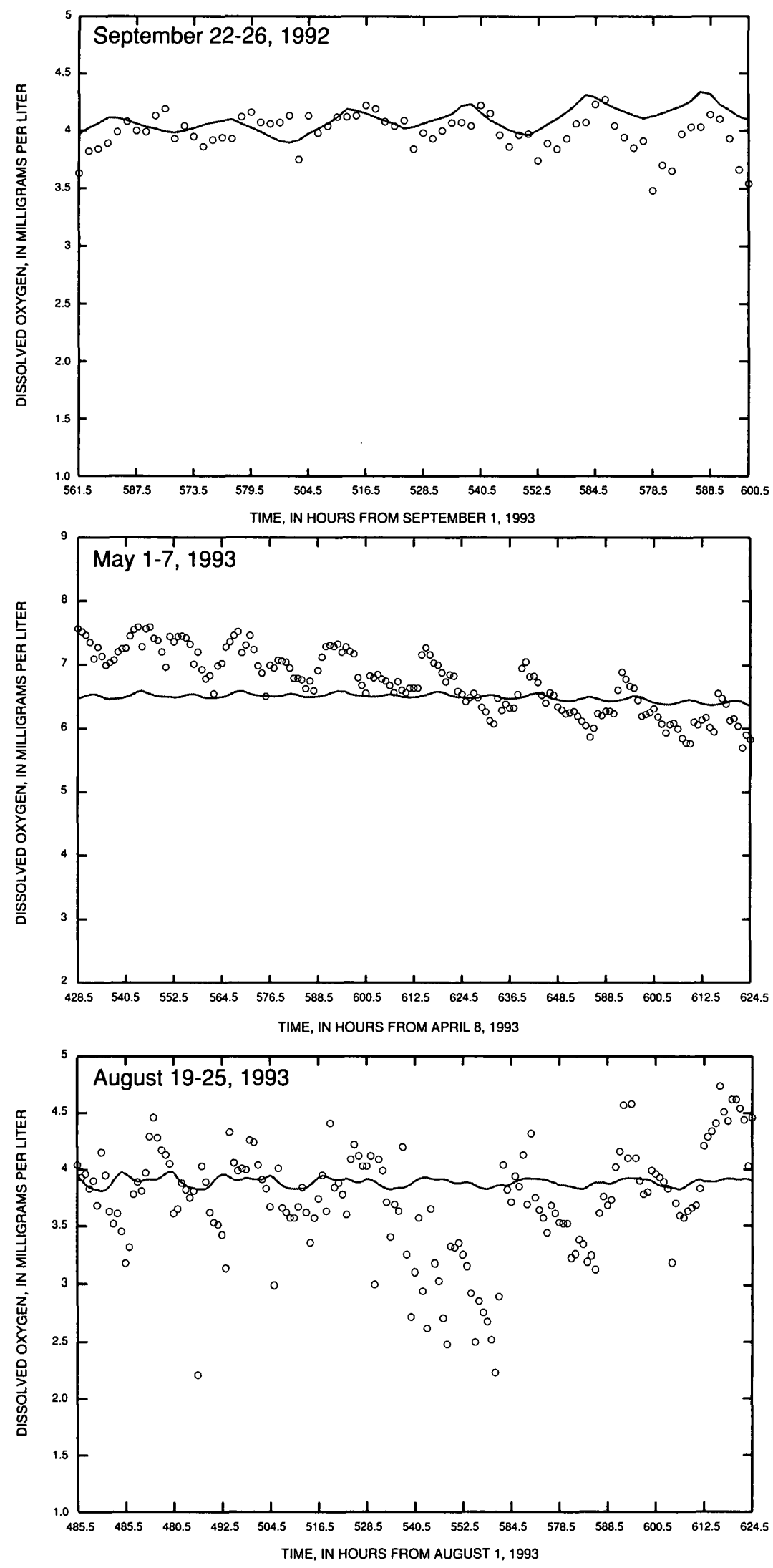

Figure 23. Simulated and measured dissolved-oxygen concentrations for three periods at station 021720869 on the Ashley River, South Carolina. 
Table 7. Stations meeting calibration and validation criterion for nine constituents [--, no data for comparison; $\mathrm{CBOD}_{\mathrm{u}}$, ultimate carbonaceous biochemical oxygen demand]

\begin{tabular}{|c|c|c|c|c|}
\hline \multirow[b]{2}{*}{ Constituent } & \multicolumn{2}{|c|}{$\begin{array}{l}\text { Calibration simulations, } \\
\text { in percent } \\
\text { (September } 25,1992 \text {, and } \\
\text { August } 23-25,1993 \text { ) }\end{array}$} & \multicolumn{2}{|c|}{$\begin{array}{c}\text { Validation simulations, } \\
\text { in percent } \\
\text { (May 4-5, 1993) }\end{array}$} \\
\hline & $\begin{array}{l}\text { Stations } \\
\text { meeting } \\
\text { criterion } 1\end{array}$ & $\begin{array}{l}\text { Stations } \\
\text { meeting } \\
\text { expanded } \\
\text { criterion }\end{array}$ & $\begin{array}{l}\text { Stations } \\
\text { meeting } \\
\text { criterion }\end{array}$ & $\begin{array}{l}\text { Stations } \\
\text { meeting } \\
\text { expanded } \\
\text { criterion }\end{array}$ \\
\hline Algal biomass ${ }^{3}$ & 66 & 100 & 100 & 100 \\
\hline Organic nitrogen & 78 & 78 & 100 & 100 \\
\hline Ammonia nitrogen & 78 & 100 & 100 & 100 \\
\hline Nitrite nitrogen ${ }^{4}$ & 67 & 67 & -- & -- \\
\hline Nitrate nitrogen & 89 & 89 & 100 & 100 \\
\hline Organic phosphorus & 67 & 78 & 100 & 100 \\
\hline Dissolved phosphorus & 56 & 89 & 100 & 100 \\
\hline $\mathrm{CBOD}_{\mathrm{u}}$ & 78 & 78 & 66 & 66 \\
\hline Dissolved oxygen $^{5}$ & 78 & 89 & 33 & 100 \\
\hline
\end{tabular}

\footnotetext{
${ }^{1}$ Mean simulated constituent concentration during the sampling period within the range of the minimum and maximum measured concentrations.

2 Mean simulated constituent concentration during the sampling period within a range 20 percent larger than the minimum or maximum measured range.

3 May and August 1993 data sets only.

${ }^{4}$ September 1992 data set only.

${ }^{5}$ Not including time series data.
}

The simulations using the calibration data set of September 1992 show that the model generally follows the longitudinal trends of the measured data (fig. 21). The model did not simulate the high ammonia concentrations measured at Middleton Plantation but simulated the measured trend (river mile 20.1, fig. $21 \mathrm{~b}$, table 2). The $\mathrm{CBOD}_{\mathrm{u}}$ simulations (fig. $21 \mathrm{~g}$ ) followed the trend of the measured data with higher concentrations in the upstream reaches of the Ashley River and decreasing concentrations downstream.

The mean dissolved-oxygen simulations (fig. $21 \mathrm{~h}$ ) were near the lower range of the measured data but the simulations captured the longitudinal profile of the river of decreasing dissolved-oxygen concentrations at Middleton Plantation (river mile 20.1), then increasing concentrations at Drayton Hall (river mile 14.2), followed by decreasing concentrations at stations 021720869 and 02172088 (river mile 9.8 and 7.1 , respectively) before increasing at the downstream boundary. For the August 1993 calibration simulations (fig. 20), the nutrient simulations follow the measured trends for the lower reach of the river.

The simulations for the validation data set of May 1993 (fig. 22) show the mean simulated con- 
centrations generally were within the range of the measured concentrations. The algal biomass concentrations, although within the range of the measured data, are near the lower range of the measured concentrations. The model under simulated the $\mathrm{CBOD}_{\mathrm{u}}$ concentrations (fig. 22g) and slightly over predicted the measured dissolved-oxygen concentrations (fig. 22h).

In addition to comparing the simulated dissolved-oxygen concentrations to the measured field readings during the nutrient sampling, the simulated and measured dissolved-oxygen concentrations also were compared with continuous (15-minute recording interval) dissolved-oxygen concentrations from station 021720869 (fig. 23). There were two significant differences in the methods used for collecting dissolvedoxygen data from the gaging stations as compared to the dissolved-oxygen profiles measured during the nutrient sampling. First, the probes for the gaging stations were set at fixed elevations that did not vary with changes in water level. Station 021720869 was instrumented with two sets of probes; the probes were set approximately $3 \mathrm{ft}$ from the bottom and $3 \mathrm{ft}$ below the mean low-water elevation. The values from the two probes were averaged to compute a mean value. The dissolved-oxygen profiles measured during the nutrient sampling were recorded at $3 \mathrm{ft}$ intervals from the water surface. Second, the gaging station was attached to a bridge pier located near the left side of the center channel, whereas the dissolved-oxygen profiles were taken in the center channel of the Ashley River.

The 4-day simulation from September 22-25, 1992 , shows that simulated dissolved-oxygen concentrations closely followed the measured dissolved-oxygen concentrations, but the simulated concentrations did not show the slight decreasing trend of the measured data (fig. 23a). The average measured concentration was $4.0 \mathrm{mg} / \mathrm{L}$ with a standard deviation of 0.16 $\mathrm{mg} / \mathrm{L}$ as compared to an average simulated concentration of $4.1 \mathrm{mg} / \mathrm{L}$ and a standard deviation of $0.10 \mathrm{mg} /$ L. The simulations for May 1-7 and August 19-25, 1993 (figs. 23b and 23c), are within the range of the measured data but do not simulate the amplitude. For the two periods, the mean simulated and measured concentrations are 6.50 and $6.73 \mathrm{mg} / \mathrm{L}$, and 3.89 and $3.71 \mathrm{mg} / \mathrm{L}$, respectively, whereas the standard deviation of the mean simulated and measured concentrations of the two periods differ by an order of magnitude, 0.005 and $0.48 \mathrm{mg} / \mathrm{L}$ and 0.04 and 0.50 $\mathrm{mg} / \mathrm{L}$, respectively.

\section{Sensitivity Analysis}

Sensitivity of the water-quality model to changes in model input data was analyzed by evaluating the mean dissolved-oxygen concentrations of the Ashley River at station 021720869 from September 16-30, 1992. Three groups of model inputs were evaluated: model input variables (including rate constants and settling rates), meteorological input data, and boundary input data of water-quality constituent concentrations. The calibration simulation for station 021720869 was used to compute a base value (table 8) to compare with the simulated dissolved-oxygen concentrations for the sensitivity analysis simulation. Test values for model input data were increased by approximately 25 percent while all other inputs were unchanged. Time-dependent inputs to the model, such as the meteorological input data, reaeration rates, and boundary constituent concentrations were changed for each simulation time-step.

A normalized sensitivity index $\left(\mathrm{S}_{\mathrm{ij}}\right)$ was developed to represent the percent change in the output variable (the mean dissolved-oxygen concentration at station 021720869) resulting from a 1-percent change in each rate constant or input data (Brown and Barnwell, 1987). The normalized sensitivity index is:

$$
\mathrm{S}_{i j}=\left(\Delta \mathrm{Y}_{\mathrm{j}} / \mathrm{Y}_{\mathrm{j}}\right) /\left(\Delta \mathrm{X}_{\mathrm{i}} / \mathrm{X}_{\mathrm{i}}\right)
$$

where

$\mathrm{S}_{i j}$ is the normalized sensitivity index for output $Y_{j}$ to input $X_{i}$;

$\Delta Y_{j}$ is the change in the output variable;

$\mathrm{Y}_{\mathrm{j}}$ is the original value of the output variable;

$\Delta \mathrm{X}_{\mathrm{i}}$ is the change in the input variable; and

$\mathrm{X}_{\mathrm{i}}$ is the original value of the input variable.

\section{WATER-QUALITY MODEL APPLICATIONS}

The water-quality model of the Ashley River was used to simulate two hydrologic and water-quality scenarios to evaluate their effects on the simulated dissolved-oxygen concentrations and, ultimately, to gain a better understanding of the river system. The September 1992 calibration data set was used for the scenario simulations. Simulated model output was analyzed for 10 sites in the model domain (fig. 24). 
Table 8. Sensitivity indices for the Branched Lagrangian Transport Model inputs for station 021720869 on the Ashley River, S.C.

[mg/L, milligrams per liter; -- , no data; -, negative]

\begin{tabular}{cccc}
\hline Model Input & $\begin{array}{c}\text { Original } \\
\text { value }\end{array}$ & $\begin{array}{c}\text { Test } \\
\text { value }\end{array}$ & $\begin{array}{c}\text { Mean } \\
\text { simulated } \\
\text { dissolved } \\
\text { oxygen } \\
\end{array}$ \\
& & $\begin{array}{c}\text { Sensitivity } \\
\text { index }\end{array}$ \\
& & $16-30,1992$ \\
& & $(\mathrm{mg} / \mathrm{L})$ \\
\hline
\end{tabular}

Base value ${ }^{\prime}$

-.

4.064

Model input variables (table 6)

\begin{tabular}{|c|c|c|c|c|}
\hline A1 & 3.010 & 3.770 & 4.189 & 0.122 \\
\hline ALGSET $^{2}$ & 0.000 & 0.250 & 4.092 & 0.007 \\
\hline ALPHA0 & 67.000 & 84.000 & 4.146 & 0.080 \\
\hline ALPHA1 & 0.090 & 0.120 & 4.094 & 0.022 \\
\hline ALPHA2 & 0.020 & 0.025 & 4.064 & 0.000 \\
\hline ALPHA3 & 1.400 & 1.750 & 4.376 & 0.307 \\
\hline ALPHA4 & 2.150 & 2.690 & 3.578 & -0.476 \\
\hline ALPHA5 & 3.430 & 4.290 & 3.745 & -0.313 \\
\hline ALPHA6 & 1.140 & 1.430 & 4.049 & -0.014 \\
\hline B1 & 1.130 & 1.420 & 4.078 & 0.013 \\
\hline BET1 & 1.000 & 1.250 & 4.092 & 0.027 \\
\hline BET2 & 0.200 & 0.250 & 4.050 & -0.014 \\
\hline BET3 & 0.500 & 0.630 & 3.937 & -0.120 \\
\hline CKI & 0.060 & 0.075 & 3.930 & -0.131 \\
\hline $\mathrm{CK} 2$ & 0.250 & 0.320 & 4.952 & 0.780 \\
\hline CK4 & 6.000 & 7.500 & 4.904 & 0.826 \\
\hline CK5 & 70.000 & 88.000 & 4.763 & 0.669 \\
\hline CKL & 0.020 & 0.025 & 4.106 & 0.041 \\
\hline $\mathrm{CKN}$ & 0.260 & 0.330 & 4.168 & 0.095 \\
\hline CKP & 0.040 & 0.050 & 4.064 & 0.000 \\
\hline GRO & 2.000 & 2.500 & 3.941 & -0.121 \\
\hline NO2L & 0.850 & 0.640 & 3.868 & 0.195 \\
\hline PN & 0.250 & 0.320 & 4.067 & 0.003 \\
\hline
\end{tabular}


Table 8. Sensitivity indices for the Branched Lagrangian Transport Model inputs for station 021720869 on the Ashley River, S.C.--Continued

[mg/L, milligrams per liter; -- , no data; -, negative]

\begin{tabular}{|c|c|c|c|c|}
\hline Model input & $\begin{array}{l}\text { Original } \\
\text { value }\end{array}$ & $\begin{array}{c}\text { Test } \\
\text { value }\end{array}$ & $\begin{array}{c}\text { Mean } \\
\text { simulated } \\
\text { dissolved } \\
\text { oxygen } \\
\text { September } \\
\text { 16-30, 1992 } \\
\text { (mg/L) }\end{array}$ & $\begin{array}{l}\text { Sensitivity } \\
\text { index }\end{array}$ \\
\hline RSPRT & 0.330 & 0.420 & 4.172 & 0.097 \\
\hline SHADO & 0.100 & 0.125 & 4.097 & 0.032 \\
\hline SHADI & 0.010 & 0.013 & 4.159 & 0.078 \\
\hline SIG2 & 3.000 & 3.750 & 4.064 & 0.000 \\
\hline SIG3 & 10.000 & 12.500 & 3.946 & -0.116 \\
\hline SIG6 & 10.000 & 12.500 & 3.952 & -0.110 \\
\hline \multicolumn{5}{|c|}{ Meteorological inputs } \\
\hline Equilibrium temperature ${ }^{3}$ & 1.000 & 1.250 & 2.728 & -1.315 \\
\hline Solar radiation ${ }^{3}$ & 1.000 & 1.250 & 4.031 & -0.033 \\
\hline Wind velocity ${ }^{3}$ & 1.000 & 1.250 & 4.080 & 0.016 \\
\hline \multicolumn{5}{|c|}{ Constituent concentration inputs } \\
\hline Algal biomass ${ }^{3}$ & 1.000 & 1.250 & 4.029 & -0.034 \\
\hline Ammonia $^{3}$ & 1.000 & 1.250 & 4.045 & -0.018 \\
\hline $\mathrm{CBOD}_{\mathrm{u}}{ }^{3}$ & 1.000 & 1.250 & 3.994 & -0.069 \\
\hline Dissolved oxygen $^{3}$ & 1.000 & 1.250 & 4.138 & 0.073 \\
\hline Dissolved phosphorus ${ }^{3}$ & 1.000 & 1.250 & 4.064 & 0.000 \\
\hline Nitrate $^{3}$ & 1.000 & 1.250 & 4.055 & -0.009 \\
\hline Nitrite $^{3}$ & 1.000 & 1.250 & 4.052 & -0.012 \\
\hline Organic nitrogen ${ }^{3}$ & 1.000 & 1.250 & 4.022 & -0.041 \\
\hline Organic phosphorus ${ }^{3}$ & 1.000 & 1.250 & 4.063 & -0.001 \\
\hline Temperature $^{3}$ & 1.000 & 1.250 & 3.907 & -0.154 \\
\hline
\end{tabular}

1 Simulated mean dissolved-oxygen concentrations for September 16-30, 1992.

2 Sensitivity index computed by using test value for input variable instead of original value.

3 Time-dependent model input; original and test values are multiplicative factors. 


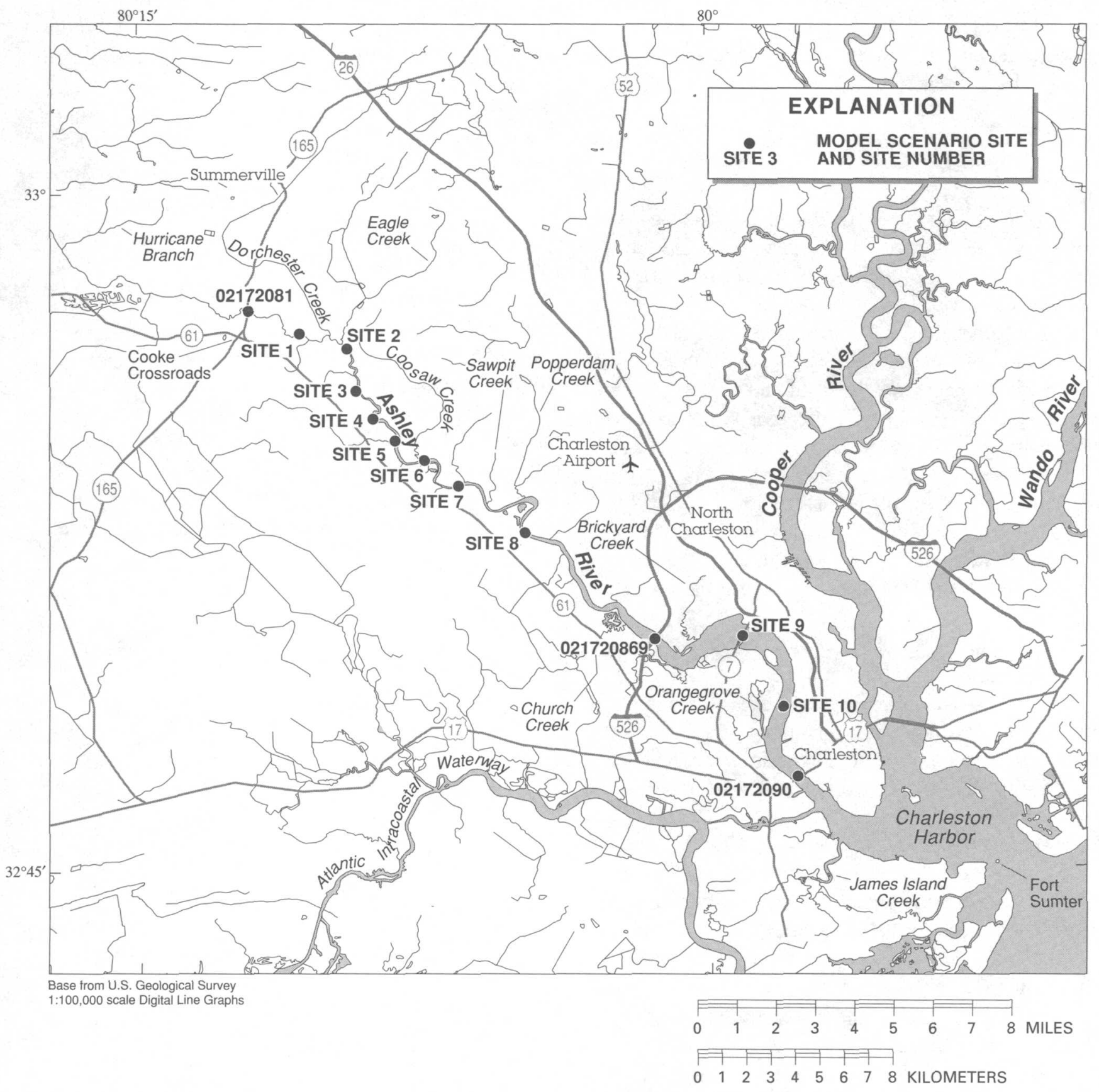

Figure 24. Sites used for model scenarios on the Ashley River, South Carolina. 
These sites were chosen to adequately define the longitudinal dissolved-oxygen profile of the river. Two types of scenarios were simulated. The first scenario simulated the travel time of a conservative tracer in the upper reach of the river to evaluate the fiushing characteristics of the river. The second scenario evaluated the effect of setting all the dischargers to advanced secondary, advanced, and reclaimed-use levels of wastewater treatment.

\section{Time of Travel}

One characteristic of tidal sloughs, such as the Ashley River, is the relatively long flushing time, or residence time, due to the limited freshwater inflow and reversing flows. To evaluate the time of travel of the Ashley River, the BLTM was used to simulate a slug injection of a conservative tracer and subsequent flushing of the tracer from the upstream segment of the model at station 02172081 . In the transport model, the upper segment of the model (from river mile 26.7 to 27.9 , fig. 7) was set with an initial condition of $100 \mathrm{ppt}$ and all the other segments were set with concentrations of $0.0 \mathrm{ppt}$. The system was then simulated for 60 days from September 1, 1992, and the resulting tracer concentrations at six selected sites downstream were evaluated.

A streamflow hydrograph (24-hour running average) at station 02172081 and the tracer time series for six sites (24-hour running average) are shown in figure 25 . The average flow at station 02172081 was $136 \mathrm{ft}^{3} / \mathrm{s}$, with minimum and maximum instantaneous flows of -120 and $405 \mathrm{ft}^{3} / \mathrm{s}$, respectively, during the 60-day data set (not shown in fig. 25). Time series of the tracer concentrations were analyzed for six locations in the model to evaluate the time of travel for the leading edge of the dye (defined as a concentration greater than $0.1 \mathrm{ppt}$, or 0.1 percent of the initial tracer concentration) and the peak concentration to reach each location (table 9).

The leading edge of the tracer reached site 6 ( $7.4 \mathrm{mi}$ downstream from the injection site) after 28.5 hours and the peak concentration (10 percent of the injected concentration) occurred 112 hours after the beginning of the simulation (table 9 , fig. 25b). The leading edge of the tracer reached site 10 (at the lower end of the system and $23.7 \mathrm{mi}$ downstream of the injection point) after 376 hours and the peak concentration ( 0.6 percent of the injected concentration) occurred after 1,105 hours (fig. $25 \mathrm{c}$ ).

\section{Levels of Wastewater Treatment}

A water-quality model can be utilized by waterresource managers to evaluate the effects of wastewater loads on dissolved-oxygen concentrations, especially in determining the amount of wastewater that a receiving waterbody is able to assimilate. The assimilative capacity of a stream is its capacity to carry a particular pollutant, without violating an instream waterquality standard. The capacity of a stream to assimilate oxygen-consuming substances is a function of many factors including streamflow, water temperature, reaeration, benthic oxygen demand, and channel geometry. In terms of water-resource management, this capacity is expressed as pounds per day of UOD that can be assimilated without violating the State water-quality standard for dissolved oxygen.

Wastewater effluent contains many oxygen-consuming constituents, primarily ammonia and biodegradable organic substances. The UOD is the total, theoretical demand for oxygen from carbonaceous and nitrogenous sources. The SCDHEC defines UOD by the equation (L.E. Turner, South CArolina Department of Health and Environmental Control, oral commun., April 5, 1998):

$$
\begin{gathered}
\mathrm{UOD}=\left(\mathrm{BOD}_{5} \times \mathrm{F}_{\text {ratio }}+\mathrm{NH}_{3}-\mathrm{N} \times 4.57\right) \\
\times \text { Flow } \times 8.34
\end{gathered}
$$

where

UOD is the ultimate oxygen demand, in pounds per day;

$\mathrm{BOD}_{5}$ is the five-day carbonaceous biochemical oxygen demand, in milligram per liter;

$\mathrm{F}_{\text {ratio }}$ is the conversion factor from $\mathrm{BOD}_{5}$ to ultimate carbonaceous biochemical oxygen demand;

$\mathrm{NH}_{3}-\mathrm{N}$ is the ammonia concentration, in milligrams nitrogen per liter;

4.57 is the stoichiometric ratio of the milligrams of oxygen consumed per milligram of ammonia-nitrogen oxidized;

Flow is wastewater flow, in million gallons per day; and

8.34 is the conversion factor to pounds per day. 

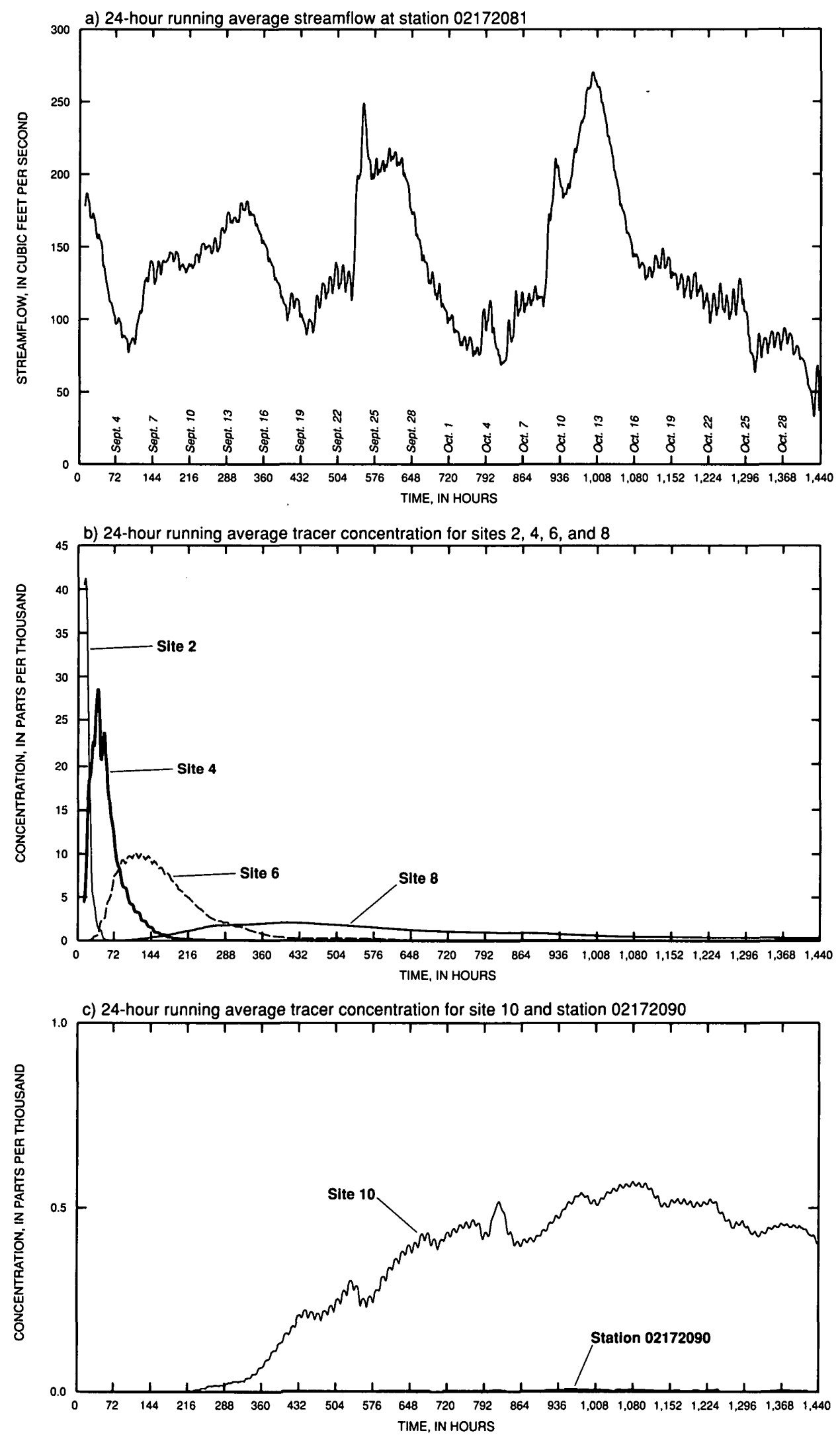

Figure 25. Flow hydrograph and tracer graphs for six sites on the Ashley River, South Carolina for September 1-October 30, 1992. 
Table 9. Time of leading edge, time of peak concentration, and peak concentration for sites on the Ashley River, S.C.

[ppt, parts per thousand; --, no data]

\begin{tabular}{lccccc}
\hline $\begin{array}{c}\text { Location } \\
\text { (fig. 24) }\end{array}$ & $\begin{array}{c}\text { River } \\
\text { mile }\end{array}$ & $\begin{array}{c}\text { River miles } \\
\text { from tracer } \\
\text { injection } \\
\text { site }\end{array}$ & $\begin{array}{c}\text { Time of } \\
\text { leading } \\
\text { edge } \\
\text { (hours) }\end{array}$ & $\begin{array}{c}\text { Time of peak } \\
\text { concentration } \\
\text { (hours) }\end{array}$ & $\begin{array}{c}\text { Peak } \\
\text { concentration } \\
\text { (percent or ppt) }\end{array}$ \\
\hline 102172081 & 27.9 & 0 & 0 & 0 & 100 \\
Site 2 & 24.4 & 3.5 & 3.5 & 15.5 & 41 \\
Site 4 & 21.9 & 6.0 & 15.5 & 39.5 & 29 \\
Site 6 & 19.9 & 8.0 & 28.5 & 112 & 10 \\
Site 8 & 14.2 & 13.7 & 104 & 408 & 2.0 \\
Site 10 & 4.2 & 23.7 & 376 & 1105 & 0.6 \\
02172090 & 2.2 & 25.7 & $2-$ & 3950 & 0.016 \\
\hline
\end{tabular}

${ }^{1}$ Upstream location of segment of slug injection of conservative tracer.

${ }^{2}$ Concentrations were below 0.1 parts per thousand.

${ }^{3}$ Peak occurred earlier than for site 10 due to tidal dilution effects from downstream boundary.

The procedure for determining the assimilative capacity of an upland stream is well established. The procedure involves a statistically computed low-flow value that is used in conjunction with a critical water temperature in a simulation model. The results are interpreted in accordance to the State water-quality standards. For many reasons, the procedure for coastal waters is not well established. The dynamic, oscillatory nature of streamflows in estuarine waterbodies makes statistically determined low-flow values very difficult to compute. Critical dissolved-oxygen concentrations may not occur during low-flow periods when estuarine waterbodies are influenced by ocean water with usually higher dissolved-oxygen concentrations. Most water-quality standards are based on water-quality data from upland streams and not from coastal waters, where, in the case of South Carolina, the waters may not meet the dissolved-oxygen concentration standard due to natural conditions. For these waters, effluent releases are permitted only if the instream dissolved-oxygen concentration is minimally affected, which is quantified as less than a $0.1 \mathrm{mg} / \mathrm{L}$ decrease from the natural condition (South Carolina Department of Health and Environment Control, 1993).

The water-quality standard for waterbodies that do not meet the standard due to natural conditions is currently (1998) under review by the SCDHEC. An alternative to the $0.1 \mathrm{mg} / \mathrm{L}$ allowable decrease being considered is to allow a 10 percent reduction below the "naturally" occurring dissolved-oxygen concentration if it can be demonstrated that the resident aquatic species shall not be adversely affected. Other issues of concern are critical flow periods and the time interval to use for interpretation of model output for estuarine systems that are dominated by semi-diurnal tidal cycle frequencies of 24.4 hours, 14 days, and 28 days.

Resolving these issues, although necessary for determining the assimilative capacity and NPDES permit limits for coastal waters, are beyond the scope of this report. However, for this report, various pointsource loading conditions are compared with a condi- 
tion where there is no point-source discharge into the system (a no-load condition). The effects of the pointsource loading conditions then can be evaluated by comparing the differences in the dissolved-oxygen concentrations for each simulation. The model is used to compare relative differences between various pointsource loading conditions rather than to predict the absolute dissolved-oxygen concentration of the system under a particular point-source loading, hydrologic, and meteorological conditions. The modeled absolute value could be in error, but relative differences in the simulated results are more likely to be accurate. The results from these scenarios are intended to demonstrate the utility of the model in making waterresource management decisions and are not intended to be interpreted as a regulatory application of the model.

Effluent standards set the levels of treatment for municipal and industrial wastewater discharges. Historically, there were three levels of wastewater treatment: primary, secondary, and advanced treatment. With the advancements in wastewater-treatment technology, additional levels of treatment are now widely used and point-source dischargers are better able to process wastewater to lower BOD and ammonia concentrations. These treatment levels now include secondary, advanced secondary, advanced, and reclaimed use.

The dischargers to the Ashley River are treating their effluent at the secondary treatment level $(30 \mathrm{mg} /$ $\mathrm{L} \mathrm{BOD}_{5}, 20 \mathrm{mg} / \mathrm{L}$ ammonia-nitrogen, and $1 \mathrm{mg} / \mathrm{L}$ dissolved oxygen) or higher. Three scenarios were simulated by setting the effluent discharge at the permitted levels and the effluent concentrations to advanced secondary, advanced, and reclaimed treatment levels.

Point-source concentrations were only changed for dischargers that were below a particular level of treatment. The BOD and ammonia concentrations, and the UOD for each level of treatment are listed in table 10 .

During the calibration period of September 1992, the point-source loading was at 92 percent of the fully permitted loading. The largest effect of the loading is seen at site 5 , where the 24 -hour mean dissolved-oxygen concentration of September 25, 1992, was decreased by 29.0 percent (table 11 , fig. 26). Setting the point-source loadings at a minimum of advanced secondary treatment levels reduces the fully permitted UOD to the system by 33 percent and

Table 10. Biochemical oxygen demand, ammonia-nitrogen and dissolved-oxygen concentrations, and ultimate oxygen demand for three wastewater-treatment levels

$\left[B O D_{5}, 5\right.$-day biochemical oxygen demand; $\mathrm{mg} / \mathrm{L}$, milligrams per liter; UOD, ultimate oxygen demand; lb/d, pounds per day]

\begin{tabular}{lcccc}
\hline \multirow{2}{*}{$\begin{array}{c}\text { Treatment } \\
\text { level }\end{array}$} & \multicolumn{4}{c}{ Effluent concentration for each point-source discharge } \\
\cline { 2 - 5 } & $\begin{array}{c}\mathrm{BOD}_{5} \\
(\mathbf{m g} / \mathrm{L})\end{array}$ & $\begin{array}{c}\text { Ammonia- } \\
\text { nitrogen } \\
(\mathbf{m g} / \mathrm{L})\end{array}$ & $\begin{array}{c}\text { Dissolved } \\
\text { oxygen } \\
(\mathbf{m g} / \mathrm{L})\end{array}$ & $\begin{array}{c}\text { Total UOD } \\
\text { for model } \\
(\mathbf{l b} / \mathrm{d})\end{array}$ \\
\hline Advanced secondary & 20 & 10 & 2 & 4,600 \\
Advanced & 10 & 2 & 6 & 1,530 \\
Reclaimed use & 5 & .5 & 6 & 592 \\
\hline
\end{tabular}

${ }^{1}$ UOD calculated by using permitted discharge rates and setting effluent concentrations within the model boundary to a minimum treatment of the specified level. 


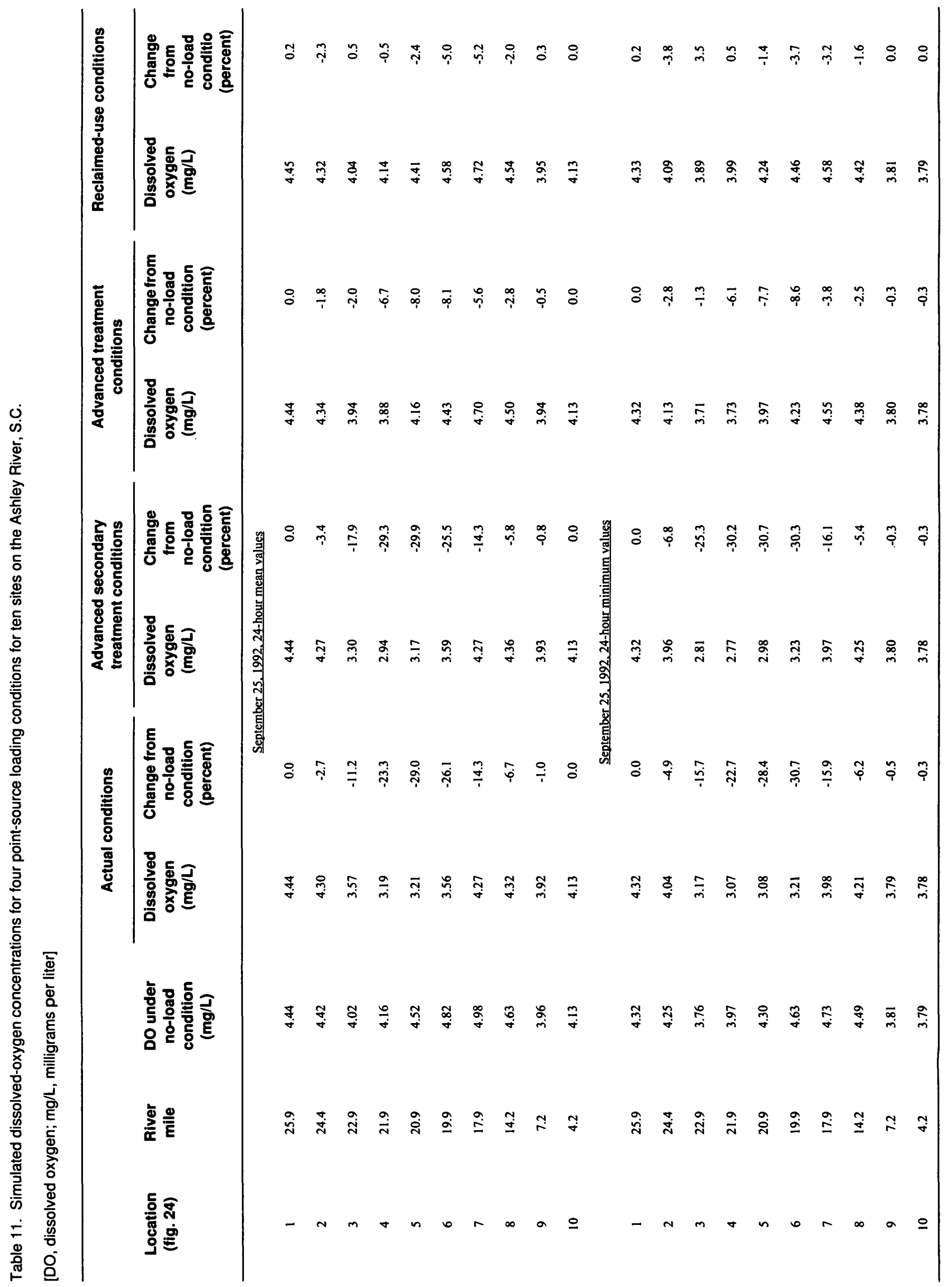

52 Simulation of Temperature, Nutrients, Biochemical Oxygen Demand, and Dissolved Oxygen in the Ashley River near Charleston, South Carolina, 1992-95 


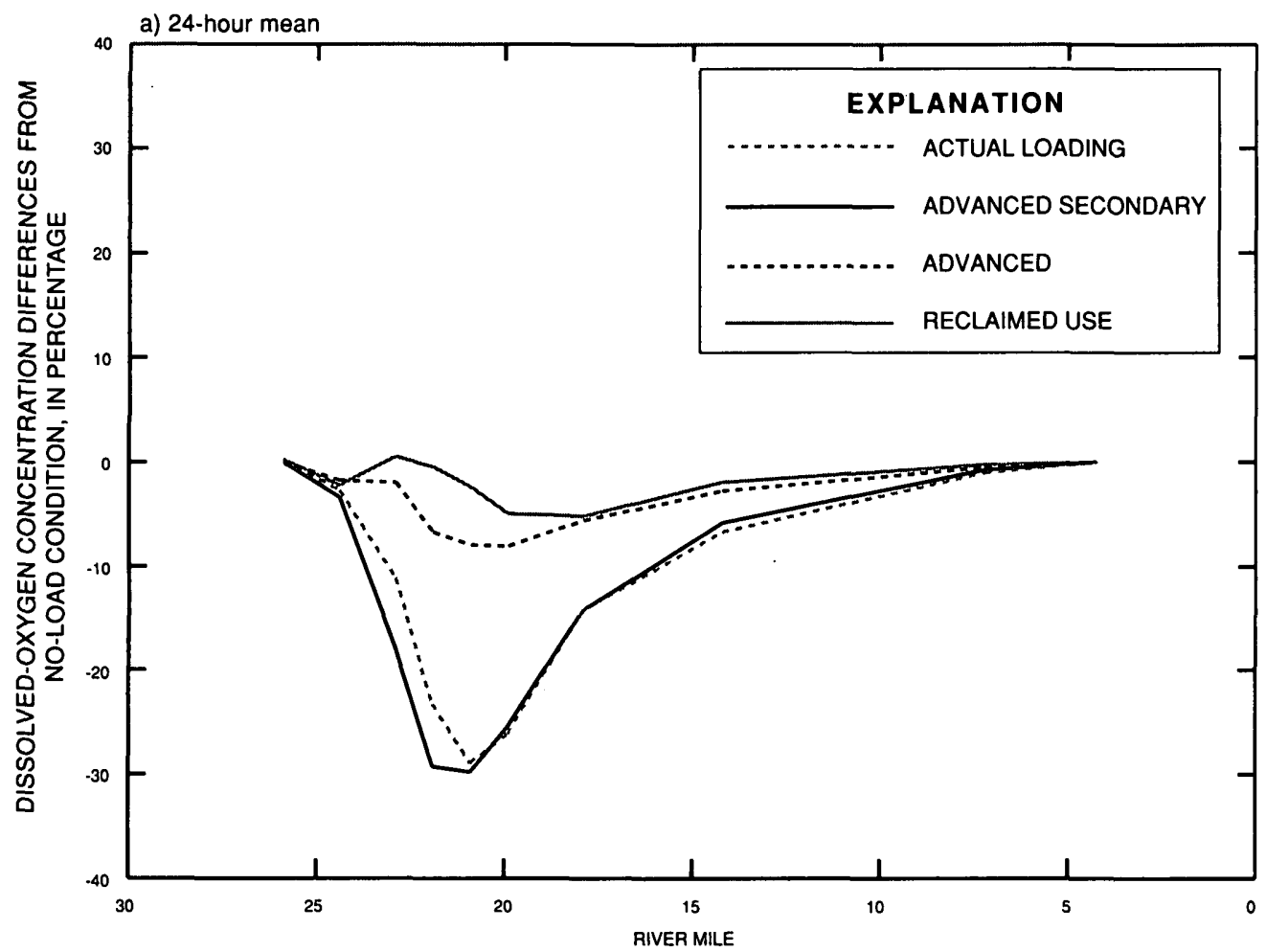

b) 24 -hour minimum

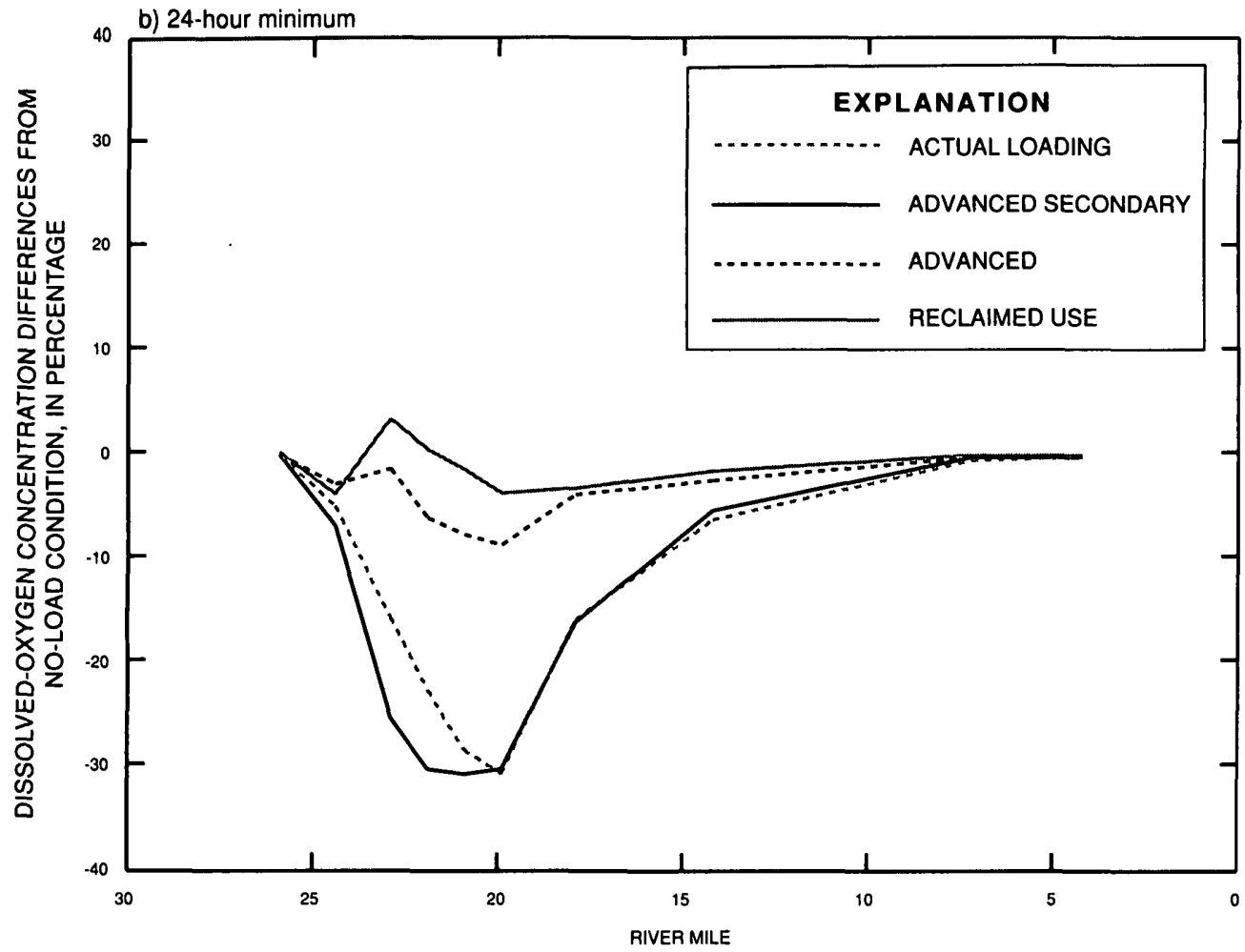

Figure 26. Longitudinal profiles of 24-hour mean and minimum dissolved-oxygen concentration differences from the no-load condition for four point-source loading condition on the Ashley River, South Carolina for September 1-October 30, 1992. 
decreases the 24-hour mean dissolved-oxygen concentration from the no-load condition by 29.9 percent or less (table 11, fig. 26). There are two explanations for the slight differences between the dissolved-oxygen concentration for these loading conditions. First, as previously mentioned, the dischargers on the Ashley River are treating wastewater effluent at secondary treatment levels or higher, so that the effects of setting all dischargers at advanced secondary are small as compared to the higher levels of treatment. Second, the increase in treatment levels decreased the longitudinal algal biomass concentration (an indictor of the phytoplankton community) for each treatment level conditions. Nitrogen in the forms of ammonia and nitrate are essential to the phytoplankton community and other primary producers of oxygen. The decrease in ammonia-nitrogen in the effluent decreases the phytoplankton community and, therefore, oxygen production, as seen in the lower dissolved-oxygen concentrations under the advanced secondary treatment conditions for sites 2 to 5 .

At advanced treatment levels, representing a 78percent reduction in the UOD loading to the system, the difference of the 24-hour mean dissolved-oxygen concentration from the no-load condition is 8.1 percent or less. Increasing the treatment level to reclaimed-use, representing a 91 percent reduction in the UOD loading to the system, further reduces the difference from the no-load condition to 5.2 percent or less. The decreases in the 24-hour mean and minimum dissolved-oxygen concentrations from the advanced condition to the reclaimed-use condition at site 2 are due to the decrease in primary oxygen production caused by the decrease in ammonia-nitrogen and its effects on the phytoplankton community.

\section{SUMMARY}

The U.S. Geological Survey one-dimensional dynamic-flow model BRANCH and the Branched Lagrangian Transport Model (BLTM) were calibrated and validated for the Ashley River near the Charleston Harbor area of South Carolina. The study area included the Ashley River from S.C. Highway 165 at Bacon Bridge near Summerville S.C., to S.C. Highway 17 at Charleston, 2.2 miles upstream from the confluence of the Ashley River with the Charleston Harbor. Data included water levels from three locations, tidal-cycle streamflow measurements from four locations, and salinity concentrations at six locations.
Data used in applying, calibrating, and validating the water-quality model included nutrient and biochemical oxygen demand concentrations collected over a tidal cycle at six locations during two sampling surveys; nutrient and biochemical oxygen demand concentrations collected over five tidal cycles at three locations during two sampling surveys; continuous water-temperature data for three locations; and continuous dissolved-oxygen concentration data for three locations. The streamflow, mass-transport, and waterquality models were calibrated by adjusting model parameters until simulated hydraulic and water-quality values were within the range of measured hydraulic and water-quality data. A sensitivity analysis was performed for all of the model parameters and boundary data.

The water-quality model of the Ashley River was used to simulate two hydrologic and point-source loading conditions to evaluate effects on the system. Scenarios included a slug injection of a conservative tracer in the upper reach of the river to evaluate the time of travel in the system and setting point-source discharges at various levels of wastewater treatment to evaluate the effect on the dissolved-oxygen concentrations.

To test the time of travel, the system was simulated for 60 days. The upstream segment of the model was set with an initial condition of $100 \mathrm{ppt}$ and the other segments were set with a concentration of 0.0 ppt. The leading edge of the tracer (defined as a concentration greater than $0.1 \mathrm{ppt})$ reached site $6(7.4 \mathrm{mi}$ downstream from the injection site) 1.2 days after the beginning of the simulation and the peak concentration, 10 percent of the injected concentration, reached the site in 4.7 days. The leading edge of the tracer reached site 10 (23.7 miles downstream from the injection site) 15.7 days after the beginning of the simulation and the peak concentration, 0.6 percent of the injected concentration, reached the site in 46 days.

Various point-source loading conditions to the system were evaluated. Setting all the point-source loadings to a minimum of advanced secondary treatment $[10 \mathrm{mg} / \mathrm{L}$ of ammonia-nitrogen and $20 \mathrm{mg} / \mathrm{L}$ of biochemical oxygen demand (BOD)] decreased the total permitted loading to the system by 33 percent and decreased the 24-hour mean dissolved-oxygen concentrations for September 25, 1992, from the no-load condition by 29.9 percent or less. Setting all the pointsource loadings to a minimum of advanced treatment ( $2 \mathrm{mg} / \mathrm{L}$ of ammonia-nitrogen and $10 \mathrm{mg} / \mathrm{L}$ of BOD) 
decreased the total permitted loading to the system by 78 percent and decreased the 24-hour mean dissolvedoxygen concentrations from the no-load condition by 8.1 percent or less. Setting all the point-source loadings to a minimum of reclaimed use $(0.5 \mathrm{mg} / \mathrm{L}$ of ammonia-nitrogen and $5 \mathrm{mg} / \mathrm{L}$ of BOD) decreased the total permitted loading to the system by 91 percent and decreased the 24-hour mean dissolved-oxygen concentrations from the no-load condition by 5.2 percent or less.

\section{REFERENCES}

Blood, E.R., Choi, Kyoung-sik, Darbar, Parveen, 1995, Final report for the landuse model sub-component for the contracts entitled "Development and application of dynamic water quality models for the Charleston Harbor Estuary System: Linking hydrodynamics, land use, and wetlands exchanges:" Submitted to the Charleston Harbor Project, Office of Coastal Resource Management, South Carolina Department of Health and Environmental Control, $90 \mathrm{p}$.

Bower, D.E., Sanders, C.L., and Conrads, P.A., 1993, Retention time simulation for Bushy Park Reservoir near Charleston, South Carolina: U.S. Geological Survey Water-Resources Investigations Report 93-4070, $47 \mathrm{p}$.

Bowie, G.L., Mills, W.B., Porcella, D.B., Campbell, C.L., Pagenkopf, J.R., Rupp, G.L., Johnson, K.M., Chan, P.W.H., Gherini, S.A., and Chamberlin, C.E., 1985, Rates, constants, and kinetics formulation in surface water quality modeling, $2 d$ ed.: U.S. Environmental Protection Agency, EPA/600/3-85/040, 455 p.

Brown, L.C., and Barnwell, T.O., Jr., 1987, The enhanced stream water quality models QUAL2E and QUAL2EUNCAS--Documentation and user manual: Athens, Georgia, U.S. Environmental Protection Agency, Environmental Research Laboratory, EPA/600/3-87/007, $189 \mathrm{p}$.

Chestnut, David, 1989, A review of Charleston Harbor water-quality data 1974-1987: South Carolina Department of Health and Environmental Control Technical Report No. 002-89, 124 p.

Chigges, J.A., Banks, J.B., and Knowles, S.C., 1989, Water quality characteristics of stormwater runoff in tributaries of the Ashley River Estuary Charleston, South Carolina: South Carolina Department of Health and Environmental Control, 90 p.

Conrads, P.A., Cooney, T.W., and Long, K.B. 1997, Hydrologic and water-quality data from selected sites in the Charleston Harbor Estuary and tributary rivers, South Carolina, Water Years 1992-95: U.S. Geological Survey Open-File Report 96-418, 987 p.
Conrads, P.A., and Smith, P.A., 1996, Simulation of water level, streamflow, and mass transport for the Cooper and Wando Rivers near Charleston, South Carolina, 1992-95: U.S. Geological Survey Water-Resources Investigations Report 96-4237, 51 p.

-.-- 1997, Simulation of temperature, nutrients, biochemical oxygen demand, and dissolved oxygen in the Cooper and Wando Rivers near Charleston, South Carolina, 1992-95: U.S. Geological Survey Water-Resources Investigations Report 97-4151, $58 \mathrm{p}$.

Drewes, P.A., and Conrads, P.A., 1995, Assimilative capacity of the Waccamaw River and the Atlantic Intracoastal Waterway near Myrtle Beach, South Carolina, 1989-92: U.S. Geological Survey Water-Resources Investigations Report 95-4111, $58 \mathrm{p}$.

Jobson, H.E., 1977, Thermal model for evaporation from open channels: Congress of the International Association for Hydraulic Research Proceedings, 17th, Baden, Germany, v. 2, p. 95-102.

--- 1980, Comment on "A new collocation method for the solution of the convection-dominated transport equation," by Pinder, G.E., and Sharpiro, Allen, 1979, (in Water Resources Research, v. 15, no. 5, p 1177-1182): Water Resources Research, v. 16, no. 6, p. 1135-1136

-.-.- 1987, Temperature and the solute-transport simulation in streamflow using a Lagrangian reference frame: U.S. Geological Survey Water-Resources Investigations Report 87-4163, 73 p.

--- 1997, Enhancements to the Branched Lagrangian Transport Modeling System: U.S. Geological Survey WaterResources Investigations Report 97-4050, $56 \mathrm{p}$.

Jobson, H.E., and Schoelhamer, D. H., 1987, Users manual for a Branched Lagrangian Transport Model: U.S. Geological Survey Water-Resources Investigations Report 87-4163, $73 \mathrm{p}$.

Kjerfve, Bjorn, 1976, The Santee-Cooper: A study of estuarine manipulations, in Wiley, M.L., ed., Estuarine Processes, v.1:. Academic Press, New York, p 44-56.

Kjerfve, Bjorn, and Magill, K.E., 1990, Salinity changes in Charleston Harbor 1922-1987: Journal of Waterway, Port, Coastal, and Ocean Engineering 166, p 153-168.

Miller, R.L., Bradford, W.L., and Peters, N.E., 1988, Specific conductance--theoretical considerations and application to analytical quality control: U.S. Geological Survey Water-Supply Paper 2311, 16 p.

National Oceanic and Atmospheric Administration, 1992a, Charleston Harbor--Chart 11524 (39th ed.): U.S. Department of Commerce, National Ocean Service.

---- 1992b, Climatological Data South Carolina, July 1992: U.S. Department of Commerce, National Climatic Data Center, v. 95 , no. 7 [variously paged].

---- 1992c , Climatological Data South Carolina, September 1992: U.S. Department of Commerce, National Climatic Data Center, v. 95, no. 9 [variously paged] 
--- 1993a, Climatological Data South Carolina, April 1993: U.S. Department of Commerce, National Climatic Data Center, v. 96, no. 4 [variously paged].

-.-- 1993b, Climatological Data South Carolina, May 1993: U.S. Department of

Commerce, National Climatic Data Center, v. 96, no. 5 [variously paged].

-..- 1993c, Climatological Data South Carolina, July 1993: U.S. Department of Commerce, National Climatic Data Center, v. 96, no. 7 [variously paged].

---- 1993d, Climatological Data South Carolina, August 1993: U.S. Department of Commerce, National Climatic Data Center, v. 96, no. 8. [variously paged].

--- 1993e, Climatological Data South Carolina, October 1993: U.S. Department of Commerce, National Climatic Data Center, v. 96, no. 10 [variously paged].

-.-- 1993f, Climatological Data South Carolina, November 1993: U.S. Department of Commerce, National Climatic Data Center, v. 96, no. 11 [variously paged].

--- 1993g, Climatological Data South Carolina, December 1993: U.S. Department of Commerce, National Climatic Data Center, v. 96, no. 12 [variously paged].

-.-- 1995, Tide tables 1995, high and low predictions - East Coast of North and South America, including Greenland: U.S. Department of Commerce, National Ocean Service, $301 \mathrm{p}$.

O'Conner, D.J. and Dobbins, W.E., 1958, Mechanism of reaeration in natural streams: American Society of Civil Engineer Transaction Paper no. 2934, p. 641-684.

Schaffranek, R.W., Baltzer, R.A., and Goldberg, D.E., 1981, A model for simulation of flow in singular and interconnected channels: U.S. Geological Survey Techniques of Water-Resources Investigations, book 7, chap. C3, 100 p.

Smith, G.D., 1985, Numerical solution of partial differential equations, finite difference methods ( $3 \mathrm{rd}$ ed.): Brunel University, p. 43-45.South Carolina Department of Health and Environmental Control, 1993, Water classifications and standards (Reg. 61-68) and classified waters (Reg. 61-69) for the State of South Carolina: $36 \mathrm{p}$.

-.- 1996, Watershed water quality management strategy -Catawba-Santee Basin: Technical Report No. 002-96, $266 \mathrm{p}$.

South Carolina Land Resources Conservation Commission, 1990, SPOT Satellite Image Based Land Use/Land Cover data.

Thomann, R.V., and Fitzpatrick, J.J., 1982, Calibration and verification of a mathematical model of the eutrophication of the Potomac Estuary: prepared for Department of Environmental Services, Government of the District of Columbia.

Thompson, D.B., 1992, Numerical methods 101-convergence of numerical models, in Jennings, M., and Bhowmik, N.G., eds., Hydraulic engineering: saving a threatened resource--in search of solutions: New York, American Society of Civil Engineers, p. 398-403.

Thomson, N.R., Sykes, J.F., and Lennox, W.C., 1984, A Lagrangian porous media mass transport model: Water Resources Research, v. 20, no. 3, p. 391-403.

Townsend, A.S., and Brock, N., 1992, Ashley River special area management plan: South Carolina Coastal Council, $155 \mathrm{p}$.

Van Dolah, R.F., Wendt, P. H., and Wenner, E.L., eds. 1990, Physical and ecological characterization of the Charleston Harbor estuarine system, Final Report: South Carolina Coastal Council, Charleston, South Carolina, 634 p.

Weiss, L.A., Schaffranek, R.W., and deVries, M.P., 1994, Flow and chloride transport in the tidal Hudson River, N.Y.: Proceedings, 1994 National Hydraulic Engineer Conference, American Society of Civil Engineers, New York, p. 1300-1305. 